Publicación especial NIST 1262

\section{Aprendiendo del impacto del huracán María en Puerto Rico: Un informe de progreso}

Joseph A. Main

Maria Dillard

Erica D. Kuligowski

Benjamin Davis

Jazalyn Dukes

Kenneth Harrison Jennifer Helgeson

Katherine Johnson Marc Levitan Judith Mitrani-Reiser Scott Weaver

DongHun Yeo Laboratorio de ingeniería Instituto Nacional de Estándares y Tecnología

Luis D. Aponte-Bermúdez Universidad de Puerto Rico en Mayagüez y Stantec, Inc.

Joel Cline Servicio Nacional de Meteorología Administración Nacional Oceánica y Atmosférica

Thomas Kirsch

Centro Nacional de Medicina y Salud Pública en Desastres Universidad de Ciencias de la Salud de Servicios Uniformados

Esta publicación está disponible de forma gratuita en: https://doi.org/10.6028/NIST.SP.1262es

enero de 2021

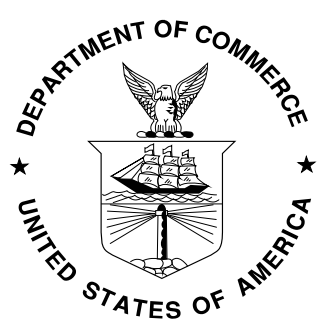

EE.UU. Departamento de Comercio Wilbur L. Ross, Jr., Secretario

Instituto Nacional de Estándares y Tecnología Walter Copan, Director y Subsecretario de Comercio del NIST para Estándares y Tecnología 
En este documento se pueden identificar determinadas entidades comerciales, equipos o materiales para describir adecuadamente un procedimiento o concepto experimental. Dicha identificación no pretende implicar una recomendación o aprobación por parte del Instituto Nacional de Estándares y Tecnología (NIST, por su sigla en inglés), ni pretende implicar que las entidades, materiales o equipos sean necesariamente los mejores disponibles para ese propósito.

Relevo de responsabilidad No. 2

La política del NIST es utilizar el Sistema Internacional de Unidades en todas las publicaciones. En este documento, sin embargo, las unidades se presentan en el sistema predominante en la disciplina relevante, aunque en algunos casos se puede presentar más de un sistema de unidades.

Derechos de autor

Esta publicación del NIST es un trabajo del gobierno de los Estados Unidos que no está sujeto a la protección de los derechos de autor dentro de los Estados Unidos bajo el Título 17 del Código de los Estados Unidos § 105. Esta publicación puede incluir contenido protegido por derechos de autor (como fotografías) utilizado con el permiso del titular de los derechos de autor acreditado. La reproducción, redistribución o reutilización de dicho contenido con derechos de autor aparte de esta publicación puede requerir permiso, que debe solicitarse al titular de los derechos de autor acreditado. Cuando no se acredite ninguna fuente o titular de derechos de autor para una figura o tabla en esta publicación, la fuente es NIST, que agradecería una atribución.

Relevo de responsabilidad No. 3

Este documento fue traducido por cortesía del Instituto Nacional de Estándares y Tecnología (NIST). La traducción de este documento fue realizada por Lazar Translating \& Interpreting. Esta traducción se proporciona como un servicio público y no es una traducción oficial del gobierno de los EE. UU. ni del NIST. Esta traducción se proporciona "TAL CUAL" y el gobierno de los EE. UU. no se hace responsable de la precisión de la traducción. La versión oficial en inglés de esta publicación está disponible de forma gratuita en el Instituto Nacional de Estándares y Tecnología (NIST): https:/ / doi.org/10.6028/NIST.SP.1262

This document was translated courtesy of the National Institute of Standards and Technology (NIST). The translation of this document was made by Lazar Translating \& Interpreting. This translation is provided as a public service and is not an official US Government or NIST translation. This translation is provided "AS-IS" and the US Government does not make any representations as to the accuracy of the translation. The official English language version of this publication is available free of charge from the National Institute of Standards and Technology (NIST): https:// doi.org/10.6028/NIST.SP.1262

Publicación especial 1262 del Instituto Nacional de Estándares y Tecnología Publ. Esp. 1262 del Inst. Nac. de Std. y Tec., 76 páginas (enero de 2021) CODEN: NSPUE2

Esta publicación está disponible de forma gratuita en: https://doi.org/10.6028/NIST.SP.1262es 


\section{Contribuyentes al Programa del Huracán María}

\section{Equipo Nacional de Seguridad en la Construcción}

Joseph Main, investigador técnico principal, febrero de 2020 a la fecha

Maria Dillard, investigadora técnica principal asociada, febrero de 2020 a la fecha

Erica D. Kuligowski, ex investigadora técnica principal, febrero de 2018 a febrero de 2020

Luis D. Aponte-Bermúdez (Universidad de Puerto Rico en Mayagüez y Stantec, Inc.)

Joel Cline (Servicio Nacional de Meteorología Nacional, Administración Nacional Oceánica y Atmosférica)

Benjamin Davis

Jazalyn Dukes

Kenneth Harrison

Jennifer Helgeson

Katherine Johnson

Thomas Kirsch (Centro Nacional de Medicina y Salud Pública en Desastres, Universidad de Ciencias de la Salud de Servicios Uniformados)

Marc Levitan

Judith Mitrani-Reiser

Scott Weaver

DongHun Yeo

\section{Personal técnico del NIST}

Jarrod Loerzel

Cynthia Rivas

Emily Walpole

Camila Young

\section{Apoyo institucional del NIST}

Regina Avila (Biblioteca del NIST)

Keith Martin (Biblioteca del NIST)

\section{Asociados del NIST}

Dereka Carroll-Smith

Zeinab Farahmandfar

Gerard Lemson

Alfredo Roa-Henriquez

Raphaelle Rodzik

Alex Szalay

Tingting Zhao

Todos los colaboradores están en el Laboratorio de Ingeniería del NIST, excepto donde se indique. 


\section{Agradecimientos}

El Instituto Nacional de Estándares y Tecnología (NIST) desea agradecer a todos los que han proporcionado datos e información en apoyo del Programa del Huracán María del NIST. Como se describe en el cuerpo del informe, el NIST ha recibido considerable cooperación e información de muchas organizaciones diferentes, incluidas agencias gubernamentales de Puerto Rico, agencias federales, empresas y asociaciones comerciales, hospitales, escuelas y servicios públicos. El equipo del huracán María del NIST también quisiera reconocer con gratitud el tremendo apoyo de este esfuerzo por parte de los líderes del NIST, incluidos Walter Copan, Kent Rochford, Howard Harary y Jason Averill. Muchas entidades del NIST han brindado apoyo institucional crítico, incluida la Oficina del Asesor Jurídico Principal, la Oficina de Protección de Investigaciones, la Oficina de Gestión y Organización, la Oficina de Gestión de Acuerdos y Adquisiciones, la Oficina de Asuntos Legislativos y del Congreso, la Oficina de Asuntos Públicos, el personal de Tecnología y Seguridad de Datos del Laboratorio de Ingeniería, y otros. Dave Butry, Long Phan y Jiann Yang proporcionaron valiosos comentarios de revisión sobre este informe de progreso, y Cynthia Rivas preparó los mapas incluidos en el informe. 


\section{Dedicatoria}

El 20 de septiembre de 2017, un poderoso huracán de categoría 4 azotó el Estado Libre Asociado de Puerto Rico. El impacto resultante del huracán María en la isla, su economía y su gente fue catastrófico. Además de las vidas perdidas y las lesiones sufridas, la tormenta afectó a muchos servicios prestados y de los que dependen empresas, escuelas, instituciones de atención médica, personas y gobiernos de todos los niveles. Puerto Rico todavía está experimentando los impactos de esa tormenta, al mismo tiempo que lidia con las interrupciones a partir de una serie de eventos sísmicos y una emergencia de salud pública grave.

Este estudio del Instituto Nacional de Estándares y Tecnología (NIST) está examinando las características del huracán y los impactos específicos en Puerto Rico, sus edificios y sistemas de infraestructura y servicios seleccionados. El objetivo es mejorar nuestra comprensión de este tipo de evento y recomendar mejoras en los códigos, estándares y prácticas de construcción que harían que las comunidades en Puerto Rico y en todo Estados Unidos sean más resilientes a los huracanes y otros desastres.

Este informe está dedicado a aquellos cuyas vidas se perdieron o fueron interrumpidas por este huracán, y a aquellos que actuarán en base a los hallazgos y recomendaciones de informes futuros para mejorar la seguridad de las personas en Puerto Rico y en otros lugares. 


\section{Resumen}

El 20 de septiembre de 2017, el huracán María tuvo un impacto devastador en gran parte de Puerto Rico, dañando edificios de los que dependían sus comunidades para atención médica, seguridad, comunicaciones, educación, negocios y más. Para comprender mejor cómo fallaron los edificios y la infraestructura, y cómo podemos prevenir tales fallas en el futuro, en 2018, el Instituto Nacional de Estándares y Tecnología (NIST) lanzó un esfuerzo de varios años para estudiar cómo se desempeñaron los edificios críticos durante la tormenta, así como también cómo funcionaron los sistemas de comunicaciones de emergencia. El Programa del Huracán María del NIST está investigando (1) el entorno del viento y las condiciones técnicas asociadas con muertes y lesiones, (2) el desempeño de edificios críticos representativos y áreas seguras designadas en esos edificios, incluida su dependencia de las líneas de sustento, y (3) el desempeño de los sistemas de comunicaciones de emergencia y la respuesta del público a tales comunicaciones. Estos corresponden a los tres objetivos de una investigación técnica bajo la Ley del Equipo Nacional de Seguridad en la Construcción (Ley NCST). Bajo el Programa Nacional de Reducción del Impacto de Vendavales (NWIRP, por sus siglas en inglés), autorizado por la Ley Nacional de Reducción de Impacto de Vendavales, el NIST también está llevando a cabo un estudio de investigación sobre los impactos y la recuperación de (1) negocios y cadenas de suministro, (2) servicios de educación y salud, y (3) sistemas de infraestructura que apoyan el funcionamiento de edificios críticos y comunicaciones de emergencia. Como componentes complementarios del Programa del Huracán María del NIST, la investigación técnica del NCST

y el estudio de investigación del NWIRP están estrechamente coordinados. Este informe explica en detalle la justificación para lanzar este esfuerzo, las áreas específicas seleccionadas para la investigación y el estudio por parte de un equipo interdisciplinario, y el enfoque que está utilizando el NIST, que incluye aprovechar la información recopilada por otros, pero también realizar una amplia recopilación de datos originales y análisis. El informe también resume el progreso hasta la fecha.

Palabras clave: huracán María; desempeño del edificio; comunicaciones de emergencia; mortalidad; lesiones; Puerto Rico; infraestructura; negocios; cadenas de suministro; hospitales; escuelas; refugios; recuperación. 


\section{Tabla de Contenido}

Contribuyentes al Programa del Huracán María .iii

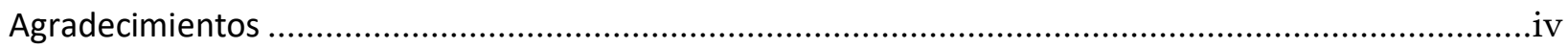

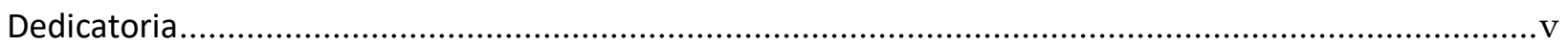

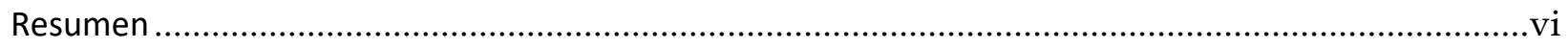

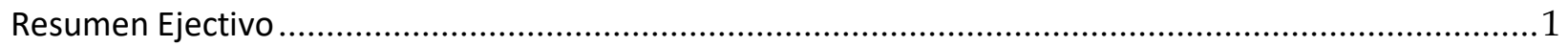

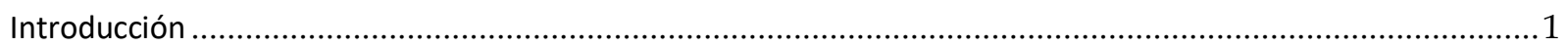

Respuesta del NIST y alcance del Programa del Huracán María................................................................... 2

Avances en la ejecución del Programa del Huracán María ......................................................................................

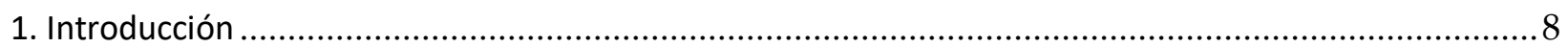

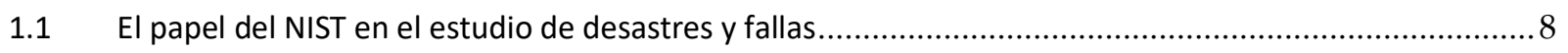

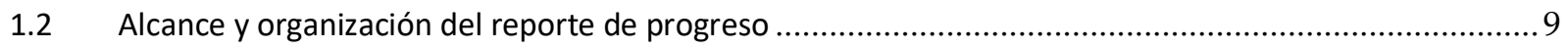

2. Reconocimiento preliminar y decisión de establecer un equipo ................................................11

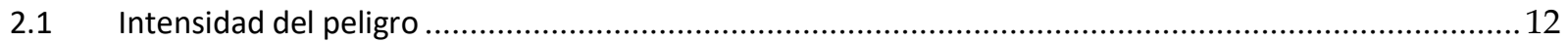

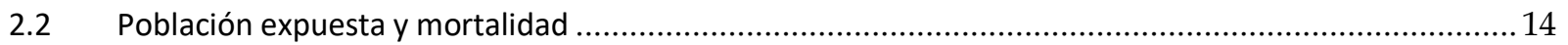

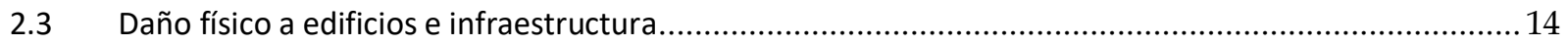

2.4 Desafíos de desalojo y respuesta a emergencias ............................................................................... 17

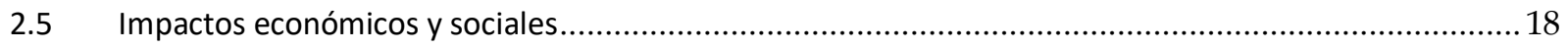

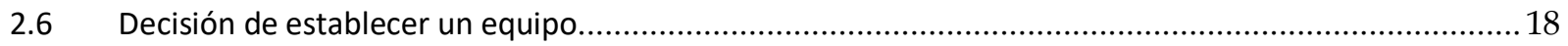

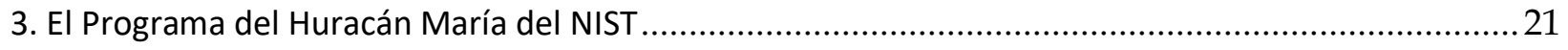

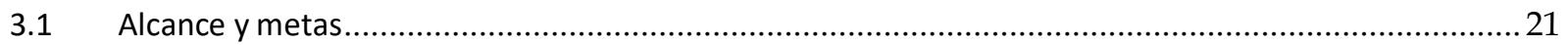

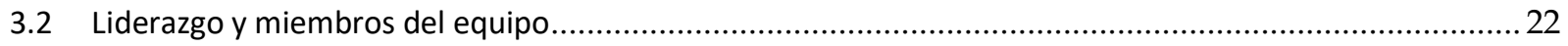

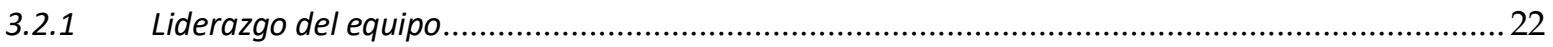

3.2.2 Miembros del Equipo Nacional de Seguridad en la Construcción..................................................... 22

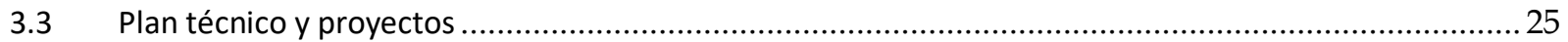

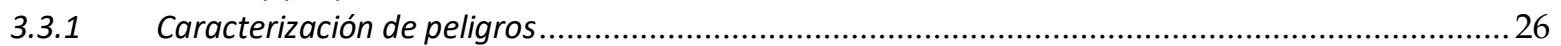

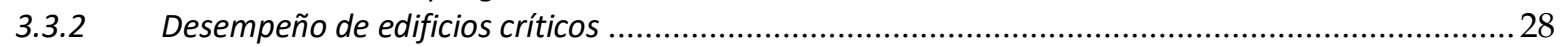

3.3.3 Respuesta pública a comunicaciones de emergencia ..................................................................29

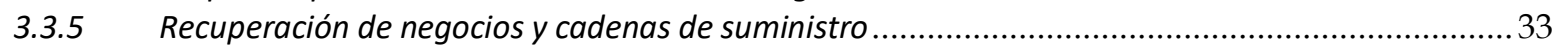

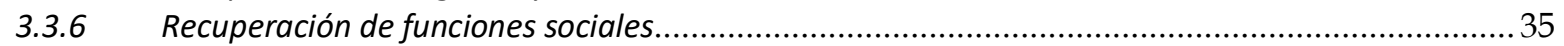

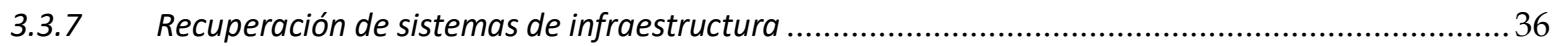

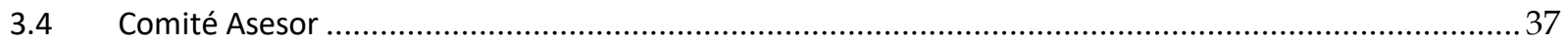

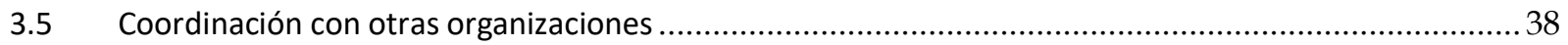


3.6 Duración y costo estimados. .39

3.7 Impacto de los eventos en Puerto Rico después del huracán María. .39

4. Avances en la ejecución del Programa del Huracán María............................................................. 42

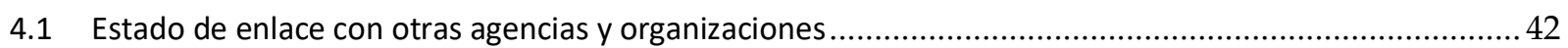

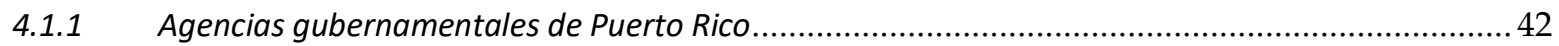

4.1.2 Organizaciones del sector público y privado de Puerto Rico ........................................................... 43

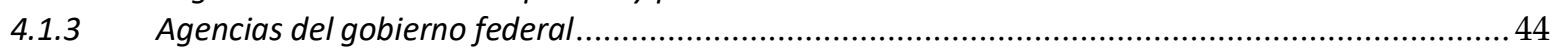

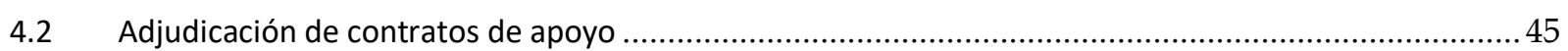

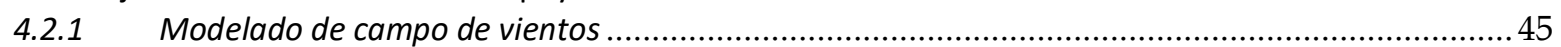

4.2.2 Prueba de túnel de viento y medición de campo de vientos ........................................................... 45

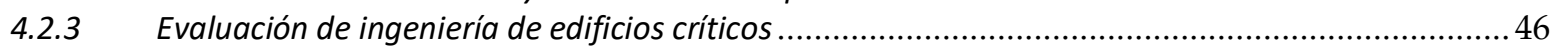

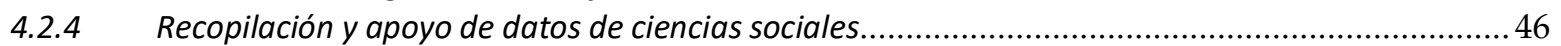

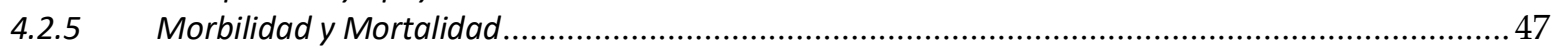

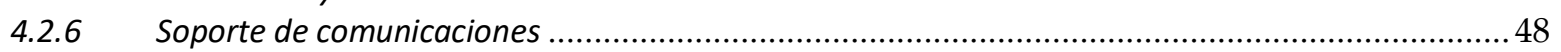

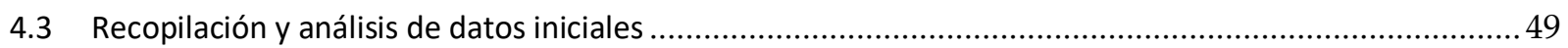

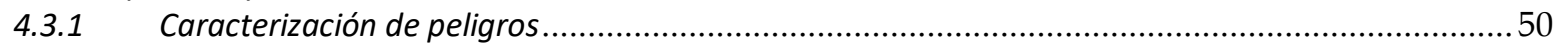

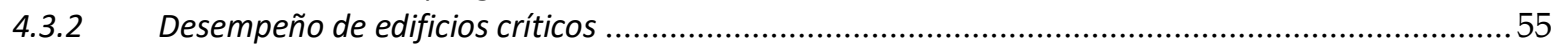

4.3.3 Respuesta pública a comunicaciones de emergencia ...................................................................5

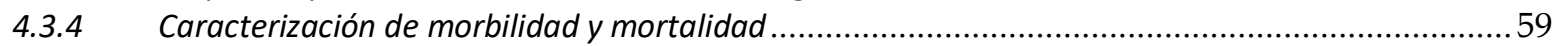

4.3.5 Recuperación de cadenas comerciales y de suministro ............................................................5

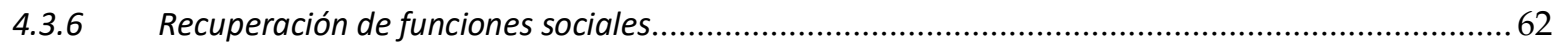

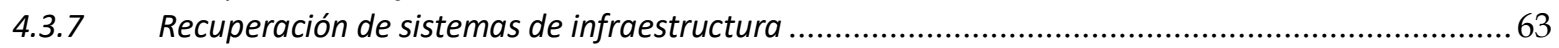

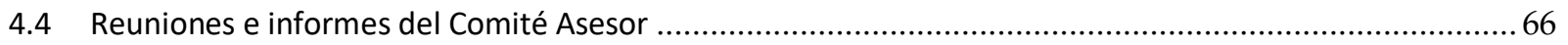

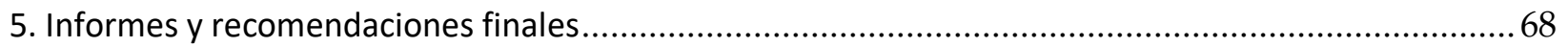




\section{Resumen Ejectivo}

\section{Introducción}

El 20 de septiembre de 2017, el huracán María tuvo un impacto devastador en gran parte de Puerto Rico, dañando edificios de los que dependían sus comunidades para atención médica, seguridad, comunicaciones, educación, negocios y más. Para comprender mejor cómo fallaron los edificios y la infraestructura, y cómo podemos prevenir tales fallas en el futuro, en 2018, el Instituto Nacional de Estándares y Tecnología (NIST) lanzó un esfuerzo de varios años para estudiar cómo se desempeñaron los edificios críticos durante la tormenta, así como también cómo funcionaban los sistemas de comunicaciones de emergencia. En última instancia, el objetivo de este esfuerzo es recomendar y alentar la adopción generalizada de códigos, estándares y prácticas de construcción mejorados que harían que las comunidades en Puerto Rico y en los Estados Unidos sean más resilientes a los huracanes y otros eventos peligrosos. El NIST, una agencia no reguladora de ciencia e ingeniería del Departamento de Comercio de EE. UU., tiene una larga historia de estudios imparciales de desastres y fallas con el objetivo de aprender de ellos. Los estudios de desastres y fallas del NIST se centran en la búsqueda de hechos, no en la búsqueda de fallas, y los eventos se estudian por separado de las decisiones de otras agencias y organizaciones sobre la financiación de la reparación, la recuperación u otros esfuerzos de asistencia.

Este informe explica en detalle la justificación para lanzar este esfuerzo, las regiones específicas de enfoque, seleccionadas por el equipo interdisciplinario y la estrategia que está utilizando el NIST, que incluye aprovechar la información recopilada por otros, pero también realizar una amplia recopilación y análisis de datos originales. El informe también resume el progreso hasta la fecha. Para obtener la información más completa y precisa posible, el NIST está coordinando esta empresa con otras organizaciones, incluidas las agencias gubernamentales de Puerto Rico, agencias federales, empresas y asociaciones comerciales, hospitales, escuelas y servicios públicos. Múltiples contratistas, incluidos expertos con base en Puerto Rico, están apoyando y agregando una capacidad sustancial al equipo de ingenieros, sociólogos, antropólogos, economistas, meteorólogos, epidemiólogos y otros expertos del NIST. Además de los empleados del NIST, los miembros formales del Equipo incluyen expertos externos del Servicio Nacional de Meteorología, el Centro Nacional de Medicina y Salud Pública en Desastres y la Universidad de Puerto Rico en Mayagüez. 


\section{Respuesta del NIST y alcance del Programa del Huracán María}

Después de que el huracán María tocó tierra en Puerto Rico como una fuerte tormenta de categoría 4, el NIST envió a cuatro miembros del personal a Puerto Rico en diciembre de 2017 para realizar un reconocimiento preliminar de los impactos del huracán, incluidos estudios de campo y entrevistas. Como parte del reconocimiento preliminar, el personal del NIST también revisó la información proporcionada por otras agencias gubernamentales, instituciones académicas y organizaciones del sector privado sobre las características del huracán y sus impactos. Las observaciones del reconocimiento preliminar se evaluaron con respecto a los criterios establecidos por la Ley del Equipo Nacional de Seguridad en la Construcción (NCST) para el establecimiento de un equipo de investigación, con consideración específica de la intensidad del peligro, la población expuesta y la mortalidad, los daños físicos a los edificios y la infraestructura, desafíos de desalojo y respuesta a emergencias, e impactos económicos y sociales. Considerando de estos factores, se concluyó que se espera que una investigación del desempeño del edificio durante y después de la tormenta, y de los desafíos en los procedimientos de desalojo y respuesta a emergencias, dé como resultado nuevos conocimientos que conducirán a importantes recomendaciones para los códigos, normas y prácticas. Con base en esta información y análisis, el 21 de febrero de 2018, el Director del NIST estableció un Equipo bajo la Ley NCST para realizar una investigación técnica del evento del huracán María.

Los objetivos de la investigación técnica del NIST son caracterizar (1) el ambiente del viento y las condiciones técnicas asociadas con las muertes y lesiones, (2) el desempeño de los edificios críticos representativos y las áreas seguras designadas en esos edificios, incluyendo su dependencia de las líneas de sustento, y (3) el desempeño de los sistemas de comunicaciones de emergencia y la respuesta del público a dichas comunicaciones. Como complemento de la investigación técnica del NCST, el NIST está llevando a cabo un estudio de investigación sobre los impactos y la recuperación de (1) negocios y cadenas de suministro, (2) servicios de educación y atención médica, y (3) sistemas de infraestructura que respaldan el funcionamiento de edificios críticos y comunicaciones de emergencia. Este estudio de investigación se está llevando a cabo bajo la autoridad de la Ley Nacional de Reducción del Impacto de Vendavales, que designa al NIST como la agencia líder del Programa Nacional de Reducción del Impacto de Vendavales (NWIRP). Como componentes complementarios del Programa del Huracán María del NIST, la investigación técnica del NCST y el estudio de investigación del NWIRP están estrechamente coordinados. Para proporcionar un alcance apropiado para el Programa del Huracán María y facilitar la integración de datos y análisis en los siete proyectos técnicos dentro del programa, se han seleccionado cuatro regiones de Puerto Rico para un enfoque particular. 
Los aspectos más destacados del progreso hasta la fecha en la ejecución del Programa del Huracán María incluyen lo siguiente:

- Información solicitada y obtenida de otras agencias y organizaciones: Para obtener la información más precisa posible, y de acuerdo con el mandato de la Ley del NCST de que el NIST coordine sus esfuerzos con otras organizaciones, el NIST ha solicitado y recibido información relevante de muchas otras agencias y organizaciones. Se han establecido memorandos de acuerdo con FEMA, que brindan al NIST acceso a información importante sobre daños a escuelas e instalaciones de atención médica. La Oficina del Subsecretario para la Preparación y Respuesta (ASPR, por sus siglas en inglés) del Departamento de Salud y Servicios Humanos (HHS, por sus siglas en inglés) ha compartido información sobre su apoyo para la recuperación de servicios sociales y de salud, centrada en hospitales y escuelas. Las agencias gubernamentales de Puerto Rico han proporcionado información adicional, incluida información sobre el programa de alojamiento proporcionado por el Departamento de la Vivienda de PR, información sobre hospitales proporcionada por el Departamento de Salud de PR, información sobre el sistema de transporte proporcionado por el Departamento de Transportación y Obras Públicas de PR, e información sobre negocios y cadenas de suministro proporcionada por la Autoridad de los Puertos de PR y el Departamento del Trabajo y Recursos Humanos de PR. El cuerpo del informe proporciona ejemplos adicionales de información solicitada y obtenida.

- Desarrollo del modelo de campo de vientos: La cuantificación precisa de la velocidad del viento es fundamental para evaluar el desempeño de los edificios y la infraestructura y proporcionar contexto para otros aspectos del programa. Los desafíos en la caracterización de campo de vientos del huracán María incluyen las mediciones limitadas disponibles, con muchas estaciones meteorológicas que fallaron durante el evento, y la influencia de la topografía montañosa de Puerto Rico, que puede causar un aumento de velocidad local significativa de los vientos, con los correspondientes aumentos en las cargas de viento sobre las estructuras. Para abordar estos desafíos, se ha desarrollado un modelo de campo de vientos inicial para el huracán María, obtenido al ajustar un modelo de campo de vientos de huracán a las observaciones meteorológicas disponibles a nivel de superficie, incluida la consideración de los efectos topográficos. Este modelo proporciona registros de tiempo estimadas de la velocidad y dirección del viento en todo el Estado Libre Asociado, con factores de aumento de velocidad topográfica tan altos como 1.8 observados en algunas regiones. Al desarrollar el modelo final de campo de vientos para el huracán María, las mejoras adicionales incluirán un modelado más refinado de los efectos topográficos basados en los resultados de las pruebas del túnel de viento, el modelado computacional y las mediciones de campo que se describen a continuación. El trabajo de modelado de campo de vientos está siendo 
subvencionado a través de un contrato otorgado a Applied Research Associates en febrero de 2019.

- Prueba de túnel de viento y modelado computacional: Los efectos de la topografía de Puerto Rico en las velocidades de viento locales y en las cargas de viento resultantes que experimentan los edificios y los sistemas de infraestructura, se están investigando utilizando una combinación de pruebas de túnel de viento y modelado de dinámica de fluidos computacional (CFD, por sus siglas en inglés). Una primera fase de las pruebas del túnel de viento, actualmente en curso, involucra modelos a escala de características topográficas, incluidos modelos de regiones seleccionadas en Puerto Rico, así como modelos de características genéricas de crestas y mesetas. Se han fabricado modelos a escala de características topográficas, se han realizado mediciones de caracterización de flujo para garantizar que el flujo entrante coincida con los perfiles del objetivo y se han completado las mediciones para un subconjunto de las pruebas del modelo topográfico. Las mediciones de los modelos topográficos se utilizarán para la validación de los modelos CFD para la evaluación de los efectos topográficos en el campo de vientos en Puerto Rico. Una fase futura de las pruebas del túnel de viento involucrará modelos a escala de edificios críticos seleccionados, para permitir una evaluación detallada de las cargas de viento influenciadas por la topografía, los edificios y el terreno circundantes. Las pruebas del túnel de viento se están realizando en un gran túnel de viento con límites de capa reconfigurables en la Universidad de Florida, a través de un contrato adjudicado en mayo de 2019.

- Despliegue de anemómetros en sitios de torres celulares: Para proporcionar datos del mundo real para la evaluación de los efectos topográficos en los perfiles de velocidad del viento y para la validación de los modelos de túnel de viento y CFD, se han desplegado anemómetros en tres torres de telefonía celular en la región de Yabucoa, en sitios donde la topografía circundante produce aumentos significativos en velocidades del viento. El equipo ha comenzado a registrar datos de velocidad del viento, incluida la captura de datos de vientos fuertes de la tormenta tropical Isaías en julio de 2020 y la tormenta tropical Laura en agosto de 2020. Estas mediciones de campo se compararán con las mediciones del túnel de viento de los perfiles de flujo en los sitios de las torres utilizando un modelo a escala de la región de Yabucoa. La medición de campo de vientos está siendo apoyada a través de un subcontrato otorgado a WeatherFlow por la Universidad de Florida. American Tower, Inc. proporciona el espacio en las torres de telefonía celular.

- Evaluación de edificios críticos: La evaluación del desempeño de los edificios críticos requiere la documentación de las características de los edificios y sus requisitos de diseño inicial, así como los daños y la pérdida de función que se sufrieron por el huracán. El apoyo en la recopilación de dicha información para hospitales, escuelas y refugios para tormentas seleccionados se brinda a través de un contrato con Stantec, Inc., 
otorgado en marzo de 2020. El personal clave del contrato tiene su base en Puerto Rico, proporcionando conocimiento local y una presencia local de importancia crítica para apoyar este esfuerzo. Se han seleccionado instalaciones específicas para la evaluación y se han establecido contactos con los administradores de estas instalaciones como parte del esfuerzo para recopilar información adicional. Actualmente se está recopilando y revisando la documentación pertinente, seguida de entrevistas con los administradores de las instalaciones. Para una de las instalaciones hospitalarias seleccionadas, ubicada en un sitio con un aumento de velocidad topográfica de los vientos particularmente significativa, se ha realizado una fotografía con drones de la instalación y se ha creado un modelo 3D de la instalación a partir de las imágenes de los drones, para respaldar la fabricación de un modelo a escala para pruebas en túnel de viento.

- Caracterización de morbilidad y mortalidad: Identificar las muertes en Puerto Rico relacionadas directa e indirectamente con el huracán María, especialmente aquellas asociadas con fallas en los edificios, requiere identificar causas específicas de muerte, incluidas las muertes indirectas que podrían haberse pasado por alto en el pasado. Para respaldar la recopilación de dicha información, en septiembre de 2020 se otorgó un contrato a la Escuela de Salud Pública del Instituto Milken (SPH) de la Universidad George Washington (GW), con miembros colaboradores del equipo de la Universidad de Puerto Rico-Escuela Graduada de Salud Pública y el Instituto de Métricas y Evaluación de la Salud de la Universidad de Washington. El plan de trabajo para este contrato se ha desarrollado y finalizado con las aportaciones del NIST. Este esfuerzo se enfocará específicamente en identificar muertes atribuidas a edificios y/o fallas en el sistema del edificio. No producirá otro recuento de muertes.

- Diseño de muestra para encuestas y entrevistas: Las metodologías de las ciencias sociales, que incluyen encuestas y entrevistas, son esenciales para los enfoques técnicos de cuatro proyectos dentro del Programa del Huracán María, incluido un proyecto del NCST centrado en la respuesta pública a las comunicaciones de emergencia y tres proyectos del NWIRP centrados en la recuperación de negocios y cadenas de suministro, funciones sociales y sistemas de infraestructura. Estos proyectos requerirán la recopilación de información de proveedores de información, hogares, empresas, escuelas, hospitales y representantes de infraestructura en los sectores de energía, agua y transporte. Se han desarrollado diseños de muestra estadísticamente sólidos para las encuestas y entrevistas que se realizarán para cada uno de estos proyectos, y actualmente se están completando las revisiones administrativas necesarias para las actividades de recopilación de información para garantizar que se sigan los protocolos adecuados. Este trabajo está siendo respaldado por un contrato adjudicado en diciembre de 2019 a Horsley Witten Group, Inc., con los subcontratistas Eastern Research Group, Inc., Issues \& Answers, Inc. y la Universidad Albizu en Puerto Rico. 
- Recopilación de datos sobre la recuperación de negocios y cadenas de suministro: Como ejemplo de las relaciones que el NIST ha establecido con otras organizaciones, el equipo del proyecto de Recuperación de Negocios y Cadenas de Suministro colaboró con Puerto Rico Manufacturing Extension, Inc., (PRiMEX) y Manufacturing Extension Partnership (MEP) del NIST, en la realización de visitas al sitio en el verano de 2019 para recopilar datos sobre la recuperación de negocios clave dentro del sector de fabricación de preparación de alimentos y el sector de fabricación de dispositivos médicos. Se han recopilado datos sobre la recuperación inicial de pequeñas y medianas empresas, recopilados a partir de observaciones de campo y otras fuentes, para respaldar los análisis futuros.

Al llevar a cabo el Programa del Huracán María, el NIST ha realizado ajustes en los planes para tener en cuenta el impacto de los eventos desde el huracán María, incluida la pandemia COVID19 y una serie de terremotos que comenzaron a afectar a Puerto Rico a fines de diciembre de 2019. Los peligros sísmicos en el contexto de peligros múltiples de Puerto Rico han sido una consideración importante desde el inicio del programa, y los expertos en ingeniería sísmica del Equipo se asegurarán de que los peligros sísmicos, además de los peligros del viento, se consideren en el desarrollo de las recomendaciones del NIST relacionadas con el huracán María. Hasta la fecha, la mayor parte del daño relacionado con los terremotos se ha concentrado en un área que está fuera de las principales regiones de enfoque del NIST, y el Equipo anticipa que este daño tendrá un impacto limitado en los esfuerzos del programa, particularmente para los proyectos dentro de la investigación técnica del NCST. Para los tres proyectos técnicos dentro del estudio de investigación NWIRP, que se centran en la recuperación de los impactos del huracán María, los investigadores del NIST están poniendo especial cuidado en diseñar instrumentos de recopilación de datos que aseguren la capacidad de tener en cuenta los efectos agravantes de la secuencia de terremotos y la pandemia en el proceso de recuperación. En respuesta a la pandemia de COVID-19, los proyectos que se basan en metodologías de encuestas y entrevistas de ciencias sociales (cinco de los siete proyectos técnicos) han modificado los planes para utilizar modos de recopilación de datos basados en el teléfono y la web. El equipo de NIST continúa explorando formas creativas de lograr los objetivos del programa, al mismo tiempo que prioriza la seguridad en este entorno incierto y complejo.

Se espera que la recopilación de datos a través de solicitudes de documentos, entrevistas, encuestas, visitas al sitio, pruebas en túneles de viento y mediciones de campo de vientos continúe hasta 2021. El NIST continuará proporcionando actualizaciones periódicas del progreso a través del sitio web del Programa del Huracán María y mediante presentaciones al Comité Asesor Federal, autorizado para proporcionar comentarios sobre la investigación del NCST. Una vez que el Equipo complete su análisis de los datos, el NIST preparará los hallazgos y recomendaciones de la investigación del NCST para revisión y comentarios públicos. El NIST difundirá ampliamente su borrador y sus informes finales. Además de tomar acción sobre cualquier recomendación del NCST dentro del ámbito del NIST para la investigación de seguimiento u otras actividades, el NIST se comunicará con todas las agencias federales 
relevantes, así como con el gobierno de Puerto Rico y otros en los sectores público y privado para fomentar el liderazgo en el apoyo de la implementación voluntaria de las recomendaciones del NCST. Finalmente, como lo requiere la Ley NCST, el NIST desarrollará y proporcionará informes públicos anuales sobre el progreso que la agencia y otros están haciendo para implementar sus recomendaciones del NCST. 


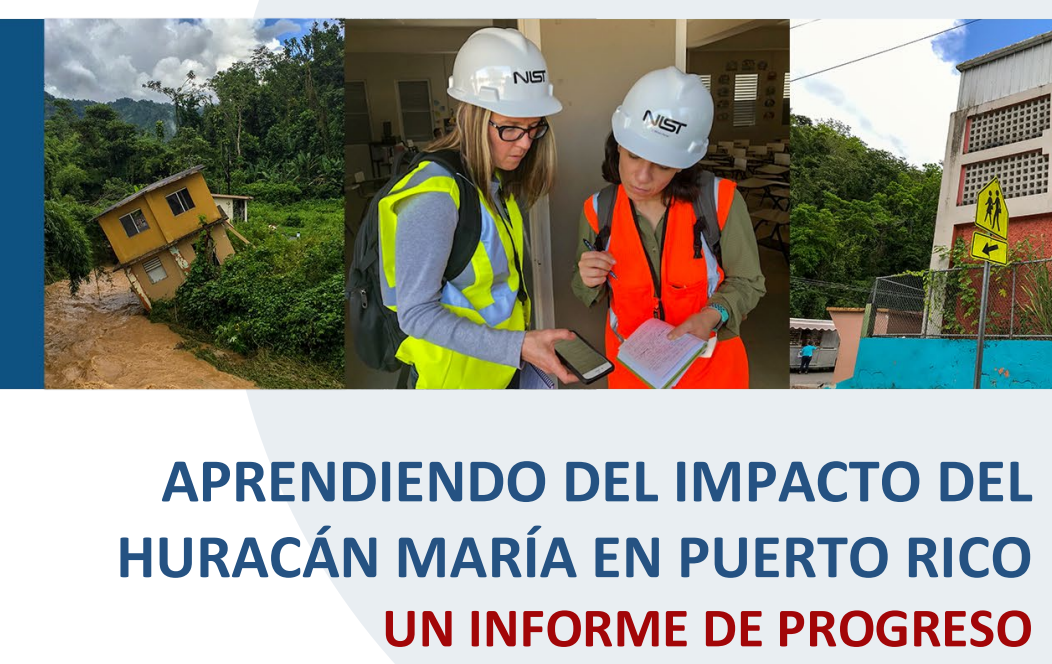

\section{Introducción}

Este informe resume el progreso realizado en el curso del programa del huracán María del NIST desde su lanzamiento formal en febrero de 2018 hasta septiembre de 2020. El informe complementa la información sobre el programa del huracán María proporcionada en un sitio web dedicado del NIST, 1 que se actualiza periódicamente y contiene información más detallada.

\subsection{El papel del NIST en el estudio de desastres y fallas}

El NIST, una agencia no reguladora de ciencia e ingeniería del Departamento de Comercio de EE. UU., tiene una larga historia de estudios imparciales de desastres y fallas con el objetivo de aprender de ellos. ${ }^{2}$ Durante muchas décadas, los estudios del NIST han permitido comprender mejor cómo se desempeñan las estructuras y cómo las personas responden a una variedad de eventos de peligro. A su vez, las recomendaciones basadas en estos hallazgos han producido estándares, códigos y prácticas mejorados. Por ejemplo, después del desastre del World Trade Center (WTC) en 2001, las recomendaciones del NIST han llevado a cambios en los estándares y códigos de consenso que rigen la construcción de edificios y la respuesta a emergencias. ${ }^{3}$ Los estados y las localidades confían ampliamente en estos estándares y códigos de consenso y los incorporan en sus propios requisitos que rigen los edificios nuevos y renovados y otras estructuras. Las recomendaciones del NIST también han llevado a cambios en las prácticas de los profesionales involucrados en el diseño y la construcción de edificios y en la respuesta y comunicación de desastres. De manera similar, los estudios del NIST sobre tornados, huracanes, incendios, terremotos y derrumbes de la construcción han dado como resultado cambios en los estándares y prácticas para mejorar la seguridad.

\footnotetext{
${ }^{1}$ www.nist.gov/topics/disaster-failure-studies/hurricane-maria

${ }^{2}$ Más información sobre el programa de estudios de desastres y fallas del NIST: www.nist.gov/topics/disasterfailure-studies

${ }^{3}$ Más información sobre las recomendaciones del estudio de desastres del WTC y su estado de implementación: www.nist.gov/topics/disaster-failure-studies/world-trade-center-disaster-study/recommendations
} 
El NIST tiene autoridad legal para estudiar desastres y fallas y hacer recomendaciones. Específicamente, la Ley del Equipo Nacional de Seguridad en la Construcción (NCST) (Ley Pública 107-231)4 autoriza al Director del NIST a establecer Equipos de investigación "para evaluar el desempeño de edificios y los procedimientos de respuesta de emergencia y desalojo a raíz de cualquier falla de un edificio que haya resultado en pérdidas sustanciales de vida o que representó un potencial significativo de pérdida sustancial de vidas ". Además, la Ley Nacional de Reducción del Impacto de Vendavales (Ley Pública 114-52), 5 designa al NIST como la agencia líder para el Programa Nacional de Reducción del Impacto de Vendavales (NWIRP) y le da al NIST la responsabilidad de "llevar a cabo investigación y desarrollo para mejorar los códigos de construcción modelo, normas voluntarias y mejores prácticas para el diseño, construcción y modernización de edificios, estructuras y líneas de sustento" con el propósito de lograr "reducciones medibles en las pérdidas de vidas y propiedades causados por vendavales".

Si bien el NIST tiene autoridad legal para estudiar desastres y fallas, no tiene autoridad reguladora para exigir que se sigan sus recomendaciones. Más bien, el NIST trabaja en cooperación con agencias gubernamentales en todos los niveles y con organizaciones de desarrollo de estándares y códigos de construcción del sector privado. El papel del NIST como parte neutral y su participación en el proceso de normas voluntarias son factores especialmente importantes que contribuyen a su éxito en la implementación de las recomendaciones.

Los estudios de desastres y fallas del NIST se centran en la búsqueda de hechos, no en la búsqueda de fallas, y los eventos se estudian por separado de las decisiones de otras agencias y organizaciones sobre la financiación de la reparación, la recuperación u otros esfuerzos de asistencia. El NIST difunde ampliamente sus hallazgos y recomendaciones del NCST, y monitorea su implementación.

\subsection{Alcance y organización del reporte de progreso}

Este informe de progreso comienza con una revisión de las características de peligro del huracán María y los impactos en el territorio estadounidense de Puerto Rico y los factores considerados en la decisión de establecer un Equipo para estudiar este desastre. Esta revisión, en la Sección 2, proporciona un resumen de las observaciones del reconocimiento preliminar del NIST sobre las características del peligro de tormentas, la población expuesta y la mortalidad, el daño físico al entorno construido, los desafíos con el desalojo y la respuesta de emergencia, y los impactos sociales y económicos, incluida la información de organizaciones asociadas que se consideró en la decisión de establecer un Equipo. La Sección 3 describe el Programa del Huracán María del NIST, incluidos su alcance y objetivos, el liderazgo y los miembros del

\footnotetext{
4 www.congress.gov/107/plaws/publ231/PLAW-107publ231.pdf

5 www.congress.gov/114/plaws/publ52/PLAW-114publ52.pdf
} 
equipo, el plan técnico y los proyectos, y el Comité Asesor del NCST6, junto con una discusión de los esfuerzos de apoyo de otras organizaciones y la duración y el costo estimados del programa. La sección 4 luego presenta el progreso hasta la fecha en la ejecución del programa, incluida la selección de áreas de estudio, el estado de enlace con otras agencias, la adjudicación de contratos de apoyo, la recopilación y análisis inicial de datos y la revisión del comité asesor. Finalmente, la Sección 5 describe el plan para la publicación de informes finales para documentar los hallazgos y recomendaciones al final del estudio, junto con los esfuerzos posteriores para implementar estas recomendaciones, en asociación con otras agencias y organizaciones.

${ }^{6}$ www.nist.gov/topics/disaster-failure-studies/national-construction-safety-team-ncst/advisory-committee 


\section{APRENDIENDO DEL IMPACTO DEL HURACÁN MARÍA EN PUERTO RICO UN INFORME DE PROGRESO}

\section{Reconocimiento preliminar y decisión de establecer un equipo}

El huracán María 7 tocó tierra en Puerto Rico el 20 de septiembre de 2017 como una fuerte tormenta de categoría 4. El NIST envió a cuatro miembros del personal a Puerto Rico del 10 al 15 de diciembre de 2017 para realizar un reconocimiento preliminar de los impactos del huracán, en coordinación con un Equipo de Evaluación de Mitigación (MAT, por sus siglas en inglés) desplegado por la Agencia Federal para el Manejo de Emergencias (FEMA). Uno de los miembros del personal del NIST también era miembro de FEMA MAT y contribuyó al Informe MAT. ${ }^{8,9}$ La Figura 1 muestra las ubicaciones de los sitios de recolección de datos del reconocimiento preliminar del NIST, incluidas las encuestas de campo y las entrevistas. Como parte del reconocimiento preliminar, el personal del NIST también revisó la información proporcionada por otras agencias gubernamentales, instituciones académicas y organizaciones del sector privado sobre las características del huracán y sus impactos. Las siguientes subsecciones resumen los hallazgos clave del reconocimiento preliminar y documentan los factores que se consideraron en la decisión de establecer un equipo para realizar una investigación adicional. El progreso posterior en la recopilación y el análisis de datos, después del reconocimiento preliminar en 2017, no se incorpora aquí, pero se informa en la Sección 4.

\footnotetext{
${ }^{7}$ En 2011, un huracán también llamado "María" azotó a Puerto Rico: www.nhc.noaa.gov/data/tcr/AL142011_Maria.pdf

${ }^{8}$ FEMA P-2020, huracanes Irma y María en Puerto Rico: Observaciones, recomendaciones y orientación técnica sobre el comportamiento de los edificios (FEMA 2018): www.hsdl.org/?view\&did=818977

${ }^{9}$ Si bien los equipos de evaluación de mitigación y los Equipos Nacionales de Seguridad en la Construcción pueden activarse para el mismo desastre, tienen propósitos diferentes pero complementarios. Los equipos de evaluación de mitigación de FEMA generalmente concluirán sus evaluaciones y publicarán informes a los pocos meses del desastre, con el objetivo de identificar rápidamente lecciones que ayuden a informar la reconstrucción en la comunidad afectada por el desastre. Las investigaciones del NIST NCST son investigaciones técnicas integrales que, por lo general, demoran de tres a cinco años en completarse y tienen como objetivo identificar los cambios recomendados en los códigos, estándares y prácticas de construcción para mitigar los riesgos de futuras fallas en los edificios y la pérdida de vidas en comunidades propensas a peligros en todo Estados Unidos.
} 


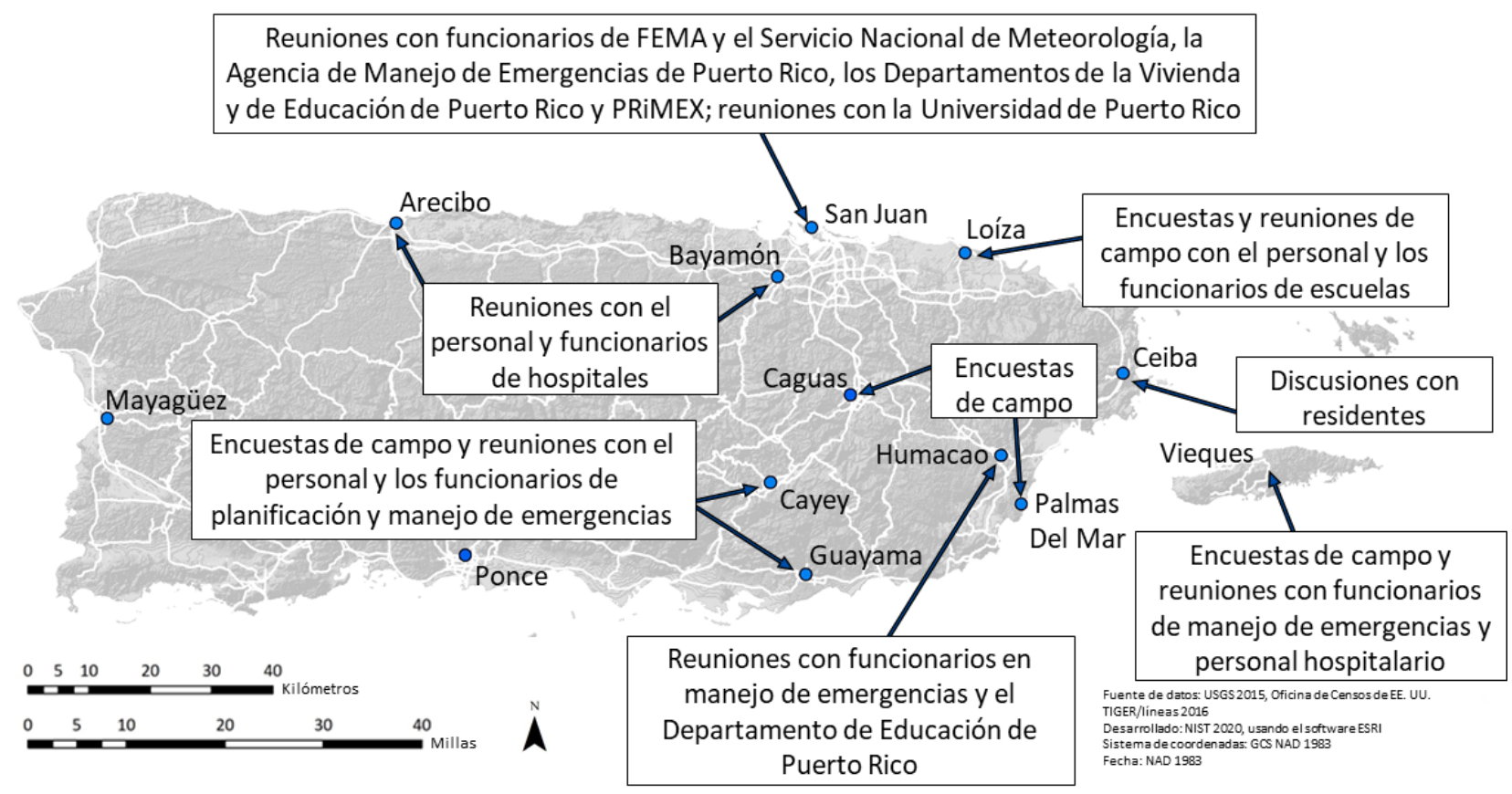

Figura 1: Ubicaciones de los sitios de recolección de datos del reconocimiento preliminar del NIST.

\section{$2.1 \quad$ Intensidad del peligro}

El huracán María, que se formó al oeste de las Antillas Menores como una tormenta tropical el 16 de septiembre de 2017, se intensificó en dos días hasta convertirse en un huracán categoría 5 en la escala Saffir-Simpson, con vientos máximos sostenidos de $175 \mathrm{mph}$. El huracán tocó tierra en Puerto Rico el 20 de septiembre de 2017, como una fuerte tormenta de categoría 4 con vientos sostenidos de $155 \mathrm{mph}$, el huracán más intenso que azotó a Puerto Rico desde el huracán Okeechobee de categoría 5 de 1928, conocido localmente como San Felipe. María impactó a Puerto Rico solo 13 días después del huracán Irma, que trajo vientos con fuerza de tormenta tropical, junto con lluvias significativas, a todo el Estado Libre Asociado.

El huracán tocó tierra cerca de Yabucoa y siguió en diagonal a través de Puerto Rico, con vientos huracanados que se extendieron por todo el Estado Libre Asociado. Las mayores velocidades del viento ocurrieron en el tercio este de Puerto Rico y en Vieques, con ráfagas máximas de viento sobre tierra estimadas en aproximadamente $140 \mathrm{mph}$, como se muestra en la Figura 2(a). Las velocidades máximas de ráfagas de viento estimadas en la Figura 2(a) se generaron pocos días después de que el huracán tocó tierra con base en las mediciones meteorológicas a nivel de superficie disponibles en ese momento, bajo una misión asignada de FEMA al NIST. Aunque se reconoció que la topografía montañosa de Puerto Rico habría resultado en un aumento significativo de la velocidad del viento en ciertas regiones, los efectos del aumento de velocidad topográfica no se incluyeron en estas estimaciones iniciales rápidas de velocidad del viento. 
El huracán María sometió a Puerto Rico a múltiples peligros además de fuertes vientos, que incluyen marejadas ciclónicas, fuertes lluvias e inundaciones y deslizamientos de tierra extensos, como se muestra en la Figura 2. La marejada ciclónica ocurrió alrededor de todo el perímetro de Puerto Rico y las islas más pequeñas del Estado Libre Asociado, con elevaciones de marejada en la mayoría de las áreas costeras que oscilan entre 2 pies y 6 pies sobre el nivel medio del mar (Figura 2(b)). La inundación resultante de la marejada ciclónica generalmente no se extendió mucho tierra adentro debido a las estrechas llanuras costeras. Se experimentaron fuertes lluvias en todo Puerto Rico, junto con inundaciones provocadas por la lluvia en gran parte del Estado Libre Asociado. Las acumulaciones totales de lluvia estimadas para el huracán María variaron entre 5 pulgadas y 40 pulgadas en todo Puerto Rico (Figura 2(c)). Sin embargo, muchas estaciones de medición de lluvia no pudieron informar debido a los daños sufridos por el huracán, lo que presenta importantes desafíos para cuantificar las precipitaciones de este evento. El huracán Irma también depositó un estimado de 5 a 15 pulgadas de lluvia en la mayor parte de Puerto Rico menos de dos semanas antes del huracán María, que dejó los suelos aún saturados de lluvia cuando el huracán María tocó tierra. Estos suelos presaturados contribuyeron a un mayor riesgo de inundaciones, inestabilidad de laderas y deslizamientos de tierra. Como se muestra en la Figura 2(d), muchos cientos de deslizamientos de tierra ocurrieron en todo Puerto Rico, principalmente concentrados dentro de las regiones montañosas centrales. Estos múltiples peligros para la seguridad de la vida presentaron desafíos en la atribución de muertes y lesiones asociadas con el evento, como se analiza con más detalle en la siguiente sección.

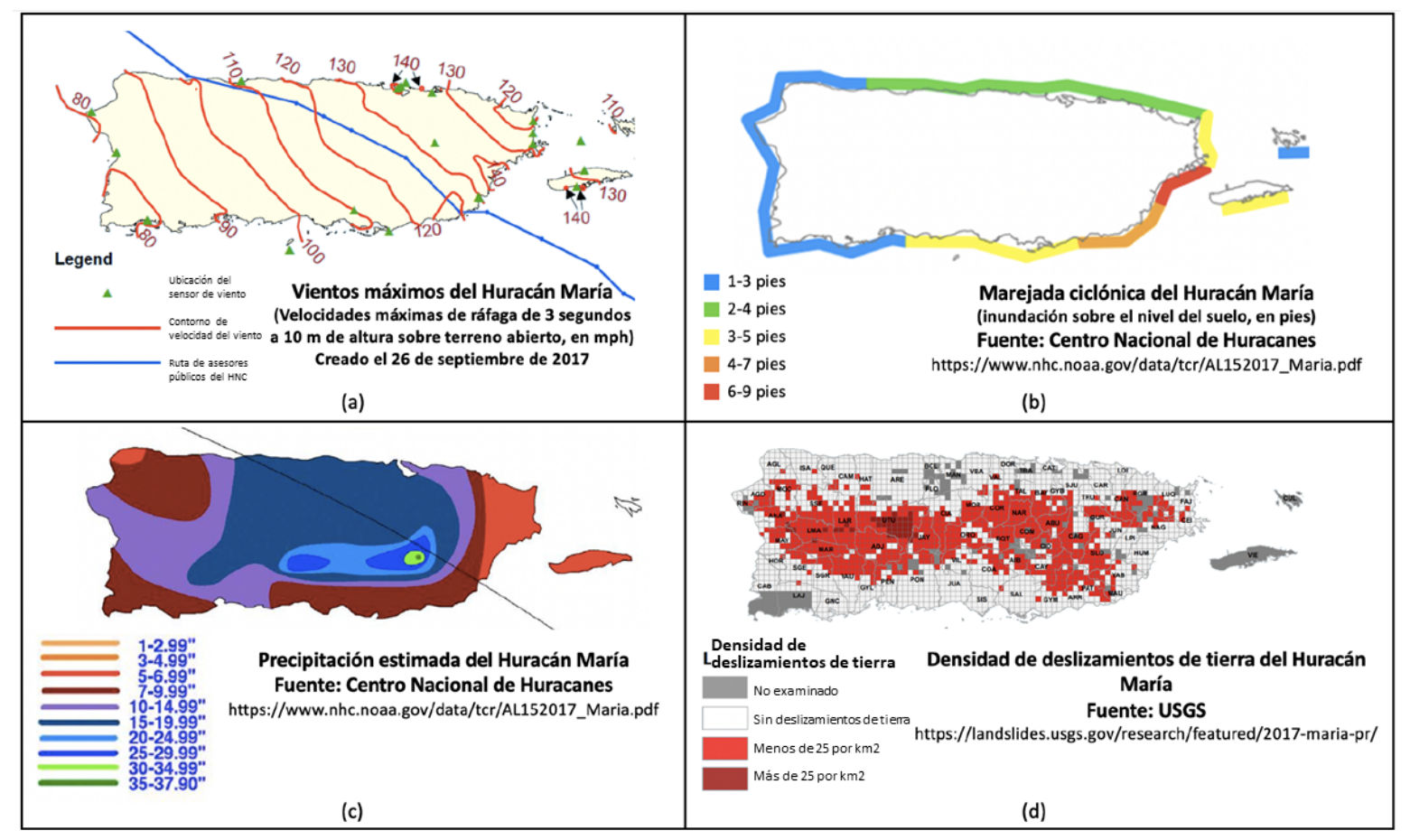

Figura 2: Peligros de tormenta del huracán María: (a) velocidades del viento, (b) marejada ciclónica, (c) lluvia, (d) deslizamientos de tierra. 
Todo el Estado Libre Asociado, con una población de 3.4 millones de personas antes del huracán María, estuvo expuesto a los impactos del huracán. Aproximadamente, 250 refugios se abrieron para el huracán, y aproximadamente el 15\% de esos refugios todavía estaban en funcionamiento en el momento del reconocimiento preliminar del NIST, tres meses después de que el huracán María tocara tierra. En ese momento, no había consenso sobre el número de muertes causadas por el huracán María, en parte debido a la ambigüedad en la definición de muertes relacionadas con el huracán. Debido a que los EE. UU. carecen de un enfoque estandarizado de recopilación de datos y presentación de informes para la atribución de muertes a eventos de desastres, 10 los certificados de defunción se utilizan como medio para evaluar las muertes relacionadas con desastres (tanto directas como indirectas). Esto a menudo resulta en una subestimación de las muertes atribuidas a desastres. En el momento del reconocimiento preliminar en diciembre de 2017, la cifra oficial de muertos por parte del Departamento de Seguridad Pública de Puerto Rico era de 64,11 aunque una estimación del New York Times indicó que la cifra real de muertos podría ser superior a 1000 según los análisis que utilizan datos de la Oficina de Registros de Estadísticas Vitales de Puerto Rico. ${ }^{12}$

\subsection{Daño físico a edificios e infraestructura}

El huracán sometió a los edificios y la infraestructura (incluidos los sistemas de transporte y servicios públicos) a velocidades de viento extremas en una gran área geográfica. La mayor parte de la mitad este de la isla experimentó ráfagas de viento máximas estimadas en exceso de $120 \mathrm{mph}$ (Figura 2(a)), y las ráfagas de viento pico máximas (aproximadamente $140 \mathrm{mph}$ ) se acercaron al nivel considerado en el diseño de algunos edificios y otras estructuras. ${ }^{13}$ Dentro del inventario de edificios, los edificios que no fueron diseñados por ingenieros experimentaron los daños físicos y la pérdida de función más graves, y se observaron daños extensos por el viento en las construcciones de madera de estructura ligera. Los edificios que no fueron diseñados por ingenieros con paredes en bloques de hormigón y techos con armazón de madera a menudo experimentaron una pérdida total del techo o daños extensos en el techo. La construcción no autorizada o "informal" tuvo un desempeño deficiente.

${ }^{10}$ Combs D.L., Quenemoen L.E., Parrish R.G., Davis J.H., 2009. "Evaluación de la mortalidad atribuida a desastres: Desarrollo y aplicación de una matriz de definición y clasificación”. International Journal of Epidemiology 28(6): pp. 1124-9.

${ }^{11}$ Como se discutió en la Sección 3.3.4, el Gobierno de Puerto Rico luego actualizó el recuento oficial de muertes a 2975 basado en el exceso de mortalidad estimado a partir de un estudio de la Universidad George Washington.

${ }^{12}$ Robles, F., Davis, K., Fink, S, Almukhtar, S., 2017. "Official Toll in Puerto Rico: 64. Las muertes reales pueden ser 1,052". El New York Times. 9 de diciembre de 2017.

${ }^{13}$ El FEMA MAT proporciona una revisión de las velocidades del viento de diseño para Puerto Rico: www.hsdl.org/?view\&did=818977 
Los sistemas de construcción diseñados por ingenieros comunes en Puerto Rico incluyen concreto reforzado y edificios de bloques de hormigón con techos de concreto, y las observaciones preliminares indicaron que este tipo de edificios generalmente sufrieron daños estructurales mínimos durante el huracán María. Se observaron algunas fallas en el techo en edificios de hormigón armado y bloques de hormigón con sistemas de techo de estructura de madera o acero, a diferencia de los techos de hormigón. Se observaron extensos daños por el viento en los sistemas de construcción de metal y se observó que la corrosión es un factor que contribuye a algunas de estas fallas inducidas por el viento en edificios de metal.

Aunque el equipo de reconocimiento preliminar observó un mejor desempeño estructural de los edificios diseñados por ingenieros, muchos de estos edificios sufrieron daños no estructurales extensos y pérdida de función debido a la penetración del agua de lluvia en las superficies exteriores del edificio. Los tipos de daños no estructurales observados que resultaron en la penetración del agua de lluvia incluyeron los siguientes (ver Figura 3):

- daños en la cubierta del techo y en el equipo sobre los techos por el viento y los escombros transportados por el viento (Figura 3a, b);

- daños en ventanas y puertas causados por el viento y los escombros transportados por el viento (Figura 3c);

- Iluvia acumulada en el techo debido a tasas de lluvia excesivas y escombros que bloquean los desagües;

- penetración de la lluvia impulsada por el viento a través del revestimiento en buen estado, como ventanas y puertas 
Se observaron comúnmente fallas inducidas por el viento en los equipos sobre los techos, y se observó que la corrosión es un factor en algunas de estas fallas.
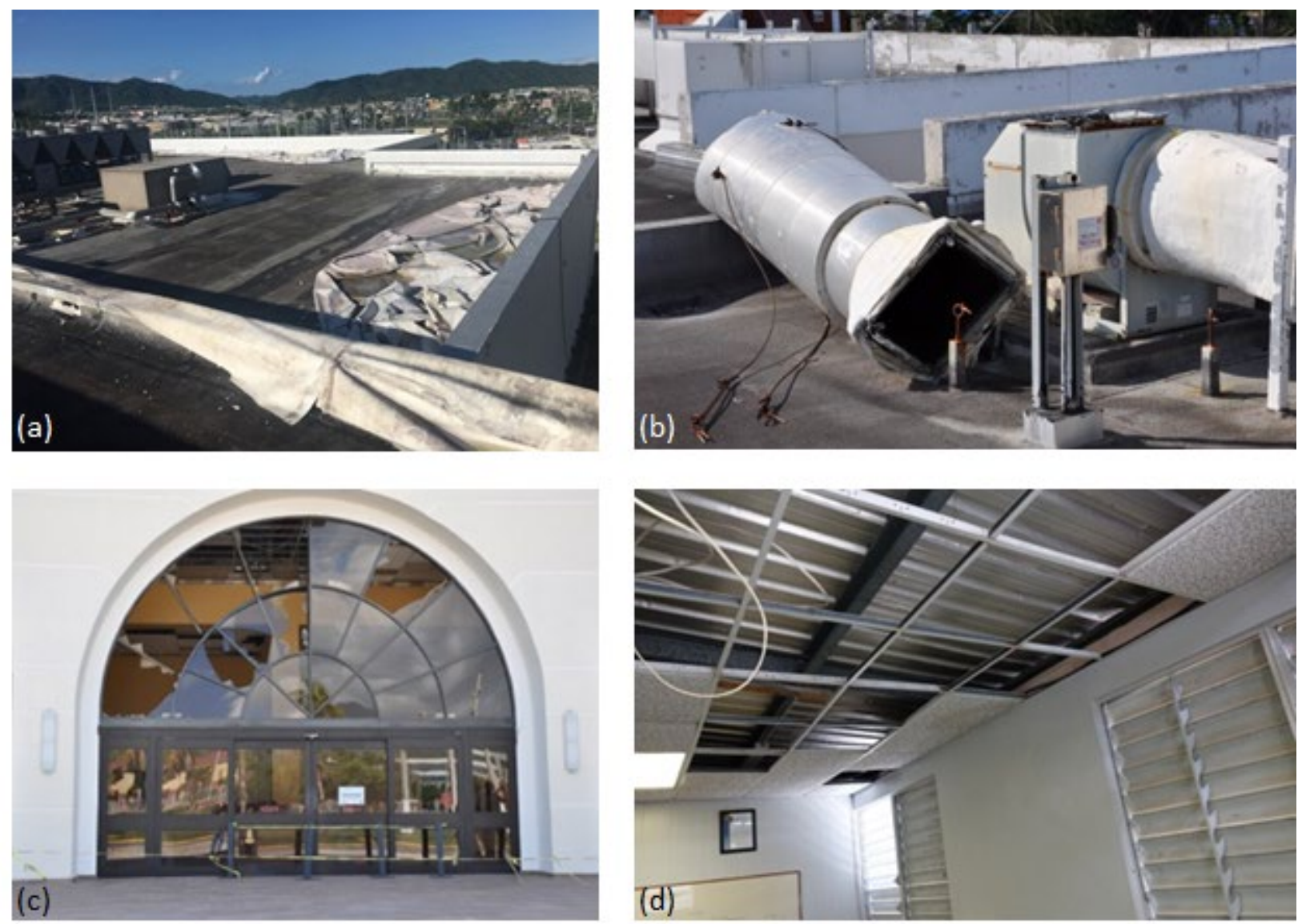

Figura 3: Daños no estructurales a edificios diseñados por ingenieros:

(a) daños en la cubierta del techo, (b) daño en el equipo del techo,

(c) daño en las ventanas, (d) daño interior causado por la penetración del agua de lluvia.

Además, el huracán María causó graves daños físicos y la pérdida de funcionamiento de los sistemas de infraestructura. Hubo un corte eléctrico completo en todo Puerto Rico, con extensos daños físicos a los sistemas de transmisión y distribución de energía eléctrica. Estas fallas de la infraestructura eléctrica tuvieron efectos en cascada en otros sistemas de infraestructura, incluidos el agua y las aguas residuales, el transporte y las comunicaciones. Hubo una pérdida casi completa de comunicaciones digitales en todo Puerto Rico. Los factores que contribuyeron a la pérdida generalizada de comunicaciones digitales, además de la pérdida de energía eléctrica, incluyeron daños físicos extensos a equipos de comunicaciones celulares montados en torres y edificios, daños extensos al cable de fibra óptica (que afectó las comunicaciones inalámbricas y alámbricas), y algunos derrumbes de torres celulares. Las fallas de infraestructura también tuvieron impactos en cascada en edificios críticos, con pérdida de energía y fallas en los generadores de respaldo que interrumpieron el funcionamiento de algunas escuelas e instalaciones de atención médica. 
La información de emergencia para el huracán María se proporcionó a través de múltiples canales y de múltiples fuentes, incluido el Servicio Nacional de Meteorología, los gobiernos locales y del Estado Libre Asociado, los medios de comunicación y las redes sociales. Investigaciones anteriores han demostrado que la credibilidad percibida de la fuente de información y los canales de comunicación son clave para una respuesta pública adecuada y eficiente a los mensajes de emergencia. Esto se vuelve especialmente cierto cuando existen numerosas fuentes que proporcionan mensajes potencialmente diferentes. Las observaciones y discusiones preliminares identificaron muchos desafíos para la respuesta de emergencia, el desalojo y otras acciones de protección durante y después del huracán; estos desafíos se vieron agravados por la falla de los sistemas de comunicaciones en todo Puerto Rico.

La falla casi total de los sistemas de comunicaciones provocó una falta de comunicación entre los funcionarios de emergencia, las instalaciones críticas, los refugios y el público durante un período prolongado. Los funcionarios y los residentes se basaron en técnicas de comunicación menos eficientes para entregar y recuperar información. Por ejemplo, hubo un uso generalizado de "corredores" para transmitir información directamente a los destinatarios previstos. Sin embargo, el transporte en la isla hizo que esta tarea fuera un desafío en muchos casos y resultó en una transmisión incompleta o retrasada de información crítica necesaria para una respuesta y recuperación efectivas. Varias estaciones de radio AM pudieron continuar sus operaciones, lo que requirió presencia física, pero permitió comunicaciones con partes del público a distancia. Los operadores de radioaficionados permitieron que algunas comunicaciones continuaran durante e inmediatamente después del huracán; sin embargo, la isla contaba con pocos operadores de este tipo antes del evento. En resumen, los administradores de emergencias, los socorristas, otros funcionarios del gobierno, las empresas y los residentes de Puerto Rico dependían principalmente de las comunicaciones tradicionales de telefonía fija y celular, pocas de las cuales estuvieron disponibles durante y por un período prolongado después del evento.

Entre las actividades de respuesta a emergencias que plantearon un desafío inmediato se encontraban los casos de inundaciones y rescates relacionados que ocurrieron en varios municipios de la isla. Estos eventos plantean preguntas sobre los tipos de advertencias de desalojo que reciben los residentes y su respuesta a estas advertencias. Por ejemplo, los informes indicaron que algunas personas se sentían más seguras permaneciendo en sus hogares que yendo a un refugio. Sin embargo, dado que algunas áreas experimentaron inundaciones por primera vez, los residentes pueden haber evaluado incorrectamente la seguridad de sus hogares. Las percepciones y preocupaciones de los residentes con respecto al desalojo y otras acciones de protección son una parte importante para comprender su comprensión de los mensajes de comunicación de riesgos y el cumplimiento de las instrucciones de desalojo. Un análisis más detallado del contenido de los mensajes, cómo se recibieron los mensajes y los procesos de toma de decisiones de desalojo es importante para determinar cómo respondió el público a los mensajes de emergencia. 
Los impactos del huracán María fueron físicos, económicos y sociales, y todos fueron extensos. Las pérdidas económicas, incluidos los cierres de establecimientos comerciales, no se documentaron completamente a diciembre de 2017. Las empresas, las personas y la economía en general en Puerto Rico dependen en gran medida de una cadena de suministro compuesta por muchas pequeñas empresas, particularmente en los sectores de manufactura y servicios, con amplios servicios de envío. Incluso sin datos precisos, es evidente que el daño que sufrieron, así como el grado y la rapidez de su recuperación, son factores clave para determinar la salud futura y el crecimiento potencial de la economía de la isla en el futuro.

Entre los impactos más graves se encuentran los que afectan las funciones sociales de Puerto Rico. Esto incluye el sector de la educación, con muchos edificios escolares que sufren daños estructurales, daños no estructurales o la pérdida de servicios de infraestructura crítica y, en algunos casos, los tres. Además, muchas escuelas que no sufrieron daños o sufrieron daños menores, también fueron designadas para servir como refugios de emergencia para las poblaciones locales. No era inusual que esas escuelas siguieran sirviendo como refugios, en lugar de escuelas, durante meses después del huracán, lo que afectó directamente la educación de la población en edad escolar de Puerto Rico y, posteriormente, complicó el cuidado infantil para muchas familias.

De manera similar, muchos de los edificios críticos en los que se confiaba para brindar atención médica a la población no sufrieron daños estructurales graves, pero las operaciones aún se vieron afectadas por la falta de capacidad de comunicaciones y energía eléctrica. Otros edificios experimentaron daños no estructurales, como fallas en el generador. Este daño, entre otros factores, afectó ampliamente la prestación de servicios de salud en Puerto Rico. Los pacientes de varias instalaciones se vieron obligados a desalojar, lo que podría provocar una mayor degradación de sus condiciones.

La combinación de daños físicos y crisis relacionadas posteriores a la tormenta (por ejemplo, distribución de alimentos, agua y combustible) generó incertidumbre y estrés entre la población. Las comunidades de Puerto Rico experimentaron importantes trastornos sociales, en algunos casos lo suficientemente graves como para poner en peligro su viabilidad futura.

Después del reconocimiento preliminar, el Equipo notó la pérdida significativa de población (emigración) que ocurrió en todo Puerto Rico como resultado del huracán María. ${ }^{14}$

\subsection{Decisión de establecer un equipo}

La Ley NCST y sus regulaciones de implementación (15 CFR Parte 270.102)15 establecen los criterios que el Director del NIST debe usar para determinar si establecer y desplegar un Equipo “después de un evento que causó la falla de un edificio o edificios que resultó en una pérdida sustancial de vidas o plantean un potencial significativo de pérdida sustancial de vidas". Los

\footnotetext{
14 https://www.census.gov/library/stories/2020/08/estimating-puerto-rico-population-after-hurricane-maria.html

15 https://www.ecfr.gov/cgi-bin/text-idx?SID=23c803795bccfbf11fcb929f4ab5692e\&mc=true\&node=pt15.1.270
} 
criterios a considerar y el análisis del evento del huracán María contra cada criterio se presentan a continuación.

Criterio 1: El evento fue uno de los siguientes:

(i) Una falla importante de uno o más edificios o tipos de edificios debido a un evento natural extremo (terremoto, huracán, tornado, inundación, etc.);

(ii) Un incendio que resultó en una falla del edificio de origen y/o se extendió más allá del edificio de origen;

(iii) Una falla importante en un edificio en condiciones significativamente menores que su base de diseño, durante la construcción o mientras está en uso activo; o

(iv) Un acto de terrorismo u otro evento que resulte en una declaración presidencial de desastre y activación del Plan Nacional de Respuesta.

Análisis: La tormenta del 20 de septiembre de 2017 en Puerto Rico cae dentro de la categoría (i). El huracán provocó fallas en muchos edificios, incluidas fallas en las superficies exteriores de los edificios y los sistemas no estructurales que resultaron en la pérdida de la función de los edificios diseñados por ingenieros que albergaban servicios esenciales. De las muchas muertes atribuidas al huracán María, aún no se conoce la cantidad de muertes que resultaron directamente de fallas en los edificios. Sin embargo, las fallas de estos edificios ciertamente plantearon un potencial significativo de pérdida sustancial de vidas.

Criterio 2: Una investigación de búsqueda de hechos del desempeño de los edificios y los procedimientos de respuesta de emergencia y desalojo probablemente resultará en un conocimiento nuevo y significativo o en recomendaciones de revisión del código de construcción necesarias para reducir o mitigar el riesgo público y las pérdidas económicas de futuras fallas en los edificios.

Análisis: El huracán produjo velocidades de viento inusuales cercanas al diseño para edificios diseñados por ingenieros y otras estructuras en una gran área geográfica que alberga un inventario de edificios heterogéneos, lo que brinda una oportunidad única para evaluar la efectividad de los objetivos de desempeño establecidos por los estándares de diseño actuales para edificios críticos. Este evento también brinda una oportunidad única para evaluar los estándares y prácticas de comunicaciones de emergencia en un entorno que experimentó fallas de infraestructura generalizadas y duraderas. Por lo tanto, se espera que una investigación del desempeño de edificios durante y después de la tormenta, y de los desafíos en los procedimientos de desalojo y respuesta a emergencias, resulte en conocimientos novedosos que conducirán a recomendaciones importantes para códigos, estándares y prácticas.

Al evaluar los criterios establecidos anteriormente, el Director del NIST también consideró los cinco factores enumerados en 15 CFR 270.102 (b) y llegó a las siguientes conclusiones con respecto a estos factores:

1. Se dispone de suficientes recursos financieros y de personal para realizar una investigación. 
2. La investigación de las fallas en los edificios causadas por el huracán María amerita las capacidades y experiencias avanzadas de un Equipo Nacional de Seguridad en la Construcción.

3. Aunque algunas de las causas técnicas de las fallas en los edificios son evidentes, es probable que la investigación dé lugar a conocimientos relevantes con potencial para nuevas recomendaciones para cambios en los códigos, estándares y prácticas.

4. El despliegue de un equipo no duplicará sustancialmente los recursos locales o estatales iguales en capacidad y calidad de investigación y análisis para un Equipo Nacional de Seguridad en la Construcción.

5. Con base en el reconocimiento preliminar de los sitios de fallas en los edificios, se recomienda un estudio adicional del evento.

Con base en la información recopilada durante el reconocimiento preliminar y el análisis de los criterios descritos anteriormente, el 21 de febrero de 2018, el Director del NIST estableció un Equipo bajo la Ley NCST para realizar una investigación técnica del evento del huracán María. 


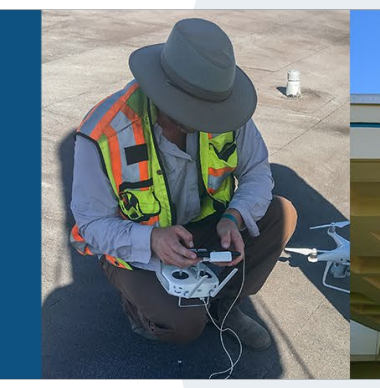

\section{El Programa del Huracán María del}

\section{NIST}

\subsection{Alcance y metas}

El Programa del Huracán María del NIST comprende dos estudios distintos pero complementarios de los impactos del huracán María en Puerto Rico, que se están llevando a cabo bajo las dos autoridades descritas anteriormente en la Sección 1.1: una investigación técnica bajo la Ley del Equipo Nacional de Seguridad en la Construcción y un estudio de investigación bajo la Ley Nacional de Reducción de Impacto de Vendavales.

Los objetivos de la investigación técnica del NCST son caracterizar:

1. el entorno eólico y las condiciones técnicas asociadas con muertes y lesiones;

2. el desempeño de los edificios críticos representativos y las áreas seguras designadas en esos edificios, incluida su dependencia de las líneas de sustento; y

3. el desempeño de los sistemas de comunicaciones de emergencia y la respuesta del público a tales comunicaciones.

Los objetivos del estudio de investigación NWIRP son caracterizar los impactos y la recuperación de:

1. manufactureros pequeños y medianos (SMMs, por sus siglas en inglés), así como empresas de la industria minorista y de servicios;

2. servicios de educación y salud; $y$

3. sistemas de infraestructura, con un enfoque en la infraestructura que respalda el funcionamiento de edificios críticos (es decir, hospitales y escuelas) y comunicaciones de emergencia.

Al realizar estos estudios distintos pero complementarios como parte de un solo esfuerzo coordinado, el Programa del Huracán María permitirá una caracterización más completa de los 
impactos del huracán en Puerto Rico de lo que cualquiera de los dos estudios proporcionaría por sí solo. Por ejemplo, las fallas de edificios pueden considerarse en el contexto de los servicios sociales que brindan los edificios y la recuperación de esos servicios a lo largo del tiempo, y las fallas de infraestructura pueden considerarse en el contexto de los edificios críticos cuyo funcionamiento apoyan. Se espera que el beneficio de este contexto más amplio fortalezca los hallazgos y recomendaciones que finalmente se desarrollarán a partir de la investigación del NCST.

\subsection{Liderazgo y miembros del equipo}

Los colaboradores del Programa del Huracán María del NIST16 representan una variedad de disciplinas técnicas, que incluyen ingeniería civil, eólica y estructural; sociología; ciencias económicas; antropología; investigación de operaciones; meteorología; y epidemiología. Un subconjunto de estos contribuyentes, que se enumeran a continuación, ha sido designado por el Director del NIST como miembros formales del Equipo Nacional de Seguridad en la Construcción que investiga los efectos del huracán María en Puerto Rico. Además de los empleados del NIST, los miembros formales del NCST incluyen expertos externos del Servicio Nacional de Meteorología, el Centro Nacional de Medicina y Salud Pública en Desastres y la Universidad de Puerto Rico en Mayagüez.

\subsubsection{Liderazgo del equipo}

A partir del 13 de febrero de 2020, el Director del NIST designó al Dr. Joseph Main como Investigador Técnico Principal de la investigación del huracán María NCST, y la Dra. Maria Dillard ha sido designada como Investigadora Técnica Principal Asociada. Antes de esa fecha, la Dra. Erica Kuligowski era la investigadora técnica principal, habiendo dirigido la investigación del NCST desde su establecimiento en febrero de 2018, y el Dr. Main anteriormente se desempeñaba como investigador técnico principal asociado. ${ }^{17} \mathrm{El}$ Dr. Main también se desempeña como Gerente de Programa para el programa más grande del huracán María, y la Dra. Maria Dillard es la Gerente Asociada del Programa.

\subsubsection{Miembros del Equipo Nacional de Seguridad en la Construcción}

La siguiente es una lista de los empleados del NIST que han sido designados por el Director del NIST como miembros formales del Equipo Nacional de Seguridad en la Construcción del huracán María. Todos estos empleados del NIST están afiliados al Laboratorio de Ingeniería

\footnotetext{
16 www.nist.gov/topics/disaster-failure-studies/hurricane-maria/hurricane-maria-team

${ }^{17}$ Los cambios de liderazgo del Programa del Huracán María se produjeron con la salida del NIST de la Dra. Erica Kuligowski.
} 
(EL, por sus siglas en inglés) del NIST. Sus afiliaciones dentro del EL y sus áreas de especialización relevantes se enumeran a continuación.

\section{Dr. Joseph Main, investigador técnico principal}

Afiliación: Ingeniero Estructural de Investigación, Grupo de Estructuras

Áreas de especialización relevantes: cargas de viento en estructuras y evaluación

computacional del desempeño estructural bajo cargas extremas, incluido el modelado de la respuesta de los sistemas estructurales más allá de la falla local al colapso global

\section{Dra. Maria Dillard, investigadora técnica principal asociada}

Afiliación: Directora Interina, Programa de Estudios sobre Desastres y Fallas, e Investigadora Científica Social, Grupo de Resiliencia Comunitaria

Áreas de especialización relevantes: respuesta de la comunidad a peligros y factores estresantes crónicos, métodos para medir y modelar la resiliencia de la comunidad, experiencia en muestreo y encuestas

\section{Dra. Erica Kuligowski, investigadora técnica principal (febrero de 2018 a febrero de 2020) Afiliación: Investigadora Científica Social, Grupo de Incendios de Interfaz Urbano-Forestal Áreas de especialización relevantes: comportamiento humano en emergencias, incluidos los comportamientos de preparación, respuesta y recuperación, comunicaciones de emergencia, resiliencia comunitaria, modelado de comportamiento y modelado de sistemas sociales}

\section{Sr. Benjamin Davis}

Afiliación: Analista de gestión y programas, Programa de Estudios de Desastres y Fallas Áreas de especialización relevantes: gestión de proyectos y soporte de contratos

\section{Dra. Jazalyn Dukes}

Afiliación: Ingeniera Estructural de Investigación, Grupo de Ingeniería Sísmica

Áreas de especialización relevantes: ingeniería sísmica, modernizaciones sísmicas de edificios e infraestructura existentes, evaluación y modelado de daños

\section{Dr. Kenneth Harrison}

Afiliación: Analista de Investigación de Operaciones, Grupo de Resiliencia de Comunidades Áreas de especialización relevantes: toma de decisiones en condiciones de incertidumbre, modelado de infraestructura, interdependencias de la infraestructura distribuida y funciones de edificios, análisis de sistemas

\section{Dra. Jennifer Helgeson}

Afiliación: Economista de Investigaciones, Oficina de Economía Aplicada

Áreas de especialización relevantes: resiliencia a los peligros en el entorno construido, con consideración de la rentabilidad de los esfuerzos de mitigación y adaptación a escala comunitaria, experiencia en muestreo y encuestas 


\section{Dra. Katherine Johnson}

Afiliación: Investigadora Científica Social, Grupo de ingeniería Sísmica

Áreas de especialización relevantes: ciencias sociales, política de mitigación del riesgo sísmico, percepción del riesgo y comunicaciones

\section{Dr. Marc Levitan}

Afiliación: Ingeniero Estructural de Investigación, Grupo de Estructuras

Áreas de especialización relevantes: estándares para la instrumentación y su implementación para medir el viento, respuesta estructural a cargas críticas de viento, desarrollo de estándares de viento, códigos de modelos y mejores prácticas de construcción

\section{Dra. Judith Mitrani-Reiser}

Afiliación: Jefa Asociada, División de Materiales y Sistemas Estructurales

Áreas de especialización relevantes: desempeño de instalaciones críticas, desarrollo de herramientas estructuradas para reconocimiento de campo, impactos económicos y de seguridad de los peligros en el entorno construido e interacción de los seres humanos con el entorno construido

\section{Dr. Scott Weaver}

Afiliación: Director, Programa Nacional de Reducción del Impacto de Vendavales Áreas de especialización relevantes: análisis dinámicos y de diagnóstico de la variabilidad del hidroclima de América del Norte en conjuntos de datos de modelos climáticos y restringidos por observación, y caracterización de eventos climáticos extremos (es decir, sequías e inundaciones).

\section{Dr. DongHun Yeo}

Afiliación: Ingeniero Estructural de Investigación, Grupo de Estructuras

Áreas de especialización relevantes: climatología de vientos extremos, vientos atmosféricos con límite de capa, aerodinámica de cuerpo no fuselado, dinámica de fluidos computacional, pruebas en túnel de viento, análisis avanzado del desempeño estructural bajo cargas de viento, desarrollo de disposiciones de carga de viento en estándares

Además de estos empleados del NIST, el Director del NIST también ha designado a los siguientes expertos externos como miembros formales del Equipo Nacional de Seguridad en la Construcción del huracán María.

\section{Dr. Luis D. Aponte-Bermúdez}

Afiliación: Contratista Federal, Stantec, Inc., y Profesor, Departamento de Ingeniería Civil y Agrimensura, Universidad de Puerto Rico en Mayagüez

Áreas de especialización relevantes: Mediciones y modelado del entorno eólico en Puerto Rico y evaluación de daños a edificios posteriores al huracán 


\section{Sr. Joel Cline}

Afiliación: Coordinador del Programa Tropical, Servicio Nacional de Meteorología (NWS), Administración Nacional Oceánica y Atmosférica (NOAA)

Áreas de especialización relevantes: peligros climáticos tropicales, vientos huracanados e inundaciones costeras, pronóstico operativo de huracanes, comunicación de riesgos, evaluación de actividades de comunicación después de un huracán

\section{Dr. Thomas Kirsch}

Afiliación: Centro Nacional de Medicina y Salud Pública en Desastres (NCDMPH), Universidad de Servicios Uniformados de Ciencias de la Salud (USUHS)

Áreas de especialización relevantes: médico de emergencias licenciado, gestión y ciencia de desastres, y métodos epidemiológicos cualitativos y cuantitativos para mejorar la evaluación y la gestión de desastres

\subsection{Plan técnico y proyectos}

El NIST ha organizado el Programa del Huracán María en siete proyectos técnicos, varios de los cuales están interrelacionados, y un proyecto administrativo. Las siguientes subsecciones describen los antecedentes, el objetivo y el plan de cada uno de los siete proyectos técnicos.

Para proporcionar un alcance apropiado para el Programa del Huracán María y al mismo tiempo conservar las principales oportunidades de hallazgos y recomendaciones que resultarán, el Equipo NIST ha seleccionado cuatro regiones de Puerto Rico para un enfoque particular. Estas regiones fueron seleccionadas a la luz de su diversidad geográfica y socioeconómica, la trayectoria de la tormenta y la variedad de peligros e impactos del huracán María en estas regiones (es decir, lluvias e inundaciones, deslizamientos de tierra, velocidades del viento e impactos en hospitales y escuelas). Las cuatro regiones seleccionadas son las regiones de San Juan, Caguas, Humacao y Utuado (Figura 4), que comprenden 26 municipios. Algunos proyectos requerirán recopilación y evaluación de información más allá de estas cuatro regiones para alinearse con las metas y objetivos del trabajo, y varios proyectos han seleccionado el municipio de Mayagüez como área adicional de estudio. Sin embargo, todos los proyectos técnicos planean priorizar la recopilación y el análisis de datos en las cuatro regiones seleccionadas, y la selección de estas regiones facilita la coordinación entre los múltiples proyectos dentro del Programa del Huracán María. La base inicial para la selección de estas regiones fue el mapa de 2017 de zonas de gestión de emergencias, que estaba en vigor en el momento del huracán María. Aunque las zonas de manejo de emergencias se han revisado desde 2017, el Equipo del NIST mantiene la selección de estas cuatro regiones de enfoque para el Programa del Huracán María. En agosto de 2018, los miembros del Equipo NIST visitaron hospitales, escuelas, refugios y comunidades seleccionados en cada una de las cuatro regiones para finalizar la selección de estas regiones de enfoque común. 


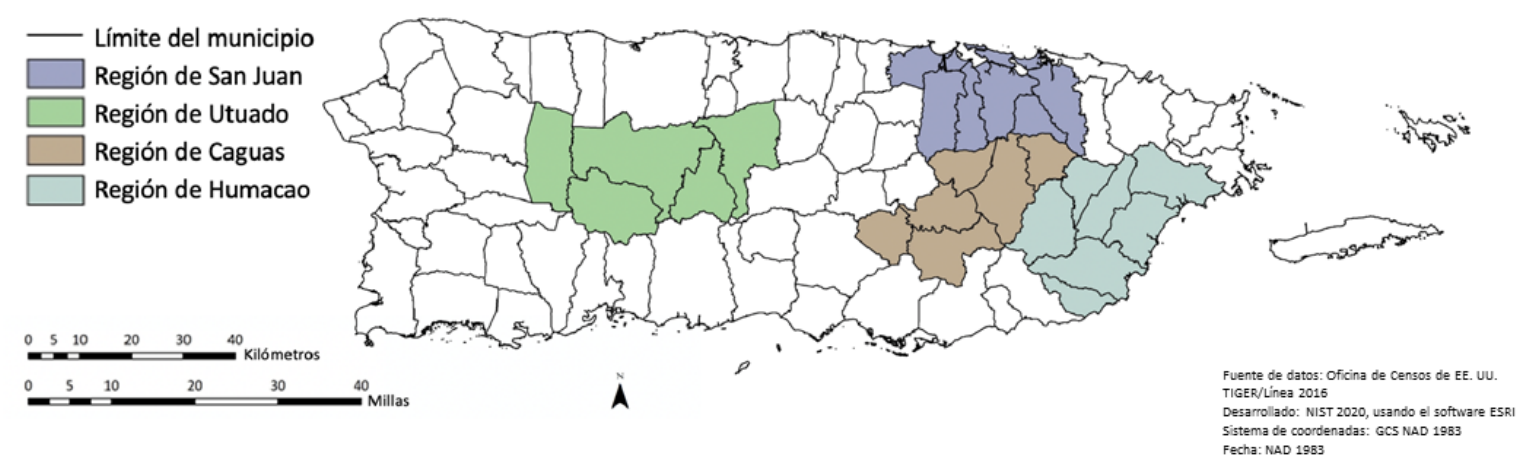

Figura 4: Regiones de estudio para el Programa del Huracán María del NIST.

\subsubsection{Caracterización de peligros}

Antecedentes: La caracterización precisa de los múltiples peligros asociados con el huracán María es de fundamental importancia para múltiples proyectos en todo el programa. La información sobre peligros es un insumo fundamental para evaluar el desempeño de los edificios y la infraestructura, y proporciona un contexto importante para la evaluación de las comunicaciones de emergencia y la respuesta pública, las muertes y lesiones, y la recuperación de las funciones comerciales y sociales. Como se discutió en la Sección 2.1, el huracán María sometió a Puerto Rico a múltiples peligros, incluidos vientos extremos, inundaciones costeras y fuertes lluvias, que resultaron en inundaciones y deslizamientos de tierra, tierra adentro. La tormenta causó grandes daños a la instrumentación, introduciendo desafíos importantes en la cuantificación de peligros. En algunos casos, se requerirá una combinación de mediciones y modelos para caracterizar la variación espacial y temporal de los peligros. Se reconoce que la topografía de Puerto Rico (colinas y montañas) puede aumentar drásticamente la velocidad del viento en comparación con el mismo patrón meteorológico sobre terreno plano, aunque este efecto no se capturó en las estimaciones iniciales de velocidad del viento para el huracán María (Figura 2(a)). La cuantificación de este "aumento de velocidad topográfica" es importante para tener una comprensión precisa de las cargas de viento experimentadas por las estructuras de interés, especialmente porque la infraestructura crítica (p. ej., torres de telefonía y torres de transmisión) a menudo se encuentran en crestas y terrenos altos, al igual que algunos edificios.

Objetivo: Caracterizar el entorno de viento asociado con el impacto del huracán María en Puerto Rico, incluidos los efectos topográficos, y documentar otros peligros asociados con el huracán, como marejadas ciclónicas, lluvias, inundaciones y deslizamientos de tierra.

Plan: El peligro del viento del huracán María en Puerto Rico está siendo investigado exhaustivamente por cuatro métodos de investigación que consisten en modelado de campo de vientos, pruebas de túnel de viento, mediciones de campo y simulaciones CFD (Dinámica de fluidos computacional). Esta investigación se enfoca en (1) la identificación de los efectos del aumento de velocidad del viento con base en el modelado de túnel de viento de la topografía de Puerto Rico, en conjunto con simulaciones CFD y mediciones de campo y (2) la integración de los resultados de estos estudios topográficos con 
un modelo de campo de vientos de huracán para caracterizar con precisión el entorno eólico asociado con el impacto del huracán María en Puerto Rico.

El plan de investigación detallado para la caracterización del peligro del viento es para:

- Desarrollar el modelo inicial de campo de vientos de huracán basado en métodos empíricos existentes utilizando observaciones a nivel de superficie de la velocidad del viento (ráfagas y media), dirección del viento y presión atmosférica en todo Puerto Rico, adquiridas de estaciones y mesonets (redes de monitoreo) meteorológicas federales, estatales y otras. El modelo inicial proporcionará datos preliminares del campo de vientos del huracán María para ayudar en el desarrollo de los planes del proyecto en la etapa inicial de la investigación.

- Realizar pruebas de túnel de viento en modelos topográficos genéricos que constan de características bidimensionales de cresta y meseta. Las pruebas topográficas genéricas proporcionarán los conjuntos de datos para validar los resultados numéricos de los modelos CFD que se están desarrollando.

- Realizar pruebas de túnel de viento en modelos de regiones de Puerto Rico que representan a Mayagüez y Yabucoa. Los datos de prueba del modelo de Mayagüez se utilizarán para la caracterización del viento en esa región y para la información de flujo de aproximación para las pruebas del modelo de edificio/área en el proyecto de Desempeño de Edificios Críticos. Los datos de campo de vientos de las pruebas del modelo de Yabucoa se compararán con las contrapartes de las mediciones de campo y las simulaciones CFD.

- Implementar e instalar anemómetros a múltiples alturas en torres celulares en un área de Puerto Rico con efectos topográficos significativos para obtener datos de velocidad del viento a escala completa. Los datos se recopilarán durante un año. Los datos de campo se utilizarán para evaluar los efectos topográficos sobre los perfiles de velocidad del viento a escala completa y compararlos con los obtenidos de las pruebas de túnel de viento y los modelos CFD.

- Desarrollar modelos CFD para simulaciones topográficas, verificar simulaciones CFD y validar los resultados CFD con datos de medición de campos y túnel de viento. Estos modelos CFD validados se utilizarán luego para evaluar y caracterizar los efectos de aumento de velocidad topográfica en Puerto Rico.

- Mejorar el modelo de campo de vientos inicial optimizando el ajuste del modelo de huracanes a los datos de campo de vientos asimétricos observados, con base en la evaluación estadística de bondad de ajuste, incluida la cuantificación de la incertidumbre, con la incorporación de registros de medición de viento adicionales que se hayan identificado.

- Finalizar el modelo de campo de vientos ajustado de manera óptima una vez que se obtengan y analicen los datos topográficos de aumento de velocidad del viento de los experimentos del túnel de viento, las mediciones de campos y las simulaciones CFD. El modelo de campo de vientos final generará los registros de tiempo de velocidad y 
dirección del viento del huracán María en ubicaciones cuadriculadas en todo Puerto Rico para caracterizar el peligro del viento para otros aspectos de la investigación.

Además de caracterizar los diversos parámetros de velocidad del viento de interés, es necesario evaluar y documentar otros peligros que afectaron a Puerto Rico durante el huracán María. Para lograr esto, el NIST está llevando a cabo actividades de acercamiento con otras agencias federales de ciencias de la tierra y ha recopilado información sobre deslizamientos de tierra, marejadas ciclónicas, lluvias e inundaciones a partir de sus análisis de los impactos de peligro del huracán María en Puerto Rico. Dada la sorprendente variabilidad en las estimaciones de lluvia total sobre Puerto Rico para los huracanes Irma y María y el papel central de la lluvia en causar inundaciones y deslizamientos de tierra, el NIST también está llevando a cabo una evaluación detallada de los problemas de la ciencia de medición asociados con las observaciones dispares de lluvia de diferentes fuentes de medición. Las mediciones de las precipitaciones juegan un papel importante como entrada principal en los modelos hidrológicos utilizados para predecir inundaciones y deslizamientos de tierra y para desarrollar mapas retrospectivos de estos peligros en las investigaciones posteriores a los vendavales.

El plan técnico para otros peligros del huracán María es para:

- Continuar el acercamiento a otras agencias y organizaciones con respecto a las fuentes de datos y las capacidades de modelado que pueden estar disponibles para caracterizar mejor los peligros y su variación espacial y temporal.

- Continuar evaluando una serie de observaciones de lluvia in situ y por detección remota para comprender mejor las diferencias de la plataforma de medición en función de la gravedad del evento u otros parámetros relevantes (por ejemplo, topografía).

- Evaluar la evolución de las precipitaciones subdiarias en función de la plataforma de medición y la gravedad del evento para comprender mejor la evolución de los sesgos de medición y las relaciones temporales con el peligro de viento primario.

\subsubsection{Desempeño de edificios críticos}

Antecedentes: Aunque el daño estructural a los edificios diseñados por ingenieros fue generalmente limitado, se sufrieron daños significativos en las superficies exteriores de los edificios, incluidos los daños a las cubiertas de los techos, los equipos en los techos, las ventanas y las puertas causados por el viento y los escombros arrastrados por el viento. La penetración del agua de lluvia a través de las superficies exteriores de los edificios resultó en daños no estructurales extensos y la pérdida de función de muchos edificios diseñados por ingenieros. La pérdida de energía y la falla de los generadores de respaldo también interrumpieron el funcionamiento de muchos edificios, incluidos algunos edificios críticos como hospitales, escuelas y refugios para tormentas. Comprender el desempeño de los hospitales y los refugios para tormentas (muchos de los cuales eran escuelas) es de particular importancia, no solo por su papel fundamental en la respuesta a desastres, sino también porque estas instalaciones fueron generalmente diseñadas con los mismos códigos y normas de construcción que se utilizan en otras partes de Estados Unidos. Por lo tanto, las lecciones aprendidas 
del desempeño de estas instalaciones pueden informar los hallazgos y recomendaciones para las mejoras que pueden ser necesarias para los códigos y estándares de construcción existentes.

Objetivo: Caracterizar el desempeño de edificios críticos en el huracán María evaluando el daño y la pérdida de función de los hospitales, escuelas y refugios para tormentas representativos con respecto a los peligros que experimentaron y evaluando los criterios de selección y los requisitos de diseño de los refugios para tormentas.

Plan: La fase inicial de recopilación de datos, en coordinación con agencias gubernamentales de Puerto Rico, socios federales y otras organizaciones, busca identificar y recopilar datos existentes relevantes sobre las características y el desempeño de edificios críticos en el huracán María. Estos edificios incluyen hospitales, escuelas y refugios para tormentas. La recopilación de datos inicial también incluirá información sobre el programa de refugios en Puerto Rico, tales como los criterios de selección de refugios y las instalaciones utilizadas durante el huracán María. Luego, se seleccionarán hospitales, escuelas y refugios representativos para una evaluación detallada en función de las características de los edificios, la exposición al peligro, los daños informados y otros factores. Se realizarán evaluaciones detalladas de las instalaciones críticas para documentar las características físicas de los edificios antes del huracán María y los impactos en los edificios que resultaron del huracán. Esto incluye impactos en la seguridad de la vida y en la función y operación de la instalación. Para un subconjunto de los edificios críticos seleccionados, se estudiarán los efectos de la topografía, los edificios y el terreno circundantes sobre las cargas de viento utilizando modelos a escala de edificios en el túnel de viento.

Los datos recopilados se utilizarán para evaluar el desempeño de los edificios críticos seleccionados, considerando las cargas de viento y otros peligros experimentados durante el huracán María, los impactos de estos peligros en la función del edificio y la seguridad de la vida de los ocupantes (incluidos los desafíos operativos encontrados), y cuán adecuados son los códigos, normas y prácticas existentes. También se evaluarán los criterios de selección y diseño de refugios y la orientación operativa para la población más grande de refugios en Puerto Rico. Se considerarán los niveles de peligro encontrados en los sitios de refugio, el daño a los edificios de refugio, la población de refugio por sitio a lo largo del tiempo, incluida la reubicación de ocupantes, y la idoneidad de los criterios de selección y diseño existentes y los planes de operaciones de refugio. Finalmente, se harán recomendaciones, según corresponda, para mejoras específicas a los estándares, códigos y prácticas de construcción. Reconociendo que Puerto Rico está sujeto a peligros sísmicos y de viento significativos, tanto los peligros de viento como los sísmicos serán considerados en el desarrollo de cualquier cambio recomendado en los códigos, normas y prácticas con base en los hallazgos de este estudio.

\subsubsection{Respuesta pública a comunicaciones de emergencia}

Antecedentes: Los datos y observaciones preliminares del reconocimiento mostraron desafíos en las comunicaciones de desalojo y emergencia. El terreno heterogéneo de la isla presentaba diversos peligros (inundaciones, fuertes vientos, marejadas ciclónicas, deslizamientos de tierra) que requerían 
diferentes acciones de protección. Existe una preferencia social por refugiarse en el lugar donde están, y hubo una falta de canales de comunicación clave durante períodos prolongados debido a cortes de energía y comunicaciones. Muchas personas requirieron rescates de emergencia, lo que demuestra la necesidad de mejoras para respaldar mejor la toma de decisiones de acciones de protección antes del evento.

Objetivo: Investigar el papel de las comunicaciones de emergencia en la respuesta pública para quienes se encuentran bajo la amenaza inminente del huracán María. Este proyecto también examinará el uso de las comunicaciones durante la respuesta y la recuperación (durante e inmediatamente después del huracán).

Plan: Se ha desarrollado un enfoque de cuatro vertientes que cumplirá los dos objetivos principales: (1) caracterizar el uso de comunicaciones de emergencia (tecnología e información) antes, durante y después del huracán; y (2) identificar los factores que influyeron en la decisión del público de tomar medidas de protección mediante el desalojo antes del huracán, incluida la comprensión del papel de las comunicaciones de emergencia en esa decisión.

1. Se realizará un análisis cualitativo del contenido de las comunicaciones y los mensajes de emergencia para evaluar su distribución y eficacia.

2. Las entrevistas semiestructuradas con proveedores de información expertos ayudarán a caracterizar la difusión del mensaje, las interacciones y limitaciones de la organización, y las áreas para facilitar la eficacia de la comunicación. Se planean treinta y cinco entrevistas para recopilar información a través de una variedad de proveedores de información relevante.

3. Los datos sobre el proceso de toma de decisiones de acciones de protección del público se recopilarán a través de encuestas estructuradas que investigarán: actividades, experiencias y percepciones de riesgo previas al huracán; conocimiento de las zonas de riesgo (incluidas las de inundaciones y deslizamientos de tierra); los tipos de información de emergencia recibida; confiabilidad de la información; otras señales ambientales / sociales; decisiones de acción protectora; necesidades de información durante y después del evento; y necesidades de salud o atención médica después del huracán. En total, se planean 1520 encuestas en las cuatro regiones de estudio (Figura 4) para proporcionar una muestra representativa de la población.

4. Las entrevistas con el público permitirán una investigación cualitativa más profunda de los factores relevantes para la toma de decisiones de desalojo. Se llevarán a cabo al menos 100 entrevistas con personas a través de la encuesta de hogares para identificar los factores clave que influyen en la toma de decisiones de acciones de protección antes y después de la tormenta.

Juntas, estas actividades permitirán al NIST evaluar el desempeño y la efectividad de los sistemas y procedimientos de comunicaciones de emergencia, evaluar la toma de decisiones de acción protectora del público y la respuesta a dichas comunicaciones, y recomendar investigaciones $\mathrm{u}$ otras acciones apropiadas necesarias para prevenir lesiones y disminuir pérdidas de vidas en eventos futuros. 


\subsubsection{Caracterización de morbilidad y mortalidad}

Antecedentes: Como se describe en la Sección 2.2, los certificados de defunción generalmente subestiman las muertes causadas por desastres debido a la falta de estándares y la recopilación y notificación de datos consistentes (es decir, certificados de defunción) para la atribución de muertes a desastres. ${ }^{18}$ En 1999 se propuso una norma para la atribución de la mortalidad relacionada con los desastres, ${ }^{19}$ pero no se adoptó ampliamente ni se aplicó a un desastre natural de gran magnitud con un período de recuperación prolongado. ${ }^{20}$ Dados estos desafíos, muchos estudios e investigaciones de científicos y reporteros de salud pública intentaron caracterizar el alcance de la mortalidad en Puerto Rico después de que el huracán María tocó tierra utilizando los datos disponibles y recopilando datos primarios. Por ejemplo, un estudio dirigido por científicos de salud pública de Harvard ${ }^{21}$ encontró que la interrupción de la atención médica fue la causa principal de las altas tasas de mortalidad sostenidas en los meses posteriores al huracán. La Escuela de Salud Pública del Instituto Milken de la Universidad George Washington estimó un exceso de mortalidad total después del huracán en 2975, que ha sido adoptado como el número oficial de muertos del huracán María en Puerto Rico.22 Este estudio concluyó que la falta de una práctica apropiada de certificación de defunción después del huracán y la falta de comunicación local sobre el informe de certificados de defunción antes de la tormenta limitaron el recuento de muertes que se informaron relacionadas con el huracán María.

Objetivo: Completar una evaluación cuantitativa de morbilidad y mortalidad de Puerto Rico con el fin de comprender mejor cómo los edificios dañados y las fallas en la infraestructura de apoyo jugaron un papel en las lesiones y muertes asociadas con el huracán María. Los resultados del estudio proporcionarán orientación para mejorar los códigos y estándares de construcción, y para informar enfoques futuros para atribuir y predecir con precisión las pérdidas de vida debido a fallas en los edificios causadas por vendavales.

\footnotetext{
${ }^{18}$ Combs D.L., Quenemoen L.E., Parrish R.G., Davis J.H., 2009. "Evaluación de la mortalidad atribuida a desastres: Desarrollo y aplicación de una matriz de definición y clasificación”. International Journal of Epidemiology 28(6): pp. 1124-9.

${ }^{19}$ Combs DL, Quenemoen LE, Parrish RG, Davis JH. Evaluación de la mortalidad atribuida a desastres: desarrollo y aplicación de una matriz de definición y clasificación. Int J Epidemiol 1999;28:1124-9.

${ }^{20}$ Centro Nacional de Estadísticas de Salud. Una guía de referencia para la certificación de muertes en caso de un desastre natural, inducido por el hombre o químico/radiológico. (Guía de referencia No. 1). CDC, Centro Nacional de Estadísticas de Salud 2017. Obtenido de https://www.cdc.gov/nchs/data/nvss/vsrg/vsrg01.pdf

${ }^{21}$ Kishore N, Marques D, et al. Mortalidad en Puerto Rico después del Huracán María. NEJM 2018; 379:162-170

${ }^{22}$ Universidad George Washington, en colaboración con la Escuela Graduada de la Universidad de Puerto Rico, 2018. "Determinación del Exceso de Mortalidad Estimado por el Huracán María en Puerto Rico", Informe de proyecto para el Gobernador de Puerto Rico, 28 de agosto de 2018.
} 
Plan: Hasta la fecha, varios estudios ${ }^{232425}$ se han centrado en evaluar el número de muertos por el huracán María utilizando enfoques de exceso de mortalidad, como comparaciones diarias y mensuales con años anteriores. Además, un solo estudio basado en la población ${ }^{26}$ caracterizó las razones predominantes asociadas con las muertes en su muestra como atribuibles a la falta de acceso a la atención médica. El proyecto de mortalidad del NIST no producirá otro recuento de muertes; en cambio, el NIST utilizará métodos científicos rigurosos para comprender los mecanismos de lesiones de aquellos que murieron debido a la tormenta, dentro del contexto más amplio de los peligros y las fallas de edificios y sistemas de infraestructura experimentadas por esas personas.

Una tarea clave de este proyecto es el desarrollo de una base de datos integrada de muertes en Puerto Rico. Los impactos de la tormenta se prolongaron en Puerto Rico durante muchos meses después de que tocó tierra, probablemente impactando el riesgo de muerte. Un estudio de exceso de mortalidad 27 encontró que el riesgo de muerte fue mayor y persistente durante casi seis meses después de la tormenta, y especialmente elevado a fines de febrero de 2018 para las poblaciones que viven en municipios de bajo desarrollo socioeconómico. El NIST recopilará y fusionará datos geocodificados sobre las muertes ocurridas en Puerto Rico hasta seis meses después de que el huracán María tocó tierra en la isla. Las posibles fuentes de datos incluyen el Sistema de Registro Vital de Puerto Rico con conjuntos de datos disponibles de la Oficina de Ciencias Forenses. Los datos adicionales a considerar son las llamadas de emergencia al 911 obtenidas del Negociado de la Policía y los datos de asistencia para funerales y entierros de la Agencia Federal para el Manejo de Emergencias (FEMA) y la Cruz Roja Americana. El objetivo es vincular tantas fuentes de datos como sea posible para las muertes individuales.

La base de datos integrada de las muertes ocurridas después del huracán María permitirá analizar la agrupación espacial y la causa de la muerte en diferentes períodos de tiempo. El análisis incluirá toda la isla. Esta tarea dará como resultado mapas que cuentan la historia de la mortalidad en la isla debido a la tormenta y ayudarán a conectar los datos recopilados por otros proyectos, como el Proyecto de Caracterización de Peligros y el Proyecto de Edificios Críticos.

Para explorar más a fondo las muertes que fueron causadas por la tormenta y comprender mejor si las fallas en los edificios y la infraestructura fueron las causas subyacentes de alguna de ellas, el NIST

\footnotetext{
${ }^{23}$ Robles, F., Davis, K., Fink, S, Almukhtar, S., 2017. "Official Toll in Puerto Rico: 64. Las muertes reales pueden ser 1.052". El New York Times. 9 de diciembre de 2017.

${ }^{24}$ Santos-Lozada AR, Howard JT. Uso de recuentos de muertes de estadísticas vitales para calcular el exceso de muertes en Puerto Rico después del huracán María. JAMA; Agosto. 2, 2018: doi:10.1001/jama.2018.10929.

${ }^{25}$ Universidad George Washington, en colaboración con la Escuela Graduada de la Universidad de Puerto Rico, 2018. "Determinación del Exceso de Mortalidad Estimado por el Huracán María en Puerto Rico", Informe de proyecto para el Gobernador de Puerto Rico, 28 de agosto de 2018.

${ }^{26}$ Kishore N, Marques D, et al. Mortalidad en Puerto Rico después del huracán María. NEJM 2018; 379:162-170

${ }^{27}$ Universidad George Washington, en colaboración con la Escuela Graduada de la Universidad de Puerto Rico, 2018. "Determinación del Exceso de Mortalidad Estimado por el Huracán María en Puerto Rico", Informe de proyecto para el Gobernador de Puerto Rico, 28 de agosto de 2018.
} 
completará autopsias verbales ${ }^{28}$ con los familiares de los fallecidos o informantes clave ${ }^{29}$ de las muertes que podrían haber sido causadas por fallas en un edificio y/o en el sistema del edificio. La muestra para el despliegue de la autopsia verbal (VA, por sus siglas en inglés) se identificará mediante la inclusión (p. ej., ocurrida dentro de los 14 días posteriores a la llegada de la tormenta) y los criterios de exclusión (p. ej., muertes para quienes la información para localizar a familiares o informantes clave no está disponible). El NIST aumentará los estándares de autopsias verbales publicados más recientemente por la Organización Mundial de la Salud de $2016^{30}$ para incluir cualquier peligro y/o preguntas específicas del edificio para caracterizar más completamente las muertes relacionadas con la tormenta.

\subsubsection{Recuperación de negocios y cadenas de suministro}

Antecedentes: Los servicios comerciales de manufactura y minoristas son una parte importante para comprender los impactos económicos del huracán María, así como la recuperación a largo plazo de Puerto Rico y sus cadenas de suministro. La actividad manufacturera en el Estado Libre Asociado representa aproximadamente el 45\% del Producto Interno Bruto (PIB) de Puerto Rico y más del 20\% de su empleo. ${ }^{31 S e g u ́ n ~ F E M A, ~ e l ~ 40 \% ~ d e ~ l a s ~ p e q u e n ̃ a s ~ e m p r e s a s ~ n u n c a ~ v u e l v e n ~ a ~ a b r i r ~ d e s p u e ́ s ~ d e ~ u n ~}$ desastre, y otro $25 \%$ que vuelve a abrir fracasan en un año. ${ }^{32}$ Los efectos del huracán María exacerbaron el estrés financiero y comercial preexistente en Puerto Rico. ${ }^{33}$

Objetivo: Caracterizar la recuperación de las pequeñas y medianas empresas (PYMES), incluidos los sectores de manufactura, comercio minorista y servicios en Puerto Rico, para brindar una mayor comprensión de la planificación de la resiliencia de la continuidad del negocio y la continuidad de la cadena de suministro y cómo estas pueden diferir entre industrias o regiones afectadas.

Plan: Se ha desarrollado un enfoque de dos vertientes que cumplirá los objetivos de comprender la recuperación de las PYMEs. Primero, el estudio modelará la cadena de suministro, aprovechando la

\footnotetext{
${ }^{28}$ La autopsia verbal (VA) es un método para determinar las causas de muerte de los individuos y las fracciones de mortalidad por causas específicas en poblaciones sin un sistema completo de registro civil. Las autopsias verbales consisten en un entrevistador capacitado que utiliza un cuestionario para recopilar información sobre los signos, síntomas y características demográficas de una persona fallecida recientemente de un individuo familiarizado con el fallecido. (Fuente: www.healthdata.org/verbal-autopsy)

${ }^{29}$ En la investigación de encuestas y entrevistas, el informante clave se refiere a la persona con quien se realiza una entrevista sobre un tema, organización o problema en particular. El informante clave es un representante (proxy) del individuo o grupo con la información deseada (Lavrakas 2008).

${ }^{30}$ Organización Mundial de la Salud. Estándares de autopsia verbal: el instrumento de autopsia verbal de la OMS de 2016. Ginebra: Organización Mundial de la Salud, 2016.

${ }^{31}$ Oficina de Estadísticas Laborales (BLS, por sus siglas en inglés). (2017). https://www.bls.gov/regions/new-yorknew-jersey/puerto rico.htm

${ }^{32}$ Agencia Federal para el Manejo de Emergencias (FEMA). (2015). "Make Your Business Resilient” (Haga a su negocio resistente) https://www.fema.gov/media-library-data/1441212988001-

1aa7fa978c5f999ed088dcaa815cb8cd/3a BusinessInfographic-1.pdf

${ }^{33}$ Ley de Estabilidad Económica, Administración y Supervisión de Puerto Rico de 2016:

https://oversightboard.pr.gov/documents/
} 
información de la red de transporte para dos industrias clave con sede en Puerto Rico: procesamiento de alimentos y manufactura de dispositivos médicos. Estas industrias han sido seleccionadas debido a su alta participación de mercado en el sector manufacturero de Puerto Rico. La manufactura de dispositivos médicos contribuye en gran medida a las exportaciones puertorriqueñas al resto de los Estados Unidos y al mundo, mientras que el procesamiento de alimentos ${ }^{34} \mathrm{es}$ un sector importante que afecta las cadenas de suministro locales (es decir, gran parte del producto terminado se queda dentro de Puerto Rico). Los datos para este esfuerzo de modelado utilizarán en gran medida los datos proporcionados por las agencias gubernamentales de Puerto Rico y los datos recopilados a través de visitas al sitio realizadas durante el verano de 2019, coordinadas en conjunto con la Asociación de Extensión de Manufactura (MEP, por sus siglas en inglés) del NIST y Manufacturing Extension, Inc. de Puerto Rico. (PRiMEX). Los esfuerzos de modelado se llevarán a cabo utilizando dos métodos:

1. Teoría de redes complejas (CNT, por sus siglas en inglés): un método para evaluar la vulnerabilidad de redes utilizando las redes de transporte de Puerto Rico, ponderada por densidad de negocios, densidad de población y tipo de camino.

2. Simulación de eventos discretos (DES, por sus siglas en inglés): un proceso de simulación que se utiliza para modelar sistemas basados en eventos y comprender explícitamente cómo los diferentes componentes de la cadena de suministro se ven afectados en diferentes condiciones.

En segundo lugar, los hallazgos iniciales del proceso de modelado descrito anteriormente informarán el muestreo y la encuesta de las PYMES en los sectores de manufactura y servicios/minorista, así como a los representantes de las empresas de transporte y envío. Para este proyecto, las preguntas de investigación se centran en el nivel institucional de las PYMES (emplea a menos de 250 personas en un sitio determinado) y se preguntan al propietario o administrador de la empresa. Las preguntas de investigación incluyen las interdependencias de la recuperación económica y de la cadena de suministro con la infraestructura física ${ }^{35}$, la recuperación social institucional y otros elementos de la resiliencia comunitaria. Está previsto que la muestra incluya 250 manufactureros pequeños y medianos (SMMs, por sus siglas en inglés) y el mismo número de PYMES en el sector minorista/de servicios (por ejemplo, comestibles, ropa y restaurantes). Además, habrá una muestra de 30 representantes de empresas de transporte/envío. Este proyecto tomará muestras de las cuatro regiones de estudio comunes en la mayoría de los proyectos (Figura 4), así como en Mayagüez y Ponce. Se incluye Mayagüez para capturar a las PYMES cerca de un hospital crítico; Ponce es el segundo puerto marítimo más grande de Puerto Rico y el hogar de muchos SMMs.

\footnotetext{
${ }^{34}$ Sector de procesamiento de alimentos (NAICS 311) El procesamiento de alimentos es parte del sector de la manufactura (NAICS 31 - 33). Esto cubre la manufactura comercial que comienza con materias primas animales, vegetales o marinas y las transforma en alimentos o productos comestibles como lácteos, carnes, vegetales, panadería, granos y cereales.

${ }^{35}$ La principal infraestructura considerada serán los sistemas de transporte mediante la aplicación de la Guía de Entrevistas de Transporte y Envíos (STIG, por sus siglas en inglés). Los servicios adicionales proporcionados por la infraestructura de utilidades (es decir, agua, electricidad, celular) se considerarán factores limitantes para la recuperación.
} 
Los métodos del proyecto también incluirán encuestas estructuradas de 300 propietarios/gerentes de PYMES divididas equitativamente entre manufactureros pequeños y medianos (SMMs), y PYMES minoristas/de servicios. Se pedirá una breve sección semiestructurada de un subconjunto de la muestra más grande. Los instrumentos de la encuesta estarán orientados a proporcionar los datos necesarios para un modelo empírico que busque explicar la variación en la variable dependiente, estado de recuperación, utilizando una selección de variables independientes. ${ }^{36}$ Estos instrumentos incluirán preguntas sobre estados preexistentes, impactos en los servicios y daños físicos (por ejemplo, edificio, contenido, maquinaria, inventario), interrupciones de la infraestructura, impactos no físicos, recursos financieros y otros recursos disponibles (por ejemplo, asistencia para la recuperación), impactos de políticas, planes establecidos, decisiones, retrasos y características de resiliencia. Las entrevistas semiestructuradas permitirán realizar preguntas en profundidad sobre temas particulares, como la solidez de la cadena de suministro y la toma de decisiones en respuesta al huracán María y durante el proceso de recuperación.

\subsubsection{Recuperación de funciones sociales}

Antecedentes: Tanto la educación como los servicios de salud son una parte importante para comprender los impactos del huracán María, así como la recuperación a largo plazo de Puerto Rico. Aproximadamente una cuarta parte de las escuelas han cerrado en Puerto Rico, lo que ha afectado de manera desproporcionada a las comunidades rurales donde se han producido la mayoría de los cierres de escuelas. ${ }^{37}$

Objetivo: Examinar las trayectorias de recuperación de las escuelas y hospitales incluidos en la muestra en Puerto Rico para identificar las características y condiciones subyacentes asociadas con la recuperación de las funciones sociales críticas del huracán María.

Plan: Para este proyecto, las preguntas de investigación se centran en la recuperación a nivel institucional y las interdependencias de las funciones sociales en la infraestructura física, la recuperación empresarial y económica, así como otros aspectos de la recuperación comunitaria. El estudio prevé la recopilación de datos de las instituciones en tres puntos en el tiempo, también conocidos como "ondas", utilizando un diseño longitudinal. El diseño permite observar los mismos casos a lo largo del tiempo para documentar mejor el proceso de recuperación. La muestra $(\mathrm{n}=410)$ incluye escuelas K-12 y hospitales públicos y privados dentro de los municipios que comprenden las cuatro regiones principales de estudio del NIST (Figura 4), así como Mayagüez.

\footnotetext{
${ }^{36}$ Los conceptos de variables independientes y dependientes se utilizan en un sentido matemático, lo que significa que el valor de una variable dependiente cambia en respuesta al de una variable independiente. En el diseño de investigación, las variables independientes son aquellas que pueden manipularse o cambiarse, mientras que las variables dependientes son las respuestas a los efectos de las variables independientes. (Fuente: Salkind, Neil J., Ed. 2010. Enciclopedia de Diseño de Investigaciones. Publicaciones Sage. http://methods.sagepub.com/Reference/encyc-of-research-design/n184.xml)

${ }^{37}$ Hinojosa, Meléndez y Severino Pietri, "Population Decline and School Closure in Puerto Rico" https://centropr.hunter.cuny.edu/sites/default/files/PDF_Publications/centro_rb2019-01_cor.pdf.
} 
Los métodos del proyecto incluyen encuestas estructuradas a representantes de hospitales e instituciones escolares en tres momentos diferentes y entrevistas semiestructuradas con un subconjunto de la muestra en un solo momento. Los instrumentos de la encuesta están orientados a proporcionar los datos necesarios para un modelo empírico que busque explicar la variación en la variable dependiente, estado de recuperación, utilizando una selección de variables independientes. La encuesta incluirá preguntas sobre servicios, daño físico (por ejemplo, edificio, contenido, equipo), daño e interrupción de la infraestructura, impactos no físicos, recursos financieros y de otro tipo, políticas, planes establecidos, decisiones, demoras y características de resiliencia. Las entrevistas permitirán realizar preguntas en profundidad sobre temas particulares, como la toma de decisiones después del huracán María y durante todo el proceso de recuperación. Además, los datos de la entrevista se utilizarán para informar los puntos de tiempo restantes de la recopilación de datos de las encuestas.

\subsubsection{Recuperación de sistemas de infraestructura}

Antecedentes: Las fallas en los sistemas de infraestructura de energía, agua y transporte presentaron desafíos de recuperación y respuesta a emergencias. El sistema eléctrico de la isla experimentó grandes daños en los sistemas de transmisión y distribución, lo que provocó un corte eléctrico completo en toda la isla con efectos en cascada en otras líneas de sustento. También hubo una pérdida casi completa de comunicaciones digitales en todo Puerto Rico.

Objetivo: Evaluar las dependencias de la función del edificio en la infraestructura (energía, agua y transporte), incluida la pérdida de función en cascada y la secuencia de las actividades de recuperación después del huracán María, y examinar las causas de la pérdida de funcionalidad y la interrupción prolongada del sistema de comunicaciones inalámbricas.

Plan: El plan consta de dos componentes: El primero se centra en la recuperación del soporte del sistema de infraestructura de transporte, agua y energía de edificios críticos. El segundo se centra en los modos de falla del sistema de comunicación inalámbrica después del huracán María.

El plan técnico para el estudio de los sistemas de infraestructura de energía, agua y transporte que dan soporte a las edificaciones críticas consta de los siguientes pasos:

1. Recopilación de datos secundarios: Se revisará una amplia variedad de fuentes de datos, incluidas fuentes de información académicas, gubernamentales y de otro tipo. Esta información se incorpora a los pasos posteriores, informando el esfuerzo de recopilación, el análisis y el modelado de datos primarios. Los datos de las agencias relevantes dentro de Puerto Rico que planifican y operan los sistemas de infraestructura de energía, agua y transporte proporcionan una fuente clave de información para este proyecto.

2. Recopilación de datos primarios: Los nuevos datos primarios se recopilan a través de entrevistas estructuradas para obtener datos a escala comunitaria relacionados con las interdependencias del sistema de infraestructura y su apoyo a edificios críticos. Se entrevistará a funcionarios involucrados en la planificación y gestión de los sistemas de 
infraestructura, así como a funcionarios municipales. Se busca información sobre el estado de la infraestructura antes del huracán María, sus impactos y recuperación. El objetivo es recopilar sistemáticamente información que pueda informar la comprensión de las interdependencias de los sistemas de infraestructura y el soporte de edificios críticos.

3. Extender el modelo de comunidades resilientes del NIST: El modelo de Alternativas para Comunidades Resilientes (ARC, por sus siglas en inglés) del NIST ${ }^{38}$ se ampliará según sea necesario en función de los resultados de los esfuerzos de recopilación de datos secundarios y primarios. El modelo ARC del NIST tiene como objetivo capturar las interdependencias en estos sistemas de infraestructura, para los cuales existen pocos instrumentos. El modelo se está desarrollando dentro del Programa de Resiliencia Comunitaria del NIST, con una versión beta lanzada en septiembre de 2020.

4. Caso de estudio: Luego, NIST ARC se aplicará a una comunidad dentro de Puerto Rico para demostrar la capacidad de abordar las interdependencias en la planificación de la resiliencia a escala comunitaria.

El plan de estudios de telecomunicaciones inalámbricas consta de los siguientes pasos:

1. Recopilar datos sobre los daños causados por el huracán María en torres de telefonía celular, equipos, cableado y componentes relacionados de los sistemas de comunicaciones inalámbricas, de agencias reguladoras, empresas de telecomunicaciones e industrias de apoyo a las telecomunicaciones.

2. Recopilar datos sobre otras causas de interrupciones del servicio, incluida la pérdida de energía y el daño al backhaul (es decir, la conexión entre el sitio celular y la red central).

3. Recopilar información sobre códigos, estándares y regulaciones que rigen el diseño y la construcción de torres de telefonía celular y equipos de comunicación inalámbrica.

4. Determinar los niveles de peligro experimentados en las ubicaciones de los sitios celulares utilizando la información del Proyecto de Caracterización de Peligros.

5. Evaluar el desempeño de las torres y el equipo con respecto a los niveles de peligro experimentados en cada sitio y los requisitos de diseño de los códigos

\subsection{Comité Asesor}

El Comité Asesor del Equipo Nacional de Seguridad en la Construcción ${ }^{39}$ es un comité asesor autorizado por el gobierno federal que asesora al NIST sobre la realización de investigaciones de fallas en los edificios realizadas bajo las autoridades de la Ley NCST. Los miembros son expertos respetados internacionalmente en una variedad de campos, seleccionados en base a su experiencia y conocimientos técnicos, historial de servicio profesional distinguido establecido y su conocimiento de los problemas que afectan los estudios del NIST. Desde el establecimiento del Equipo Nacional de Seguridad en la Construcción del huracán María en febrero de 2018, el

\footnotetext{
38 https://www.nist.gov/programs-projects/development-first-generation-community-resilience-systems-model

39 https://www.nist.gov/topics/disaster-failure-studies/national-construction-safety-team-ncst/advisory-committee
} 
Equipo ha brindado múltiples sesiones informativas públicas al Comité Asesor sobre los planes y el progreso de la investigación (ver Sección 4.5).

\subsection{Coordinación con otras organizaciones}

Para obtener la información más precisa posible, y de acuerdo con el mandato de la Ley NCST de que el NIST busque y coordine sus esfuerzos con otras organizaciones (incluidas las organizaciones estatales, locales y federales, así como la comunidad en general, según corresponda), el Equipo NIST está en contacto directo o indirecto con los siguientes:

- municipios,

- funcionarios locales y regionales de gestión de emergencias,

- Departamentos de construcción del Estado Libre Asociado,

- servicios públicos y agencias de energía, transporte y agua y aguas residuales,

- funcionarios de educación y salud,

- otros funcionarios electos y funcionarios públicos locales, regionales y del Estado Libre Asociado

- empresas y establecimientos comerciales,

- asociaciones empresariales, e

- individuos.

El NIST está trabajando con, e involucrado con otras agencias federales en la planificación y ejecución de su Programa del Huracán María, basándose en el trabajo de otros que han recopilado información y realizado evaluaciones después del huracán. Esto incluye recibir información recopilada por otras agencias. Especialmente dignos de mención son los Memorandos de Acuerdo establecidos por el NIST con la Agencia Federal para el Manejo de Emergencias (FEMA), que brindan al NIST acceso a información importante sobre daños a escuelas e instalaciones de atención médica, que se utiliza para adelantar el trabajo del Equipo de acuerdo con pautas cuidadosamente desarrolladas para garantizar un uso limitado y apropiado de esos datos. La participación de la agencia federal también incluye la participación directa de expertos del Servicio Nacional de Meteorología (NWS) de la NOAA y del Centro Nacional de Medicina y Salud Pública de Desastres de la Universidad de Servicios Uniformados, quienes se desempeñan como miembros del Equipo del huracán María del NCST. En la Sección 4.2 se proporcionan más detalles sobre algunos de estos esfuerzos de apoyo.

Varios equipos de contratistas, incluidos expertos con base en Puerto Rico, están apoyando a los ingenieros, sociólogos, antropólogos, economistas, meteorólogos, epidemiólogos, y otros investigadores del NIST que están realizando los estudios. (Consulte la sección 4.4 para obtener detalles adicionales sobre las asignaciones de los contratistas). 


\subsection{Duración y costo estimados}

El NIST llevará a cabo el Programa del Huracán María hasta que se logren las metas y objetivos establecidos. Aunque no existen precedentes directos para el Programa del Huracán María, las investigaciones anteriores del NCST han tardado entre tres y siete años en producir un informe técnico y recomendaciones finales. Como la primera investigación del NCST de un evento de huracán, el Programa del Huracán María es considerablemente más amplio en escala geográfica y alcance que las investigaciones anteriores del NCST. El Programa del Huracán María considerará múltiples peligros que afectaron a varios edificios en todo el Estado Libre Asociado de Puerto Rico, incorporará una investigación más profunda de muertes y lesiones e incluirá proyectos de investigación complementarios bajo la autoridad estatutaria del NWIRP. El establecimiento del Programa del Huracán María se anunció en febrero de 2018 y los proyectos iniciales se anunciaron en mayo de 2018. Con contratos clave para respaldar la recopilación de datos, adjudicados en enero, marzo y julio de 2020, se espera que la recopilación de datos continúe hasta el año fiscal 2021, y se espera que el análisis de datos continúe en el año fiscal 2022. Una vez finalizado el análisis de datos, la documentación y la revisión interna, se emitirá un informe preliminar para comentarios públicos. Después de considerar todos los comentarios recibidos, NIST emitirá un informe final.

En el año fiscal 2018, el NIST asignó un poco más de \$5 millones para comenzar el Programa del Huracán María. En los años fiscales 2019 y 2020, el NIST asignó un poco más de \$4 millones por año para apoyar el programa. Estos fondos, junto con cualquier financiamiento adicional que se necesitará, provienen de la redirección de las asignaciones de laboratorios del NIST.

\subsection{Impacto de los eventos en Puerto Rico después del huracán María}

El Programa del Huracán María del NIST es un proyecto grande y complejo debido a la escala geográfica del evento, el nivel extraordinario de daño, el tiempo de recuperación prolongado y la cantidad de organizaciones diferentes involucradas en los esfuerzos de respuesta y recuperación. El esfuerzo se ha complicado aún más por los eventos ocurridos desde el huracán María. Una serie de terremotos comenzaron a afectar a Puerto Rico a fines de diciembre de 2019 y han continuado periódicamente hasta septiembre de 2020. La crisis de salud pública del COVID-19, que resultó en un cierre en Puerto Rico en marzo de 2020, también afectó a Puerto Rico y las actividades del Programa del Huracán María del NIST. 
En respuesta a estos eventos, el NIST ha tomado varias acciones. Desde diciembre de 2019, el NIST ha monitoreado la secuencia de terremotos, los impactos y la respuesta (a través de la puntuación de eventos y ${ }^{40}$ la participación en llamadas de coordinación interagenciales, incluidas las organizadas por el Programa Nacional de Reducción de Riesgos de Terremotos) para evaluar los posibles efectos en las áreas de estudio de enfoque y desafíos de estos eventos a los proyectos del huracán María. La mayor parte de daños por terremotos se ha concentrado en la parte suroeste de Puerto Rico, que está fuera de las principales regiones de estudio del NIST para el trabajo del huracán María (Figura 4). A partir de septiembre de 2020, el Equipo anticipa que los daños relacionados con los terremotos tendrán un impacto limitado en los esfuerzos del programa, particularmente los proyectos técnicos dentro de la investigación técnica del NCST. Para los tres proyectos técnicos dentro del estudio de investigación NWIRP, que se centran en la recuperación de los impactos del huracán María, los investigadores del NIST están poniendo especial cuidado en diseñar instrumentos de recopilación de datos que aseguren la capacidad de tener en cuenta los efectos agravantes de la secuencia de terremotos y la pandemia en el proceso de recuperación. Los peligros sísmicos en el contexto de peligros múltiples de Puerto Rico han sido una consideración importante desde el inicio del programa, y los expertos en ingeniería sísmica del Equipo se asegurarán de que los peligros sísmicos, además de los peligros del viento, se consideren en el desarrollo de las recomendaciones del NIST relacionadas con el huracán María.

El NIST continúa evaluando las ramificaciones del COVID-19 en los proyectos del huracán María a medida que evoluciona la pandemia, y aún no se ha determinado el impacto total. Los modos de recopilación de datos y la coordinación de varios elementos de múltiples proyectos se están ajustando en relación con la orientación actual de salud pública y las decisiones a nivel institucional que toman el NIST y los contratistas. Por ejemplo, los esfuerzos de recopilación de datos en persona pueden trasladarse a otros modos, como teléfono, web y correo. Esto es particularmente cierto para los proyectos que utilizan métodos de ciencias sociales donde los tamaños de muestra requerirían una interacción sustancial con hogares, proveedores de información de comunicación de emergencia, empresas, funcionarios en escuelas y hospitales, y representantes de los sectores de energía, agua y transporte si los datos fueran a ser obtenidos cara a cara. Se están desarrollando e implementando protocolos de seguridad junto con la capacitación del personal para operar mejor en el contexto de la pandemia. Además, los esfuerzos para involucrar al personal clave en los hospitales y las empresas seleccionadas que están muy involucradas en la respuesta a la pandemia se están planificando con gran sensibilidad a las funciones y responsabilidades adicionales de estas instituciones. El equipo del

${ }^{40}$ El Programa de Estudios de Desastres y Fallos utiliza cuatro criterios (pérdida de vidas, exposición, intensidad del peligro y daño físico) para evaluar la consecuencia del evento y dos criterios (actividades de desalojo y respuesta a emergencias) para evaluar los desafíos en de desalojo y respuesta. En conjunto, estos puntajes informan si se debe desplegar un equipo de reconocimiento preliminar en un sitio de desastre o falla para realizar un estudio de campo. Las calificaciones de los criterios se basan en la mejor información disponible en el momento en que se analiza el evento. Las calificaciones pueden actualizarse a medida que haya nueva información disponible, y los eventos se pueden calificar varias veces antes de que se tome la decisión de desplegar un equipo. 
huracán María del NIST y sus contratistas están explorando formas creativas de lograr los objetivos del programa en este entorno incierto. Las recomendaciones resultantes del Programa del Huracán María serán informadas por el contexto de múltiples peligros y eventos de Puerto Rico. 


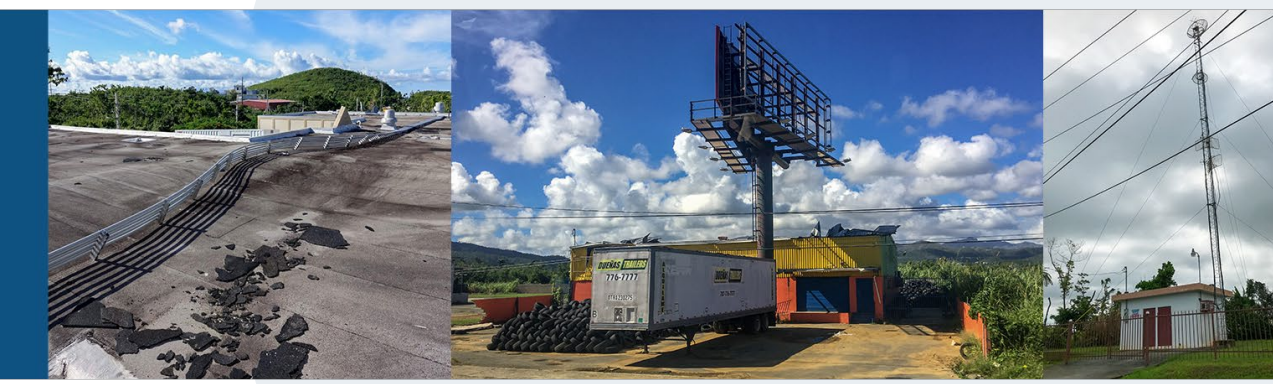

APRENDIENDO DEL IMPACTO DEL HURACÁN MARÍA EN PUERTO RICO

UN INFORME DE PROGRESO

\section{Avances en la ejecución del Programa del Huracán María}

Las siguientes subsecciones describen el progreso del NIST en la ejecución del Programa del Huracán María, que incluye el acercamiento a otras agencias y organizaciones (Sección 4.1), la adjudicación de contratos de apoyo (Sección 4.2) y la recopilación y análisis inicial de datos (Sección 4.3). Como se describe en la Sección 4.4, el NIST ha celebrado múltiples reuniones públicas con el Comité Asesor del NCST para presentar planes y avances y recibir asesoramiento.

\subsection{Estado de enlace con otras agencias y organizaciones}

\subsubsection{Agencias gubernamentales de Puerto Rico}

El NIST ha celebrado múltiples reuniones en Puerto Rico y Washington, D.C. con altos funcionarios, en casi todos los casos los más altos funcionarios, de los siguientes departamentos y agencias del gobierno de Puerto Rico, con los que NIST había tratado de contactar con base en su información anticipada y conocimientos sobre el impacto del huracán en la isla y los esfuerzos de recuperación relacionados:

- Departamento de Desarrollo Económico y Comercio

- Oficina de gestión de permisos

- Compañía de Fomento Industrial de Puerto Rico

- Departamento de Educación

- Departamento de Salud

- Departamento de la Vivienda

- Departamento de Seguridad Pública

- Departamento de Transportación y Obras Públicas 
- Administración de Asuntos Federales

- Junta de Planificación

- Autoridad de Acueductos y Alcantarillados de Puerto Rico

- Negociado para el Manejo de Emergencias y Administración de Desastres de Puerto Rico

- Autoridad de Energía Eléctrica de Puerto Rico

- Autoridad de los Puertos de Puerto Rico

- Junta Reguladora de Telecomunicaciones

El NIST también ha estado en contacto con funcionarios de la Oficina Central para la Recuperación, Reconstrucción y Resiliencia de Puerto Rico y el Departamento del Trabajo y Recursos Humanos. Además, el NIST ha mantenido reuniones iniciales con funcionarios regionales de manejo de emergencias, incluidos los directores de las Zonas de Manejo de Emergencias en operación en el momento del huracán María ${ }^{41}$ en Arecibo, Caguas, Humacao y San Juan.

El NIST ha solicitado la cooperación de estos departamentos y agencias y ha identificado el tipo de información potencialmente disponible en esas oficinas que ayudarán al NIST a obtener acceso a la información relevante. Para garantizar que los proyectos del huracán María estén lo más informados y precisos posible en su trabajo, es importante que el NIST asegure el acceso a la información que otros ya han obtenido y pueden compartir. El NIST también ha dejado en claro que su objetivo es evitar colocar cargas sobre estas agencias y otras, especialmente mientras buscan recuperarse del huracán, los terremotos y la pandemia. Las organizaciones gubernamentales de Puerto Rico relevantes para la investigación y el estudio del NIST se han reunido con el NIST varias veces y están compartiendo la información solicitada. Según sea necesario, el NIST continúa trabajando y buscando información de muchas de las agencias gubernamentales mencionadas anteriormente.

\subsubsection{Organizaciones del sector público y privado de Puerto Rico}

El NIST también ha informado o consultado con múltiples organizaciones del sector privado e instituciones académicas que operan y/o tienen sede en Puerto Rico. Éstas incluyen:

- Universidad de Puerto Rico Mayagüez

- Universidad de Puerto Rico Río Piedras

- Universidad Politécnica de Puerto Rico

- American Tower Corporation

- PR Wireless

- Extensión de Manufactura de Puerto Rico (Puerto Rico Manufacturing Extension)

- Asociación de Industriales de Puerto Rico

${ }^{41}$ Desde el huracán María en 2017, Puerto Rico ha cambiado los límites y jurisdicciones de sus Zonas de Manejo de Emergencias. 
En cada uno de estos casos, los representantes de estas organizaciones indicaron su voluntad de cooperar con los esfuerzos del NIST y ayudar proporcionando información y perspectivas o contactos recomendados para obtener información adicional. Varios han compartido datos y han ayudado al equipo.

\subsubsection{Agencias del gobierno federal}

El NIST también está trabajando con otras agencias federales e involucrando a otras en la planificación y ejecución de sus esfuerzos por el huracán María. Esto incluye, pero no se limita a:

- El NWS de la NOAA, que ha proporcionado un experto en meteorología que sirve como un miembro formal del equipo del huracán María que trabaja en las comunicaciones de emergencia y los proyectos de caracterización de peligros.

- El Centro Nacional de Medicina de Desastres y Salud Pública (NCDMPH) de la Universidad de Servicios Uniformados, que ha proporcionado un experto en epidemiología que sirve como miembro formal del equipo del huracán María que trabaja en el proyecto para comprender mejor cómo los edificios y la infraestructura de apoyo dañados desempeñaron un papel en las lesiones y muertes asociadas con el huracán.

- La Oficina del Departamento de Salud y Servicios Humanos (HHS) del Subsecretario de Preparación y Respuesta (ASPR), que ha compartido información sobre su apoyo a la recuperación de los servicios sociales y de salud, centrada en hospitales y escuelas. Además, los Centros para el Control y la Prevención de Enfermedades (CDC, por sus siglas en inglés) del HHS, han proporcionado un experto en epidemiología que sirve como asesor científico del equipo del huracán María que trabaja en el proyecto para comprender mejor si, y cómo, los edificios y la infraestructura de apoyo dañados desempeñaron un papel en las lesiones y las muertes asociadas con el huracán.

- La FEMA, que brinda asistencia, a través de memorandos formales de intercambio de información, con intercambios de datos, incluyendo información sobre el impacto de la tormenta en edificios críticos (hospitales y escuelas) a partir de las evaluaciones realizadas bajo la misión asignada por los EE. UU. Cuerpo de Ingenieros del Ejército (USACE). El NIST se unió a FEMA a fines de 2017 y contribuyó al Equipo de Evaluación de Mitigación de esa agencia y a los asesores de recuperación; ${ }^{42}$ ese despliegue preliminar informó la decisión del NIST de lanzar su Programa del Huracán María.

- USACE, que ha proporcionado información sobre el impacto de la tormenta en el sistema eléctrico y su recuperación.

- EE.UU. El Servicio Geológico de EE. UU. (USGS, por sus siglas en inglés), que ha proporcionado información y conocimientos sobre deslizamientos de tierra asociados con el huracán María.

${ }^{42}$ www.fema.gov/emergency-managers/risk-management/building-science/mitigation-assessment-team 
En algunos casos, se requirieron acuerdos formales antes de que otras agencias pudieran compartir información y datos con NIST. Estos acuerdos se desarrollaron y ahora están en vigor.

\subsection{Adjudicación de contratos de apoyo}

El NIST depende de múltiples contratistas con capacidades especializadas, incluida la experiencia del personal y las instalaciones de prueba, para respaldar y agregar una capacidad sustancial al equipo del huracán María. Hasta la fecha, se han adjudicado contratos para los siguientes tipos de asistencia, y se está trabajando o se ha completado en estas áreas:

\subsubsection{Modelado de campo de vientos}

La cuantificación precisa de la velocidad del viento es fundamental para evaluar el rendimiento de los edificios y la infraestructura y proporcionar contexto para otros aspectos del programa. El 8 de febrero de 2019 se otorgó un contrato a Applied Research Associates, Inc., para apoyar los esfuerzos de modelado de campo de vientos y desarrollar un modelo de campo de vientosdependiente del tiempo del impacto del huracán María en Puerto Rico que coincida de manera óptima con los datos medidos disponibles. La versión preliminar del modelo de campo de vientos incorpora una estimación básica de los efectos topográficos. La versión final del modelo de campo eólico incorporará observaciones meteorológicas adicionales a nivel de superficie, mejorará la caracterización de la asimetría de huracanes, optimizará el proceso de ajuste del modelo, cuantificará la incertidumbre en los resultados y perfeccionará el modelado de efectos topográficos basados en los resultados de experimentos y cálculos numéricos de túnel de viento.

\subsubsection{Prueba de túnel de viento y medición de campo de vientos}

El terreno montañoso de Puerto Rico puede tener un efecto significativo en la velocidad del viento local y las fuerzas del viento resultantes que experimentan los edificios y los sistemas de infraestructura. Para respaldar la investigación detallada de tales efectos, se otorgó un contrato a la Universidad de Florida (UF) el 1 de mayo de 2019 para realizar pruebas de túnel de viento y mediciones de campo de vientos. Se están llevando a cabo experimentos en la Instalación Experimental de Infraestructura de Investigación de Ingeniería de Riesgos Naturales de la Fundación Nacional de Ciencias (NHERI EF, por sus siglas en inglés) en Gainesville, Florida, en un gran túnel de viento con límites de capa reconfigurables. El alcance del trabajo incluye pruebas en túnel de viento de modelos topográficos y modelos de edificios. El propósito de los experimentos del túnel de viento topográfico es obtener mediciones de flujo en el campo del flujo del viento sobre características topográficas para proporcionar datos experimentales con incertidumbres cuantificadas para caracterizar los efectos de aumento de velocidad topográfica y validar modelos numéricos. Las pruebas en túnel de viento de los modelos de construcción 
permitirán una evaluación detallada de las cargas de viento en los edificios según la influencia de la topografía, los edificios y el terreno circundantes. Además de las mediciones del túnel de viento, un subcontrato de WeatherFlow provee el despliegue de anemómetros en torres de telefonía celular en Puerto Rico para obtener mediciones de campo de los efectos topográficos sobre los vientos. Estos datos del mundo real se utilizarán para validar los resultados de las pruebas del túnel de viento y los modelos numéricos.

\subsubsection{Evaluación de ingeniería de edificios críticos}

La evaluación del desempeño de los edificios críticos requiere la documentación de las características de los edificios y sus requisitos de diseño inicial, así como los daños y la pérdida de función que se sufrieron por el huracán. El apoyo para evaluar el desempeño de edificios críticos se brinda a través de un contrato otorgado a Stantec, Inc., el 3 de marzo de 2020. El personal clave del equipo de Stantec incluye al Gerente de Proyectos, Juan C. Virella Crespo, PhD, PE, Presidente de Virella Crespo \& Associates, con sede en Mayagüez, Puerto Rico, y el Líder del Equipo de Campo, Luis D. Aponte-Bermúdez, PhD, PE, profesor de la Universidad de Puerto Rico en Mayagüez. El contratista está documentando el desempeño de determinadas instalaciones críticas durante el huracán María, incluidos hospitales, escuelas y refugios para tormentas. La revisión de documentos y las visitas al sitio se complementarán con entrevistas con el personal clave de la instalación. Las características de edificios que se están revisando incluyen los componentes estructurales y no estructurales de las instalaciones (por ejemplo, tipo de cubierta de techo, tipo de sistema estructural y tipo de ventanas, puertas y sistemas de protección de apertura), edad (por ejemplo, fecha de construcción y código de construcción usado para el diseño), redundancias de utilidades (p. ej., la capacidad de cualquier generador de respaldo existente y suministros de agua de emergencia) y esfuerzos de mitigación antes de la llegada del huracán (p. ej., colocación de sacos de arena y anclaje del equipo sobre el techo). Los datos sobre daños (por ejemplo, a las superficies exteriores, sistema de techado, sistema estructural, equipo sobre el techo, etc.) ayudarán a identificar tendencias en el desempeño estructural por tipo de ocupación, era de construcción y sistema estructural. Stantec también recopilará datos sobre la funcionalidad de las instalaciones inmediatamente después de tocar tierra, incluida la reubicación de los servicios y/o de los ocupantes del edificio, el estado de disponibilidad de las líneas de sustento en los días siguientes y las condiciones peligrosas encontradas por los ocupantes del edificio.

\subsubsection{Recopilación y apoyo de datos de ciencias sociales}

Las metodologías de las ciencias sociales, como encuestas y entrevistas, son esenciales para los enfoques técnicos de cuatro de los proyectos del huracán María del NIST, donde se recopilará información de proveedores de información, hogares, empresas, escuelas, hospitales y representantes de infraestructura en los sectores de la energía, el agua y el transporte. Estos proyectos están recibiendo apoyo para la recopilación de datos de ciencias sociales a través de 
un contrato adjudicado el 12 de diciembre de 2019 a Horsley Witten Group, Inc., que contará con la ayuda de los subcontratistas Eastern Research Group, Inc., Issues \& Answers, Inc. y la Universidad Albizu en Puerto Rico. Los contratistas apoyarán el proyecto de Respuesta Pública a las Comunicaciones de Emergencia encuestando hogares en regiones en riesgo de inundaciones y entrevistando a funcionarios que brindaron información de emergencia al público para comprender mejor los factores que influyeron en los hogares para desalojar (o no desalojar) y el papel que desempeñaron las comunicaciones de emergencia en esas decisiones. Los contratistas también proporcionarán servicios de recolección de datos para tres proyectos relacionados con la recuperación después del huracán. Esto incluye encuestas de pequeñas y medianas empresas en los sectores de manufactura, comercio minorista y servicios para mejorar la comprensión de la planificación de la resiliencia de la continuidad del negocio. También se llevarán a cabo entrevistas con representantes conocedores de la cadena de suministro para el Proyecto de Recuperación de Negocios y Cadenas de Suministro. Los contratistas también realizarán encuestas en escuelas y hospitales para identificar las características y condiciones subyacentes asociadas con la recuperación de funciones sociales críticas para el Proyecto de Recuperación de Funciones Sociales y entrevistas estructuradas para examinar las dependencias de la función de los edificios en la infraestructura (energía, agua y transporte), incluida la pérdida en cascada de funciones y la secuenciación de las actividades de recuperación para el Proyecto de Recuperación de Sistemas de Infraestructura de Soporte a Edificios Críticos y Comunicaciones de Emergencia.

\subsubsection{Morbilidad y Mortalidad}

Las muertes y lesiones en Puerto Rico durante y después del huracán María pueden atribuirse a varias causas principales: exposición directa al viento, marejada ciclónica, inundaciones o deslizamientos de tierra; falla de un edificio; falla de la infraestructura crítica (por ejemplo, energía y agua); pérdida de suministros sanitarios (medicamentos o dispositivos médicos) o servicios de salud; $u$ otras condiciones. Se otorgó un contrato a la Universidad George Washington (GW) el 27 de julio de 2020, para identificar muertes en Puerto Rico relacionadas directa e indirectamente con el huracán María y, más específicamente, para identificar muertes atribuidas a falla(s) en edificios y/o en sistemas de edificios. ${ }^{43} \mathrm{GW}$ recopilará y fusionará datos sobre las muertes que ocurrieron hasta seis meses después de que el huracán María tocó tierra en Puerto Rico. Desarrollarán una base de datos integrada a partir de varias fuentes de datos, que pueden incluir el Sistema de Registro Vital de Puerto Rico, registros electrónicos de casos DMORT, registros de archivos de patología, llamadas de emergencia al 911 obtenidas de la Negociado de la Policía y datos de asistencia funeraria y de entierro de FEMA y la Cruz Roja

\footnotetext{
${ }^{43}$ Según 15 CFR $§ 270.100$, "una falla en un edificio puede involucrar uno o más de los siguientes: sistema estructural, sistema de protección contra incendios (activo o pasivo), sistema de manejo de aire y sistema de control del edificio. Los equipos establecidos bajo la Ley y esta parte investigarán estas causas técnicas de fallas en los edificios y también investigarán los aspectos técnicos de los procedimientos de desalojo y respuesta a emergencias, incluido el comportamiento de múltiples ocupantes o el sistema de desalojo (salida o acceso), el sistema de respuesta a emergencias y el sistema de comunicación."
} 
Americana. GW geocodificará las muertes y enviará una base de datos donde puede hacerse una búsqueda de texto junto con un informe que documente el proceso de fusión de fuentes de datos, así como la cobertura y calidad de los datos de cada fuente, destacando el valor agregado potencial de la integración de datos de fuentes específicas. Posteriormente, GW: analizará la base de datos integrada para calcular las tasas de mortalidad por causas específicas ajustadas por edad y género y las comparará con años anteriores; examinará cada causa general de muerte (es decir, capítulos de ICD-10) y las causas específicas de muerte atribuidas típicamente a los huracanes (p. ej., ahogamiento, muerte por un objeto caído) y las comparará con años anteriores; calculará las tasas de mortalidad por causas específicas ajustadas por edad y sexo para otras causas específicas de muerte que se identifican como significativamente mayores después del huracán María (en comparación con el año anterior); identificará cualquier aumento significativo en las tasas de muerte por causas particulares entre el período posterior a la tormenta y los años anteriores y señalará todas las muertes por esas causas en las primeras dos semanas después de la tormenta; e identificará grupos espaciales y temporales de muertes que ocurrieron hasta seis meses después de la tormenta en las áreas de estudio identificadas por el personal del NIST.

Con base en la base de datos integrada, la Escuela de Salud Pública de la Universidad de Puerto Rico (UPR), subcontratista de GW, identificará a los familiares u otros informantes clave para realizar autopsias verbales para determinar la atribución de muertes ocurridas inmediatamente después la tormenta tocó tierra. GW desarrollará un instrumento de autopsia verbal y un guion (instrucciones para el encuestado y el entrevistador) que se utilizará para determinar si una muerte fue el resultado directo o indirecto de una falla en un edificio y/o de los sistemas del edificio o el resultado indirecto de las fuerzas del huracán, incluidos vientos, marejadas ciclónicas, inundaciones o deslizamientos de tierra. Si una muerte fue el resultado directo o indirecto de falla(s) del edificio y/o de los sistemas del edificio, esto significa que la persona murió por una lesión relacionada con la falla estructural, daño al edificio o pérdida de la función de los sistemas del edificio.

\subsubsection{Soporte de comunicaciones}

El NIST se compromete a comunicar claramente las metas, el progreso y los hallazgos del Programa del Huracán María, incluida la traducción al español para llegar de la manera más eficaz a las partes interesadas clave en Puerto Rico. Varios contratos adicionales brindan soporte de comunicación para el Programa del Huracán María. El 23 de abril de 2019, se otorgó un contrato de servicios de soporte de traducción e interpretación a Lazar Translating Services, Inc. El 26 de febrero de 2019, se otorgó un contrato para servicios de soporte de redacción técnica a CatMedia, Inc. Además, el 12 de febrero de 2019 se otorgó a Strativia, LLC un contrato para el desarrollo de una estrategia de comunicación y apoyo en la implementación del acercamiento con las partes interesadas. 
Más allá de desarrollar los enfoques metodológicos iniciales e identificar las necesidades de información y los puntos de contacto, cada uno de los siete proyectos técnicos del huracán María ha avanzado en el refinamiento de la metodología, la recopilación de datos y la realización de análisis iniciales. Estos proyectos se están integrando en la medida de lo posible y en apoyo de los objetivos de la investigación del NCST y el estudio NWIRP. Esta integración se ejemplifica por el enfoque en áreas de estudio comunes, por la alineación de estrategias de muestreo y a través de elementos específicos del plan de recolección de datos. Además de planificar y coordinar los proyectos técnicos que se llevarán a cabo, el Equipo ha construido una amplia infraestructura de información para respaldar la recopilación, el intercambio y el análisis de datos. Esto incluye procesos para garantizar solo el acceso apropiado y la protección de la información de identificación personal y otra información consistente con los requisitos y las buenas prácticas del gobierno federal.

Los siguientes son varios ejemplos del progreso notable en la coordinación entre proyectos:

- El equipo del NIST se unió al Centro Nacional de Medicina y Salud Pública en Desastres para celebrar una reunión abierta en septiembre de 2018 para discutir el estado de la práctica en los métodos de recopilación de datos de campo posteriores a un desastre, incluidas las metodologías de muestreo en múltiples disciplinas.

- El Equipo desarrolló una estrategia de muestreo inicial para hospitales, escuelas y refugios que considera la información disponible sobre las características del edificio, la exposición a peligros y los daños. La estrategia de muestreo se centró en el Proyecto de Edificios Críticos, aunque informa los Proyectos de Recuperación de Funciones Sociales y Recuperación de Infraestructura.

- Se concertaron acuerdos para compartir datos y se adquirieron los siguientes tipos de datos: daños y recuperación de comunicaciones (American Tower Corporation), evaluaciones de daños a edificios (FEMA), datos de hospitales (HHS), datos de infraestructura de agua (Autoridad de Acueductos y Alcantarillados de PR), datos de infraestructura de transporte (Departamento de Transportación y Obras Públicas de PR) y datos de hospitales (Departamento de Salud de PR). Estos datos son beneficiosos para múltiples proyectos.

- Se desarrollaron borradores de estrategias de análisis de datos que definen entradas y salidas en todos los proyectos.

- Se ha desarrollado y compartido con todos los proyectos una base de datos geográficos de datos espaciales necesarios para producir mapas base para todos los proyectos técnicos.

Las siguientes subsecciones presentan el progreso en la recopilación de datos y el progreso del análisis para cada uno de los proyectos técnicos. 


\subsubsection{Caracterización de peligros}

Modelado de campo de vientos

- Se desarrolló un modelo de campo de vientos inicial para el huracán María, que proporciona registros de tiempo de la velocidad y dirección del viento en todo el Estado Libre Asociado, incluida la consideración de los efectos topográficos sobre las velocidades del viento (consulte la sección 3.3.1). Las velocidades máximas del viento estimadas con y sin efectos topográficos se muestran en la Figura 5. Este modelo de campo de vientos se desarrolló ajustando el modelo a las observaciones meteorológicas disponibles a nivel de superficie. La Figura 6 muestra los valores del Factor de Aumento de Velocidad Topográfica (TSF), definido como la relación de las velocidades máximas de las ráfagas de viento con y sin efectos topográficos. Se observan efectos de aumento de Velocidad significativos en ciertas regiones, con valores de TSF tan altos como 1.8.

- Posterior a la finalización del modelo de campo de vientos inicial, se han realizado mejoras adicionales en el modelo de campo de vientos utilizando datos de huracanes anteriores, incluido el desarrollo de una metodología para optimizar cómo el modelo se ajusta a los datos observados, con cuantificación de la incertidumbre.

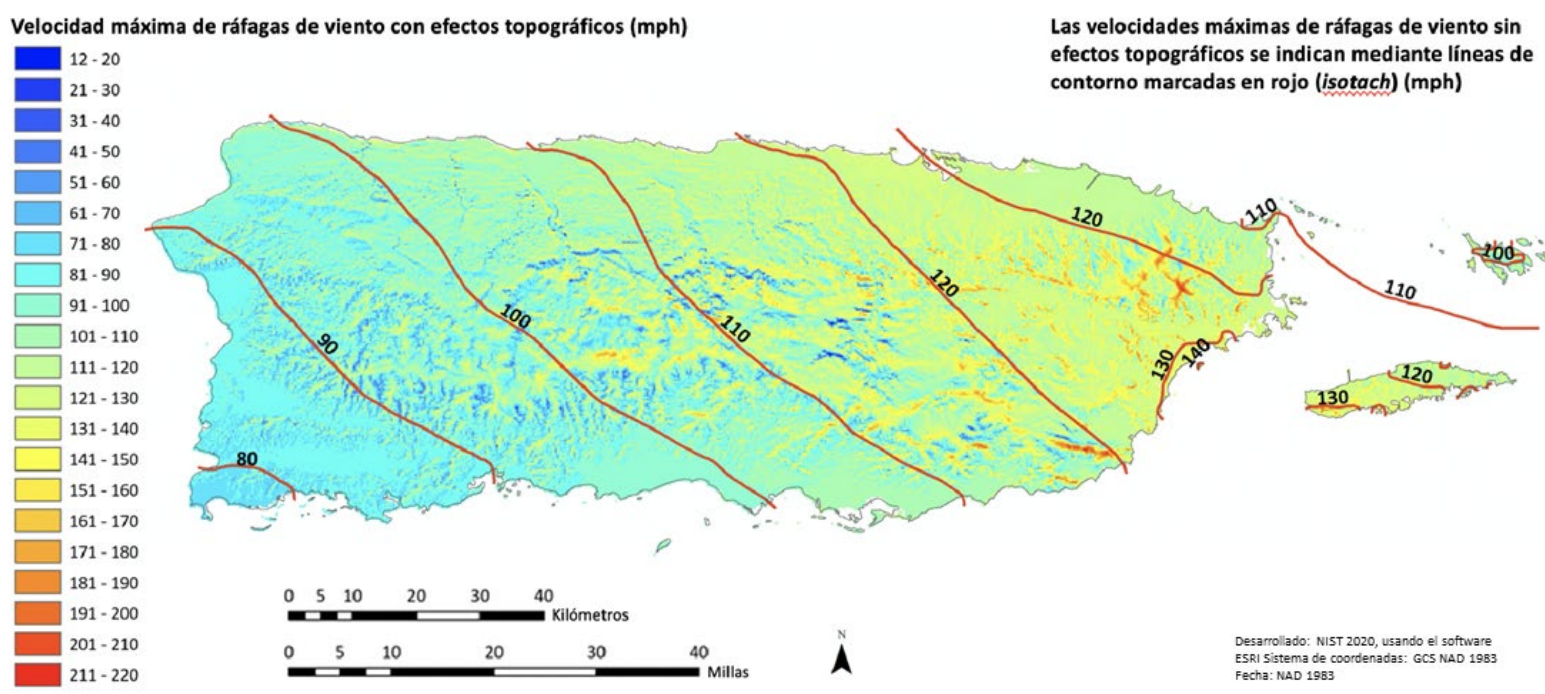

Figura 5: Velocidades máximas de ráfagas de viento estimadas con y sin efectos topográficos del modelo de campo de vientos inicial para el huracán María. 
Factor de aumento de velocidad topográfica

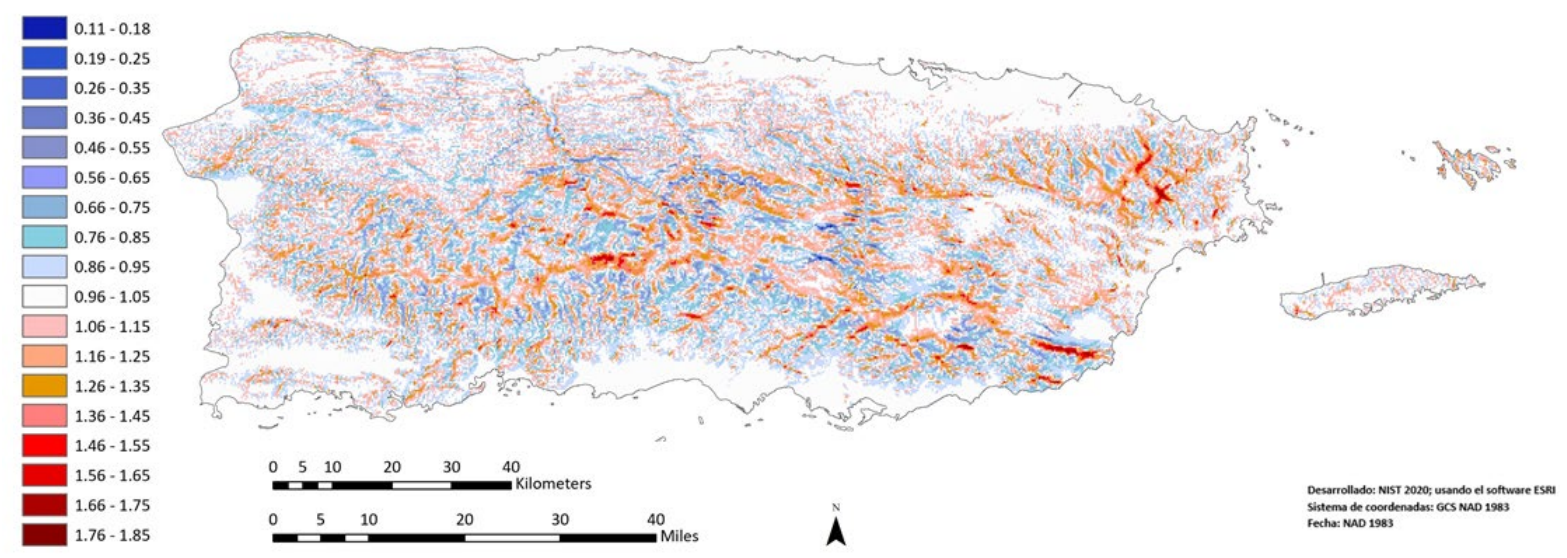

Figura 6: Factores de aumento de velocidad topográficos estimados a

partir del modelo de campo de vientos inicial.

Prueba de túnel de viento

- Se ha completado el plan de prueba para las pruebas en túnel de viento de modelos topográficos bidimensionales genéricos y se han fabricado los modelos topográficos genéricos (Figura 7). Se probarán modelos con tres tipos de rugosidad superficial: pared lisa, rugosa y en terrazas. La Figura 7 muestra ejemplos de un modelo liso y un modelo en terrazas.

- Se ha completado el plan de pruebas para las pruebas en túnel de viento de modelos a escala de las regiones de Mayagüez y Yabucoa en Puerto Rico. La figura 8 muestra el modelo de la región de Yabucoa en el túnel de viento con límites de capa de la Universidad de Florida. La fabricación del modelo de Mayagüez está en marcha.

- Se han completado las mediciones de flujo en el túnel de viento para caracterizar el perfil de flujo entrante para diferentes categorías de terreno y para garantizar que el flujo entrante coincida con el perfil objetivo. Actualmente se están realizando pruebas de modelos topográficos y se han completado las mediciones de un subconjunto de las pruebas. 


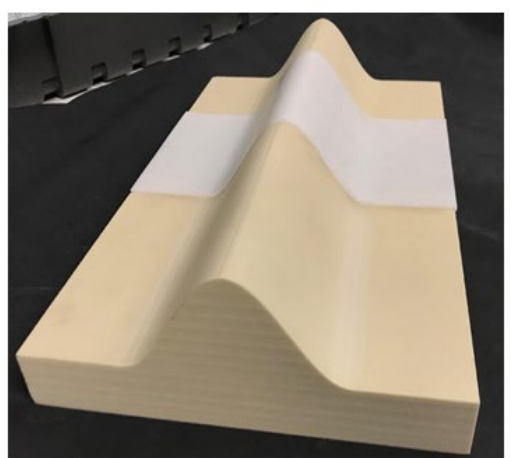

(a) Modelo de cresta con superficie lisa

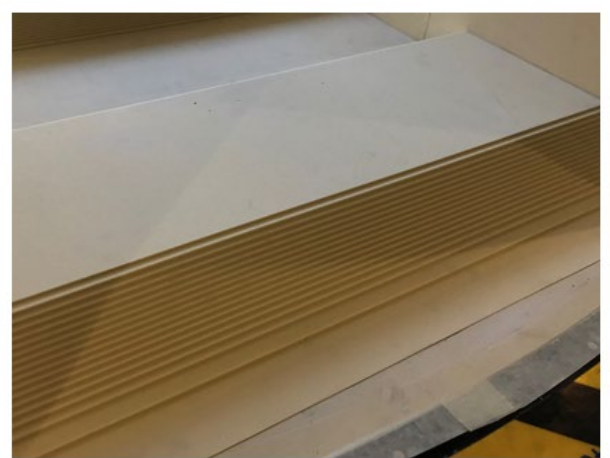

(b) Modelo de meseta con superficie escalonada

Figura 7: Modelos de túnel de viento de características topográficas bidimensionales genéricas.

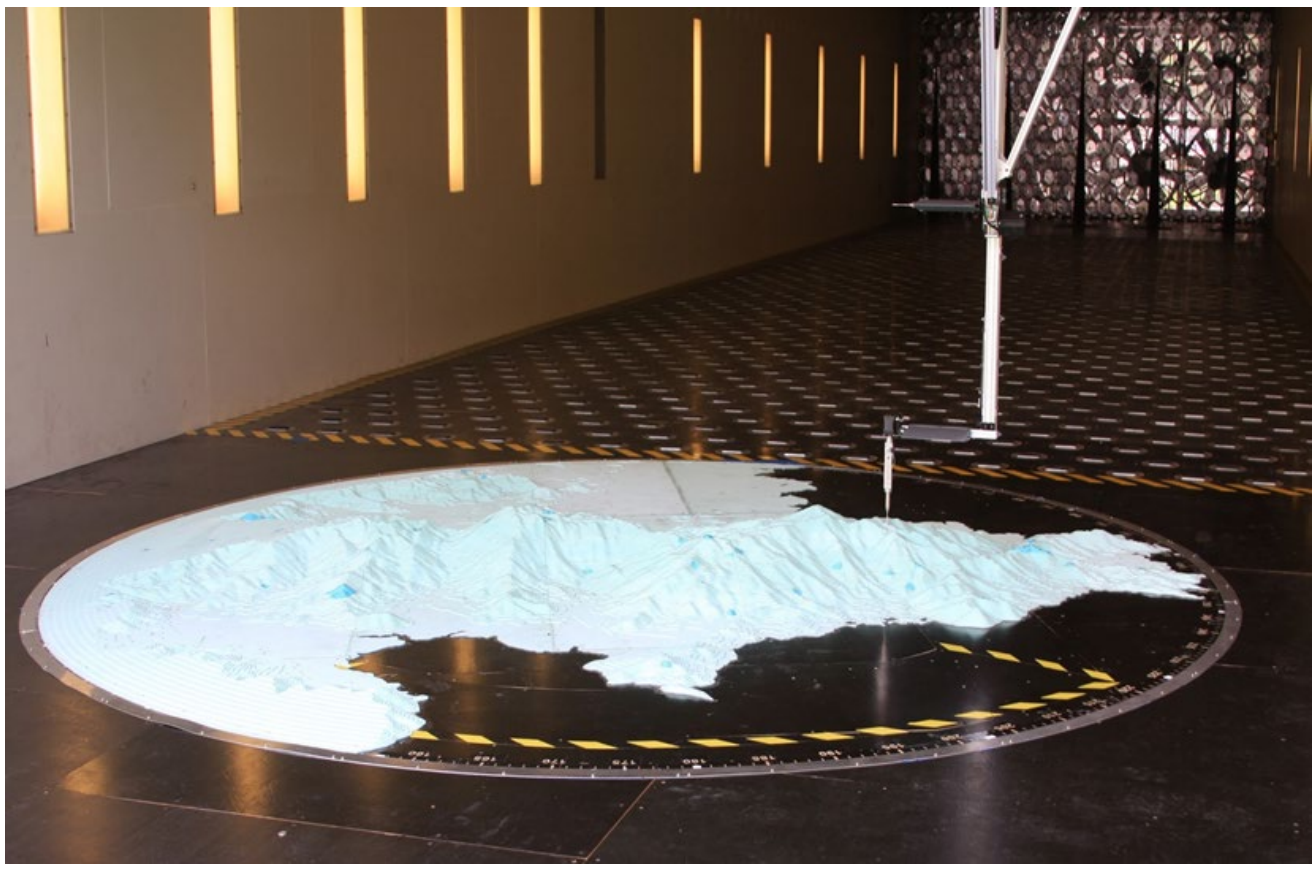

Figura 8: Modelo topográfico de la región de Yabucoa.

Simulaciones computacionales de dinámica de fluidos

- Se han desarrollado modelos topográficos computacionales de dinámica de fluidos para generar flujo de aproximación y tener en cuenta la rugosidad de la superficie del terreno, incluida la simulación del flujo sobre bloques de rugosidad en el túnel de viento, como se ilustra en la Figura 9.

- Se están realizando simulaciones de flujo sobre los modelos topográficos genéricos (Figura 10). 


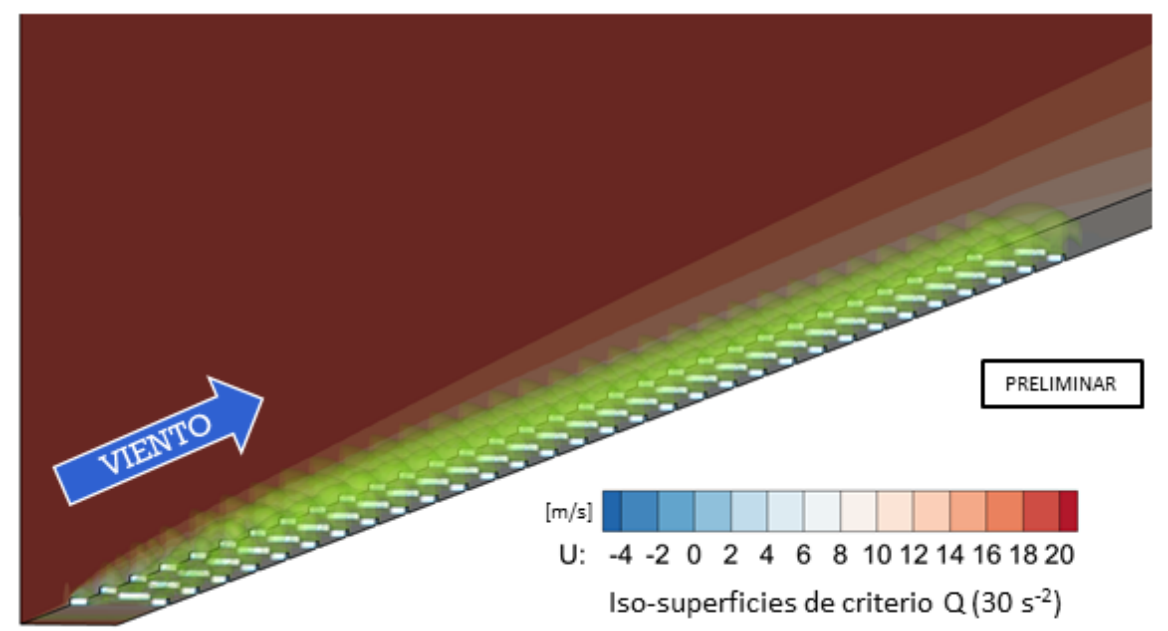

Figura 9: Simulación computacional de dinámica de fluidos del flujo de aproximación de límite de capa generado por bloques de rugosidad en el túnel de viento.

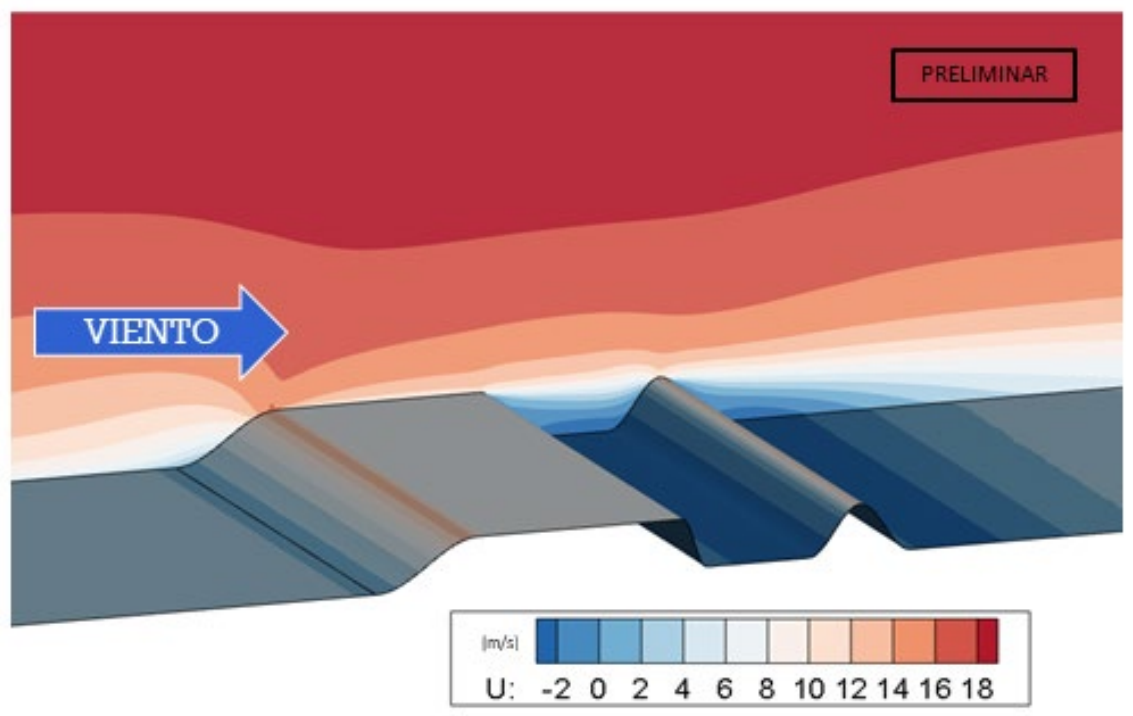

Figura 10. Campo de velocidad del viento longitudinal sobre modelos topográficos genéricos bidimensionales.

Medición de campo de vientos

- seleccionaron tres torres celulares en la región de Yabucoa para la medición de campo de los efectos de aumento de velocidad topográfica, y se desarrolló un plan de despliegue para la instalación de anemómetros a múltiples alturas en cada torre (Figura 11), con espacio en las torres, proporcionado por American Tower Corp., el dueño de las torres.

- WeatherFlow, un subcontratista del NIST, ha instalado anemómetros en los tres sitios de torres seleccionados (consulte la Sección 4.3.2), y el equipo ha comenzado a registrar datos de velocidad del viento (Figura 12), incluida la captura de datos de vientos fuertes de la tormenta tropical Isaías en julio de 2020 y tormenta tropical Laura en agosto de 2020 


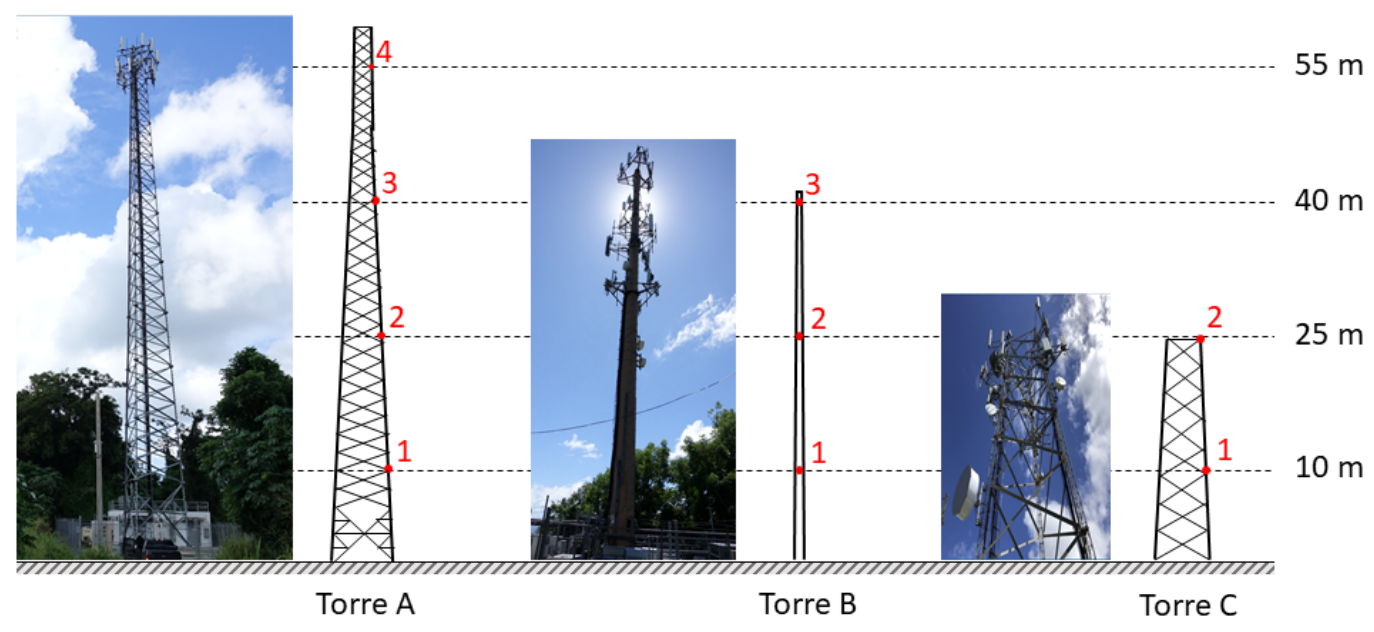

Figura 11. Posiciones de anemómetros instalados en torres de telefonía celular en la región de Yabucoa.

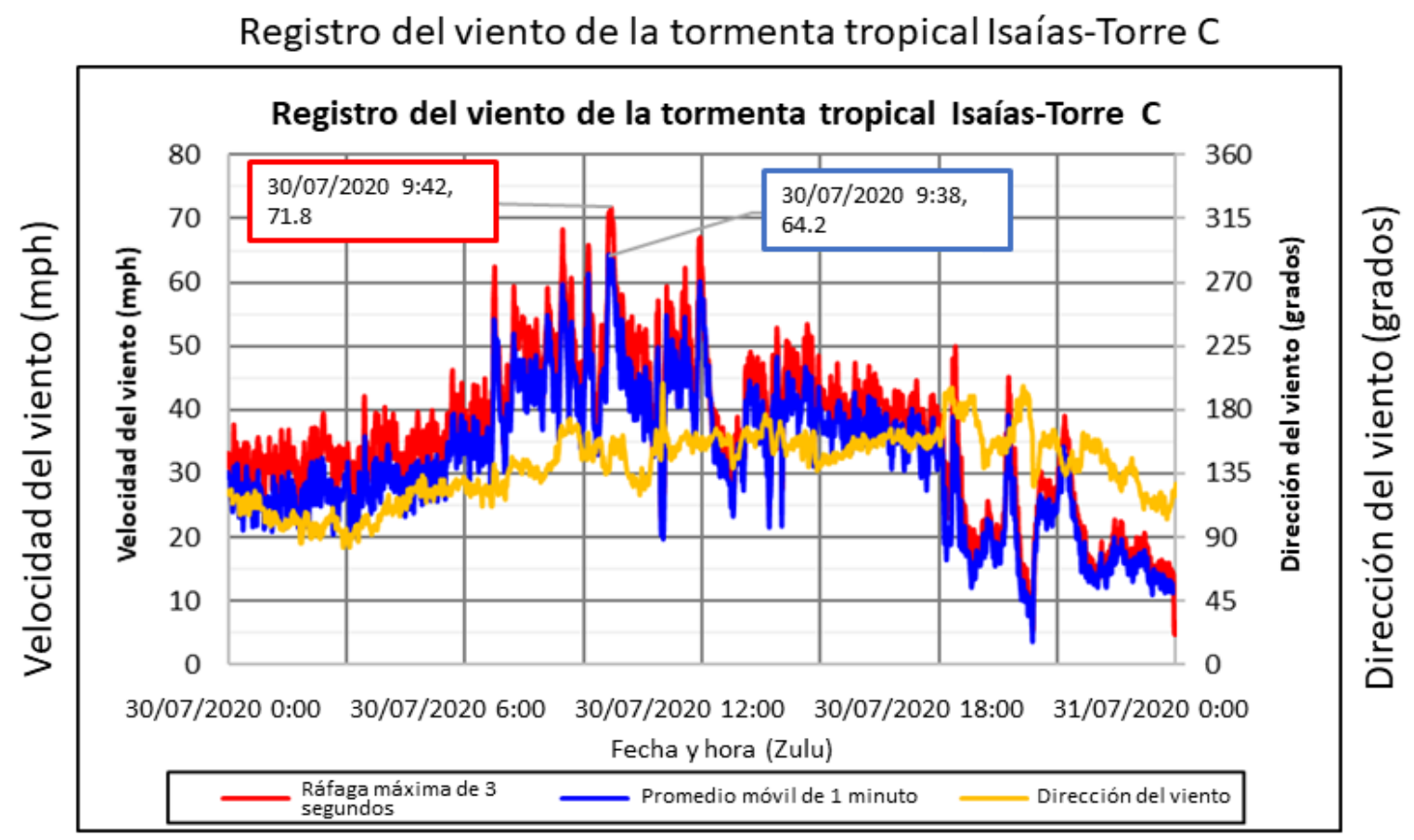

Ráfaga máxima de 3 segundos Promedio móvil de 1 minuto Dirección del viento

Figure 12. Example of wind speed data recorded from Tower C in Yabucoa. 
Caracterización de peligros no relacionados con el viento

- Se ha coordinado el acercamiento a otras agencias y organizaciones, y se han recopilado conjuntos de datos para proporcionar una evaluación en toda la isla de los peligros no relacionados con el viento, que incluyen lluvias, inundaciones, deslizamientos de tierra y marejadas ciclónicas.

- La precipitación in situ y por satélite y otros productos de datos hidrológicos se han recopilado de la NOAA, la NASA, el USGS y la Universidad de California en Santa Bárbara.

- Se completó el análisis inicial de la lluvia total de tormentas para el huracán María (Figura 13).
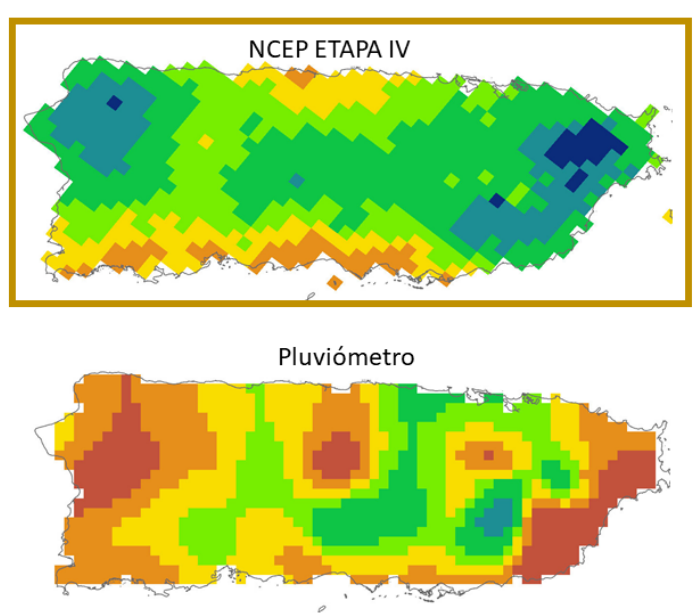

$$
\begin{aligned}
& \text { Lluvia (pulgadas) } \\
& \begin{array}{l}
5-10 \quad 15-20=30-40 \square \\
10-15-20-30=40-60
\end{array}
\end{aligned}
$$

Amplia disparidad en las mediciones de lluvia. Los sistemas de satélite no capturan la misma intensidad e influencias topográficas a pesar de la fusión de datos in situ y muestran una variabilidad espacial más débil.

Figura 13. Comparación de las estimaciones de precipitación total de tormentas terrestres (columna izquierda) y espaciales (columna derecha) para el huracán María. Los datos de la Etapa IV del NCEP (arriba a la izquierda) se consideran ampliamente como el estándar de referencia (gold standard) para las estimaciones de lluvia.

\subsubsection{Desempeño de edificios críticos}

Recolección de datos inicial

- La información sobre daños a escuelas y hospitales se ha obtenido a través de Memorandos de Acuerdo (MOA, por sus siglas en inglés) establecidos con FEMA. Esto incluye evaluaciones de escuelas e instalaciones de atención médica realizadas por EE. UU. El Cuerpo de Ingenieros del Ejército (USACE) bajo misión asignada a FEMA, así como información sobre daños del Programa de Asistencia Pública de FEMA. Se ha desarrollado una base de datos inicial de las características de la escuela/refugio utilizando datos de las evaluaciones escolares de USACE.

- Se ha obtenido información hospitalaria adicional del HHS y del Departamento de Salud de PR. 
- La información sobre el Programa de Refugios se ha obtenido del Departamento de Vivienda de Puerto Rico, incluida información sobre la población de refugios a lo largo del tiempo.

- Se han obtenido datos aéreos Lidar del Laboratorio Lincoln del MIT para sitios seleccionados en Puerto Rico para caracterizar el terreno y los edificios que rodean los edificios críticos seleccionados y los sitios de torres (Figura 14).

- La información GIS se ha obtenido de múltiples fuentes para hospitales, escuelas y albergues en Puerto Rico. Con esta información, se han evaluado los niveles de peligro en sitios de construcción seleccionados.

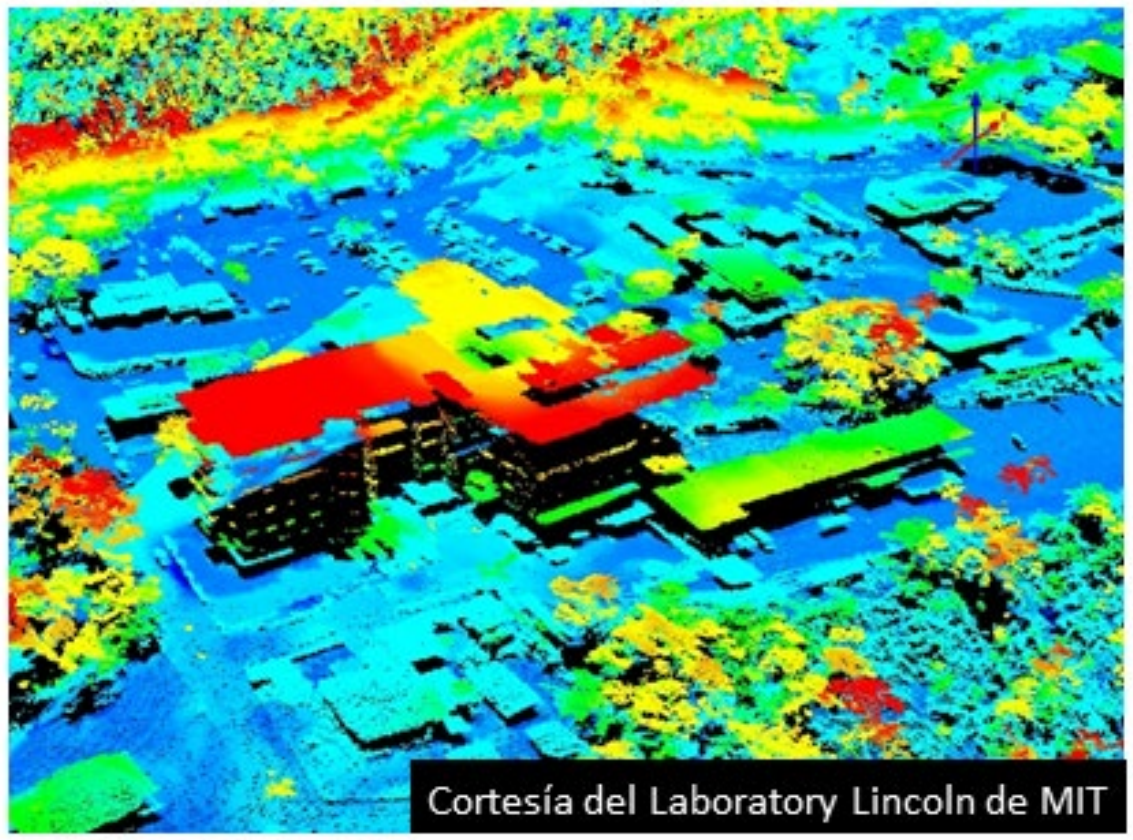

Figura 14. Datos Lidar para el Hospital Bella Vista.

\section{Selección de muestras}

- Se desarrolló una estrategia de muestreo y se seleccionaron cinco hospitales para la evaluación, con un hospital en cada una de las cuatro regiones de estudio (Figura 4) y un hospital en Mayagüez.

- La selección de un conjunto básico de edificios hospitalarios para el Proyecto de Edificios Críticos proporciona vínculos entre varios proyectos del Programa del Huracán María.

- La selección de hospitales de cada una de las cuatro regiones de estudio proporciona variación en la exposición al peligro, con las velocidades del viento más bajas en la región de Utuado y las velocidades del viento más altas en la región de San Juan (Figura 15).

- El factor de aumento de velocidad topográfica (TSF, por sus siglas en inglés) más alto se observó para el Hospital Bella Vista en Mayagüez, con un TSF de aproximadamente 1.5 (Figura 15). 
- Para los hospitales de la región de Utuado, la topografía montañosa en realidad tuvo un efecto de refugio, provocando una reducción en las velocidades del viento como lo indican los valores de TSF menores a uno (Figura 15).

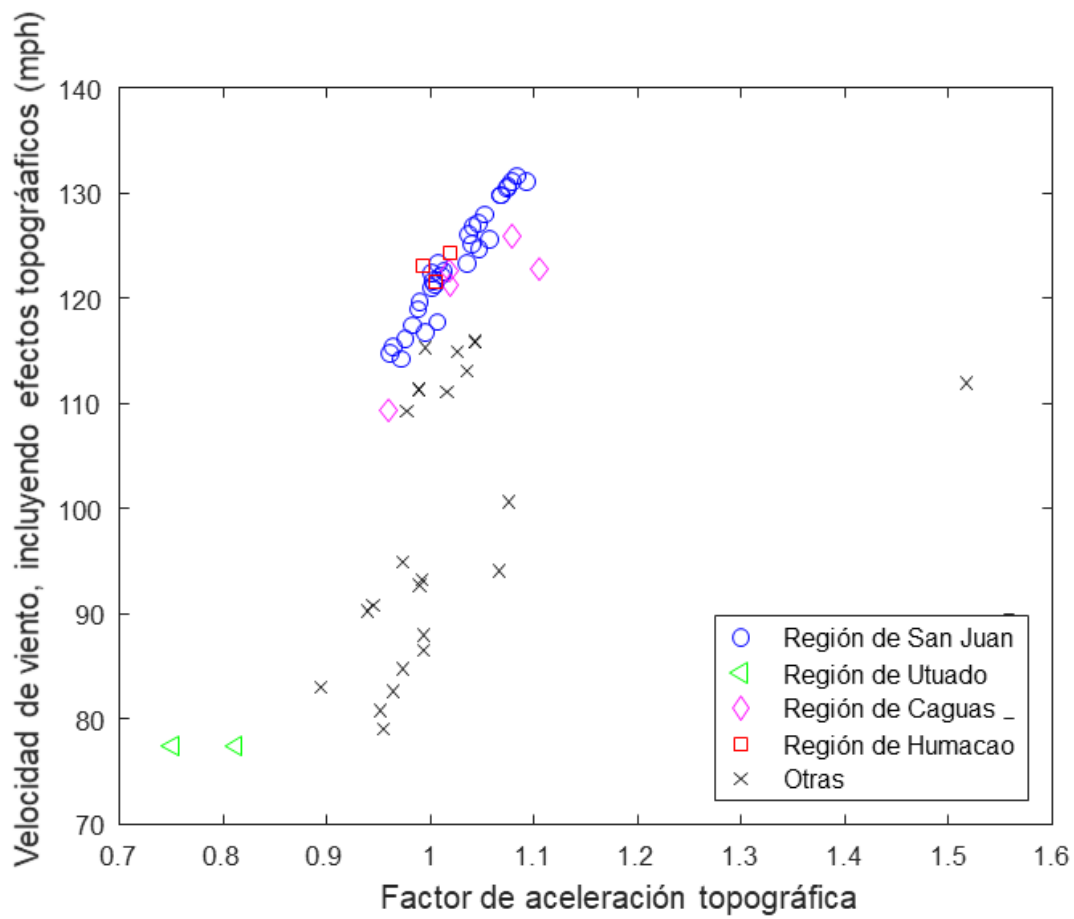

Figura 15. Velocidad máxima de ráfagas de viento durante el huracán María (incorporando efectos topográficos) versus factor de aumento de velocidad topográfica para hospitales en Puerto Rico.

Evaluaciones de instalaciones

- Las visitas al sitio y las reuniones con el personal de dos hospitales se llevaron a cabo en octubre y noviembre de 2019, que incluyeron una introducción y descripción general del Programa del Huracán María del NIST, así como recorridos por las instalaciones y conversaciones sobre el impacto del huracán María. Los dos hospitales fueron el Hospital Pediátrico Universitario en San Juan y el Hospital Bella Vista en Mayagüez.

- Se ha iniciado la primera fase del trabajo de evaluación de instalaciones, que consiste en la recopilación y revisión de documentos iniciales, para las cinco instalaciones hospitalarias seleccionadas. Stantec, Inc. (consulte la Sección 4.3.3) apoya al NIST en la realización de estas evaluaciones.

Prueba de túnel de viento

- El Hospital Bella Vista ha sido seleccionado como la primera instalación para pruebas en túnel de viento.

- Se han desarrollado planes para caracterizar los efectos topográficos sobre el flujo entrante para este trabajo de prueba en túnel de viento. El flujo entrante para las pruebas en túnel de viento del modelo de construcción (a escala 1:100) se basará en mediciones de velocimetría de imágenes de partículas de pruebas en túnel de viento de un modelo topográfico de la región de Mayagüez (a escala 1:3100). 
- Se han realizado fotografías con drones del sitio del Hospital Bella Vista para desarrollar un modelo 3D que sirva de apoyo a la fabricación de un modelo de túnel de viento. El diseño del modelo de túnel de viento, los sistemas de medición y el plan de pruebas están en curso.

\subsubsection{Respuesta pública a comunicaciones de emergencia}

\section{Recopilación de datos}

- Se recopilaron más de 1,000 mensajes durante y después del huracán María en 2017 y 2018.

- Se hicieron contactos importantes con personas clave en las agencias de predicción meteorológica y gestión de emergencias, tanto dentro de Puerto Rico como a nivel nacional durante las visitas a sitios clave, así como a través de actividades independientes de acercamiento para recopilar información de antecedentes relevante.

\section{Desarrollo de métodos}

- El NIST redujo el enfoque de este proyecto a cuatro regiones de estudio clave dentro de Puerto Rico (ver Figura 4). Estas son las regiones planificadas para la distribución de los instrumentos de recopilación de datos desarrollados para el proyecto Comunicaciones de emergencia y desalojo.

- Un grupo informal de expertos dentro del área de investigación y operaciones de comunicaciones de riesgo y mensajes de clima severo en NOAA ha ayudado con la revisión de los instrumentos de recolección de datos.

- Se ha completado una revisión de la literatura para identificar las mejores prácticas y las consideraciones importantes para la creación y distribución de mensajes de emergencia efectivos, así como los factores relevantes para la toma de decisiones de acciones de protección (desalojo).

- Se han elaborado borradores de guías preliminares para entrevistas y encuestas, y planes de análisis y distribución relacionados para recopilar información sobre la difusión y eficacia de las comunicaciones de emergencia. Se han revisado los datos públicos sobre los factores que influyen en la percepción del riesgo y los procesos de toma de decisiones con respecto a la acción de protección.

- Se ha creado una lista de posibles entrevistados para las entrevistas con los proveedores de información.

- Se ha desarrollado un plan de muestreo para el despliegue de la encuesta de hogares (1,500 encuestados) en las cuatro áreas de estudio para garantizar una respuesta adecuada en todas las variables demográficas, así como la exposición al riesgo de inundaciones y deslizamientos de tierra.

- El equipo del proyecto está trabajando en las etapas finales de las aprobaciones requeridas para la implementación de la prueba piloto de la encuesta de hogares y para las entrevistas con los proveedores de información, incluida la revisión por expertos en la materia y el personal del contratista y la traducción al español. 
Análisis

- La coordinación entre los proyectos del huracán María está en curso para identificar áreas clave de interés mutuo y para respaldar el mejor análisis general para lograr las metas del programa.

- La transcripción y catalogación de los mensajes de comunicación de emergencia han seguido respaldando el análisis de contenido cualitativo en curso.

\subsubsection{Caracterización de morbilidad y mortalidad}

Recolección inicial de datos

- El equipo del proyecto llevó a cabo reuniones con científicos y médicos dentro y fuera de la isla para capturar con precisión los datos que ya existen y que el NIST puede utilizar fácilmente.

Desarrollo de métodos

- El equipo del proyecto presentó el Programa del Huracán María y recibió aportes de la comunidad de salud pública y desastres en el Taller de Salud y Desastres organizado por el NCDMPH en abril de 2019.

- El equipo del proyecto participó en todas las reuniones públicas del Comité de Academias Nacionales sobre las Mejores Prácticas para Evaluar la Mortalidad y la Morbilidad Significativa Después de Desastres a Gran Escala, un estudio financiado por FEMA. Además, el NIST hizo una presentación en una de las reuniones, junto con médicos y expertos en salud pública de Puerto Rico, para informar el estudio de las Academias Nacionales.

- Se ha realizado una revisión de la literatura para informar el desarrollo del instrumento de autopsia verbal (VA) en virtud de un acuerdo interinstitucional (IAA, por sus siglas en inglés) con el NCDMPH.

- Se desarrollaron preguntas relevantes para el proyecto de mortalidad para incluirlas en los instrumentos de encuesta de otros proyectos (incluyendo Comunicaciones de Emergencia y Recuperación de Funciones Sociales).

\subsubsection{Recuperación de cadenas comerciales y de suministro}

Desarrollo de métodos

- El marco de muestreo se finalizó en junio de 2020. El marco incluye listas de PYMEs creadas con datos de InfoUSA para el alcance geográfico completo y todas las industrias incluidas en el ámbito de servicios, venta minorista y manufactura. También se sacaron registros para las empresas de la industria del transporte/envíos para todo Puerto Rico (para informar la selección de las entrevistas de las entidades de transporte/envíos).

- La lista de PYMEs se comparará con las PYMEs de PRiMEX (que consisten principalmente en manufactureros pequeños y medianos) para garantizar que no haya cargas adicionales para los encuestados. 
- El diseño de la muestra para el Proyecto de Recuperación de Empresas y Cadena de Suministro se ha mejorado para vincular directamente a la muestra para el Proyecto de Recuperación de Funciones Sociales. Para todos los códigos postales en el estudio del NIST, las áreas que contienen hospitales se incluirán a través de una muestra aleatoria de negocios proporcional al recuento de tipos de negocios específicos en ese código postal en comparación con los de los mismos tipos de negocios en todos los códigos postales incluidos en el alcance. Dentro de los códigos postales que no contienen hospitales, se seleccionará una muestra de PYMEs proporcional al número dentro de cada categoría.

\section{Recopilación de datos}

- Los datos se obtuvieron de la Extensión de Manufactura de Puerto Rico (PRiMEX), la Autoridad de los Puertos de PR y el Departamento del Trabajo y Recursos Humanos de PR.

- El equipo del proyecto analizó la preparación, mitigación y recuperación empresarial con varias empresas y agencias gubernamentales. Los datos sobre la recuperación de negocios clave dentro del sector de manufactura de preparación de alimentos y el sector de manufactura de dispositivos médicos se recopilaron a través de visitas al sitio junto con PRiMEX y la Sociedad de Extensión de Manufactura (MEP) del NIST en el verano de 2019.

- Los datos sobre la recuperación inicial de las PYMEs, recopilados a partir de observaciones de campo y otras fuentes, se han recopilado para respaldar los análisis futuros.

- El equipo del proyecto ha elaborado borradores de todos los instrumentos de encuestas y entrevistas para la recopilación de datos sobre la recuperación de las PYMEs. La Figura 16 proporciona una descripción general de los tipos de datos que se recopilarán a través de estas herramientas para permitir el análisis de la recuperación. Las categorías principales incluyen: (1) estado/capacidad de resiliencia anterior, (2) impactos (directos e indirectos), (3) respuesta y recuperación, y (4) estado/capacidad de resiliencia futura. Se han elaborado dos instrumentos relacionados con la manufactura, a saber, la Encuesta Empresarial de Continuidad de la Manufactura y la Guía de Entrevistas de la Cadena de Suministro de Manufactura. Se han elaborado dos instrumentos relacionados con los pequeños minoristas y las empresas del sector de servicios, a saber, la Encuesta Comercial de Continuidad de Servicios y Minoristas y la Guía de Entrevistas de Continuidad Comercial.

- El equipo del proyecto está alineando las preguntas con el Proyecto de Recuperación de Funciones Sociales y modificando las preguntas y el modo de encuesta debido a las limitaciones de COVID-19. 


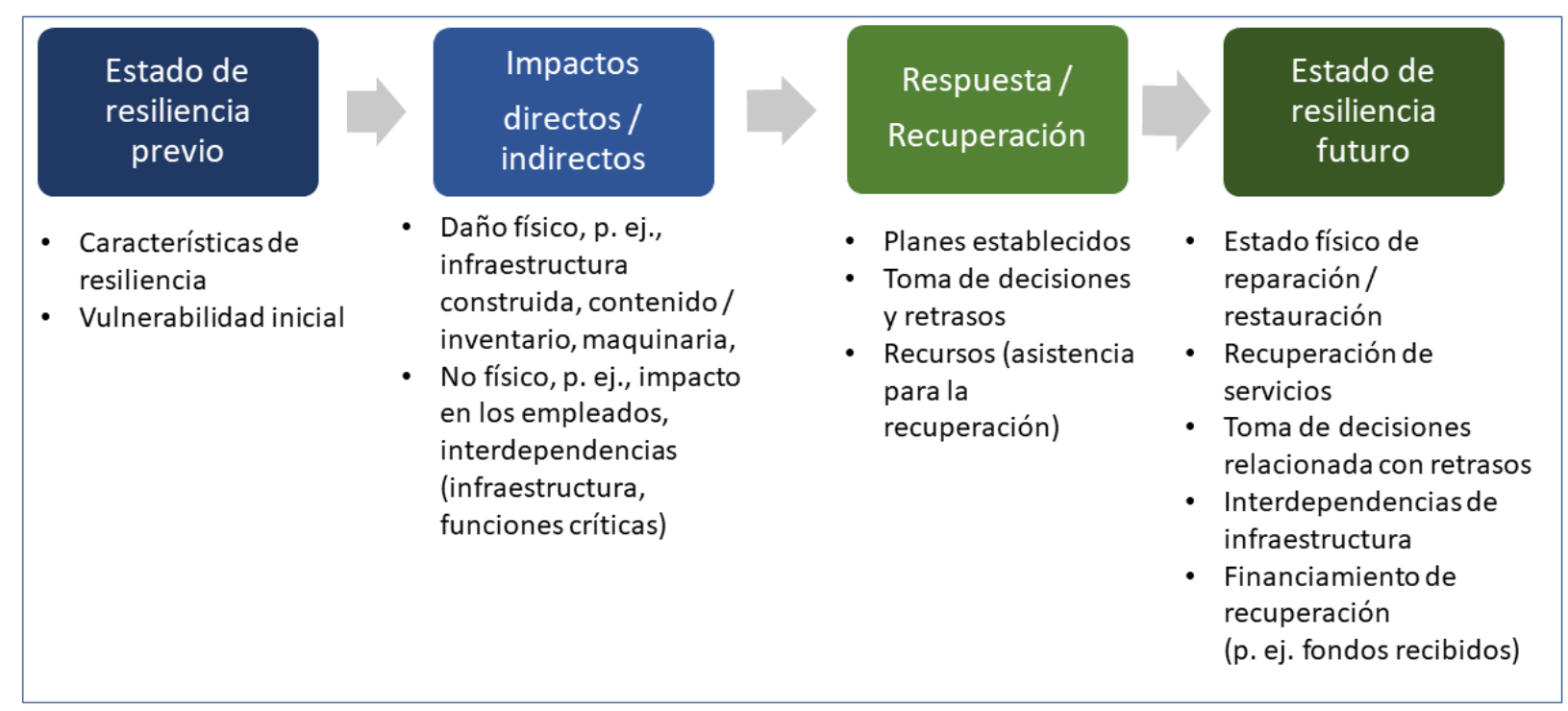

Figura 16. Resumen de las consideraciones de la encuesta para la recuperación de pequeñas y medianas empresas.

Análisis

- Se han realizado análisis espaciales de datos disponibles públicamente para redes de transporte y datos socioeconómicos para informar los planes de muestreo y análisis. El enfoque de estos análisis ha sido identificar grupos de sectores de PYMEs en relación con las carreteras principales y las instalaciones portuarias clave.

- Se han realizado análisis descriptivos básicos para comprender las necesidades inmediatas de los SMMs determinadas a través de una encuesta breve realizada por PRiMEX a través del Programa de Evaluación de Desastres de Manufactura (MDAP) MEP del NIST.

- Se desarrollaron modelos preliminares basados en la simulación de eventos discretos (DES) y la teoría de redes complejas (CNT) para los dos sectores clave (manufactura de dispositivos médicos y manufactura de preparación de alimentos) utilizando información de las discusiones de la empresa y visitas a las instalaciones de manufactura. La Figura 17 proporciona una descripción general del marco general empleado para evaluar la resiliencia de la red a través de CNT. En particular, la realización de estos análisis ha mejorado el desarrollo del marco de preguntas y muestras para los instrumentos de recopilación de datos centrados en la recuperación de las PYMEs individuales. 


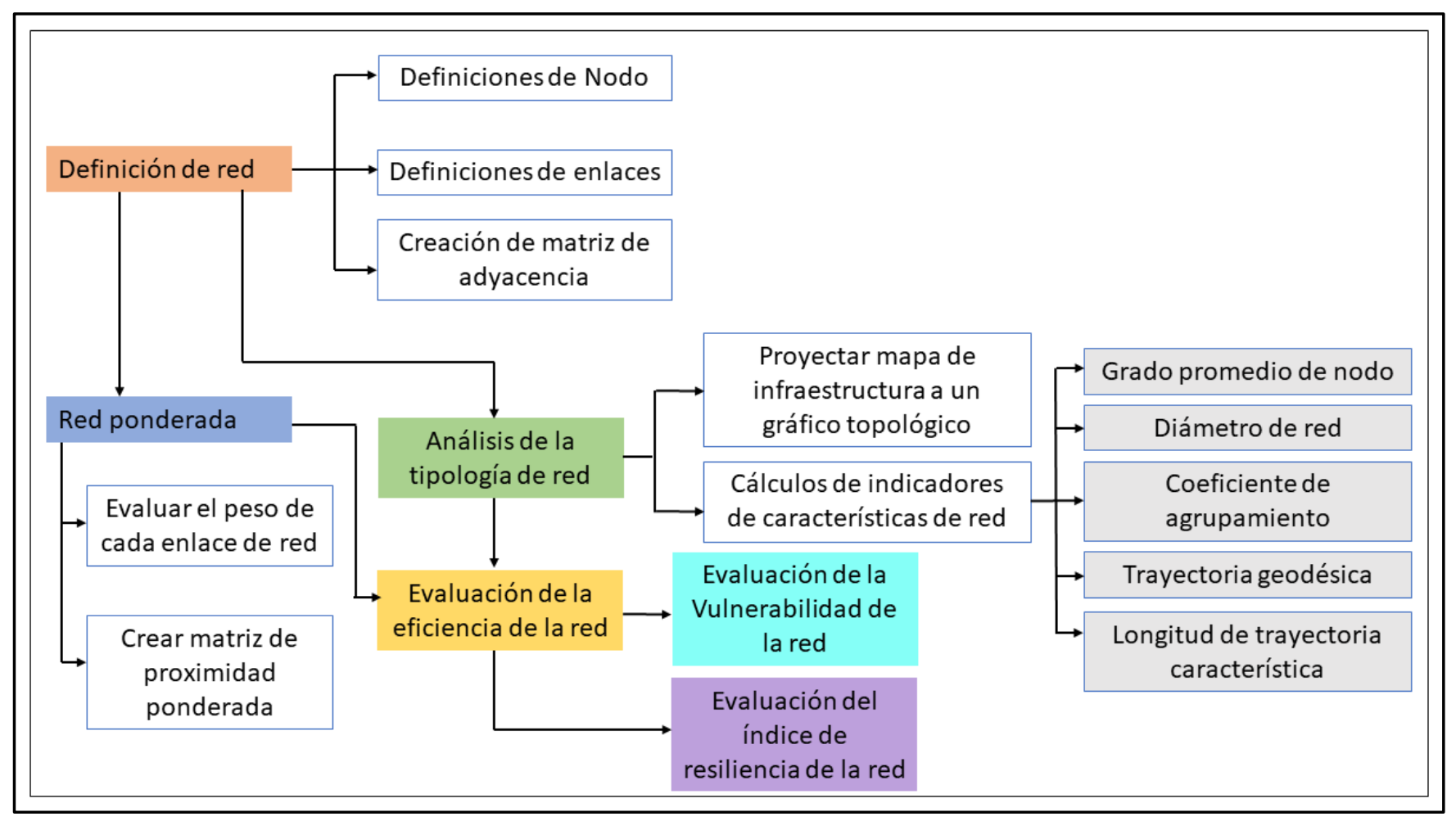

Figura 17. Proceso de evaluación CNT.

\subsubsection{Recuperación de funciones sociales}

Desarrollo de métodos

- El marco de muestreo se finalizó en mayo de 2020. Incluye listas completas de escuelas y hospitales K-12 creados con datos públicos de una variedad de fuentes, incluida la Asociación de Hospitales de Puerto Rico, el Directorio de Hospitales Americanos, el Centro Nacional de Estadísticas Educativas y el Departamento de Educación de PR.

- El diseño de la muestra para el Proyecto de Recuperación de Funciones Sociales se ha refinado para reflejar la alineación con el Proyecto de Edificios Críticos, la coordinación con el Proyecto de Morbilidad y Mortalidad y el Proyecto de Recuperación de Infraestructura, y la vinculación directa mediante muestreo secuencial con el Proyecto de Recuperación de Negocios y Cadenas de Suministro.

- El proyecto se llevará a cabo mediante la recopilación de datos en tres puntos de tiempo, que se denominan "ondas" a continuación. El equipo del proyecto ha seleccionado un diseño longitudinal para comprender la recuperación en el tiempo de la misma muestra de instituciones.

Recopilación de datos

- Los datos se obtuvieron de FEMA, HHS y el Departamento de Salud de PR para respaldar las decisiones sobre la estratificación del muestreo.

- Se han compilado datos sobre hospitales, escuelas, refugios y cierres de escuelas para respaldar análisis futuros. 
- Se están recopilando datos secundarios sobre la recuperación de hospitales y escuelas, que incluyen documentación sobre el momento y el flujo de la asistencia de recuperación y los planes de recuperación.

- Se han elaborado borradores de los instrumentos de la encuesta Onda 1 para la recopilación de datos sobre la recuperación de escuelas y hospitales; el equipo del proyecto está trabajando en modificaciones a las preguntas y al modo de encuesta debido a las limitaciones de COVID-19.

\section{Análisis}

- Se han realizado análisis espaciales de datos disponibles públicamente para escuelas y hospitales para informar los planes de muestreo y análisis. El enfoque de estos análisis fue identificar grupos de escuelas en función de la distancia a los hospitales, así como examinar las diferencias entre las escuelas ubicadas cerca de los hospitales y las más alejadas (Figura 18).

- Se han realizado análisis descriptivos básicos para comprender la población de escuelas y hospitales K-12 en Puerto Rico, así como las características de esas instituciones dentro del área de estudio.

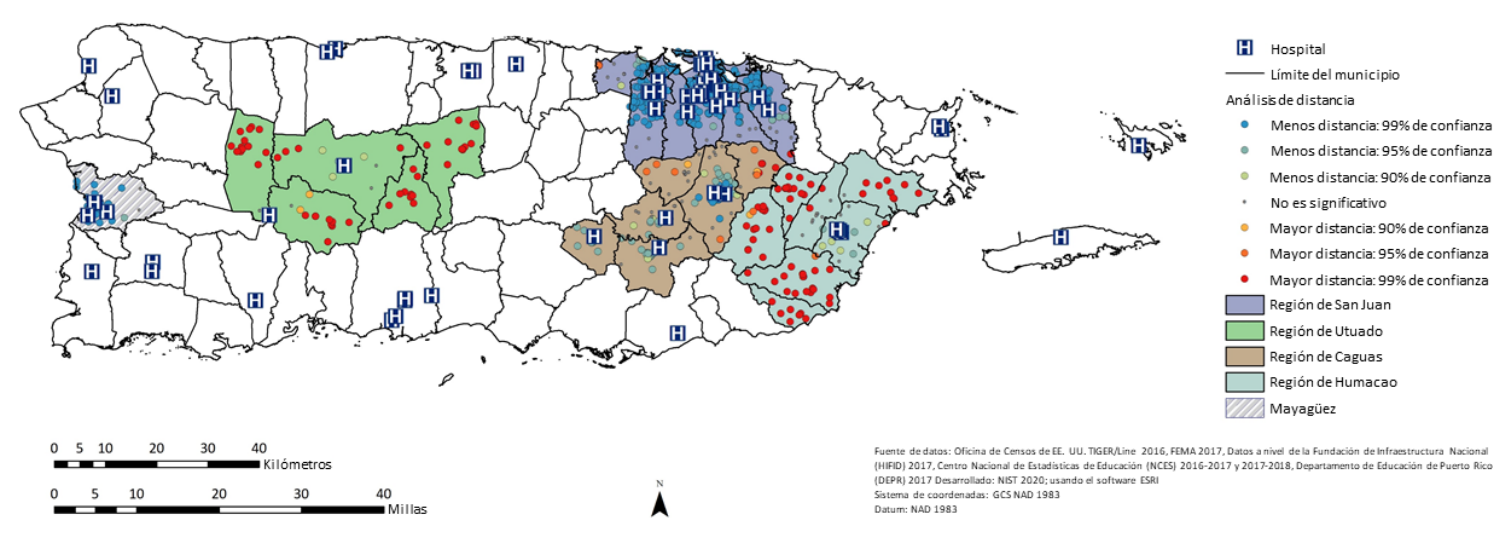

Figura 18. Resultados preliminares del análisis espacial de datos secundarios para escuelas y hospitales.

\subsubsection{Recuperación de sistemas de infraestructura}

Recopilación de datos

- A partir de las visitas del NIST a Puerto Rico para reunirse con la AEE (energía), AAA (agua) y DTOP (transporte) y a través de comunicaciones posteriores, se confirmaron los puntos de contacto de la agencia y se brindó información contextual para informar el diseño del instrumento de entrevista de infraestructura y el modelo de desarrollo.

- Se obtuvieron conjuntos de datos GIS para los sistemas de infraestructura de energía, agua y transporte. En la Figura 19, se traza un subconjunto de los datos. La figura muestra enlaces de alta capacidad de los sistemas de energía, transporte y agua junto 
con las ubicaciones de los hospitales en la base de datos de Datos a Nivel de Base de Infraestructura Nacional (HIFLD).

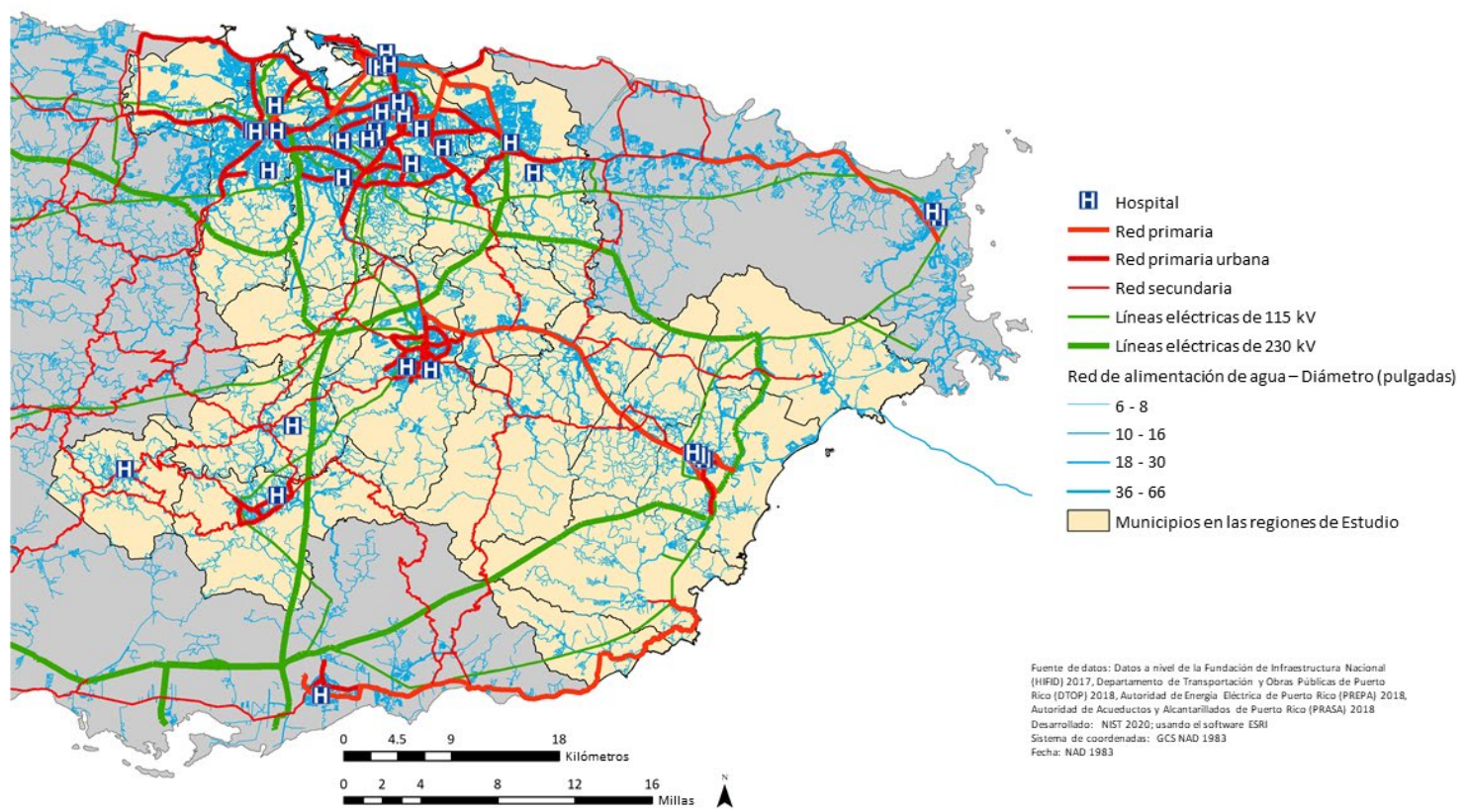

Figura 19. Enlaces de alta capacidad de los sistemas de infraestructura de agua, energía y transporte, mostrados con las ubicaciones de los hospitales para un subconjunto de los municipios objetivo del proyecto de infraestructura.

- Del DTOP de PR, el NIST obtuvo el registro de clasificación del sistema vial para Puerto Rico y las bases de datos de eventos de los huracanes María e Irma. Las ubicaciones de los eventos informados se representan en la Figura 20, junto con las carreteras primarias y secundarias. Se indica la naturaleza generalizada de los eventos en toda la región, con eventos reportados para muchos caminos primarios, secundarios y terciarios. Para cada evento, se brinda información detallada, por ejemplo, una clasificación del incidente, su ubicación y fecha, y su estado (por ejemplo, cerrado, parcialmente cerrado, cerrado) en momentos determinados, además de la fuente de información. 


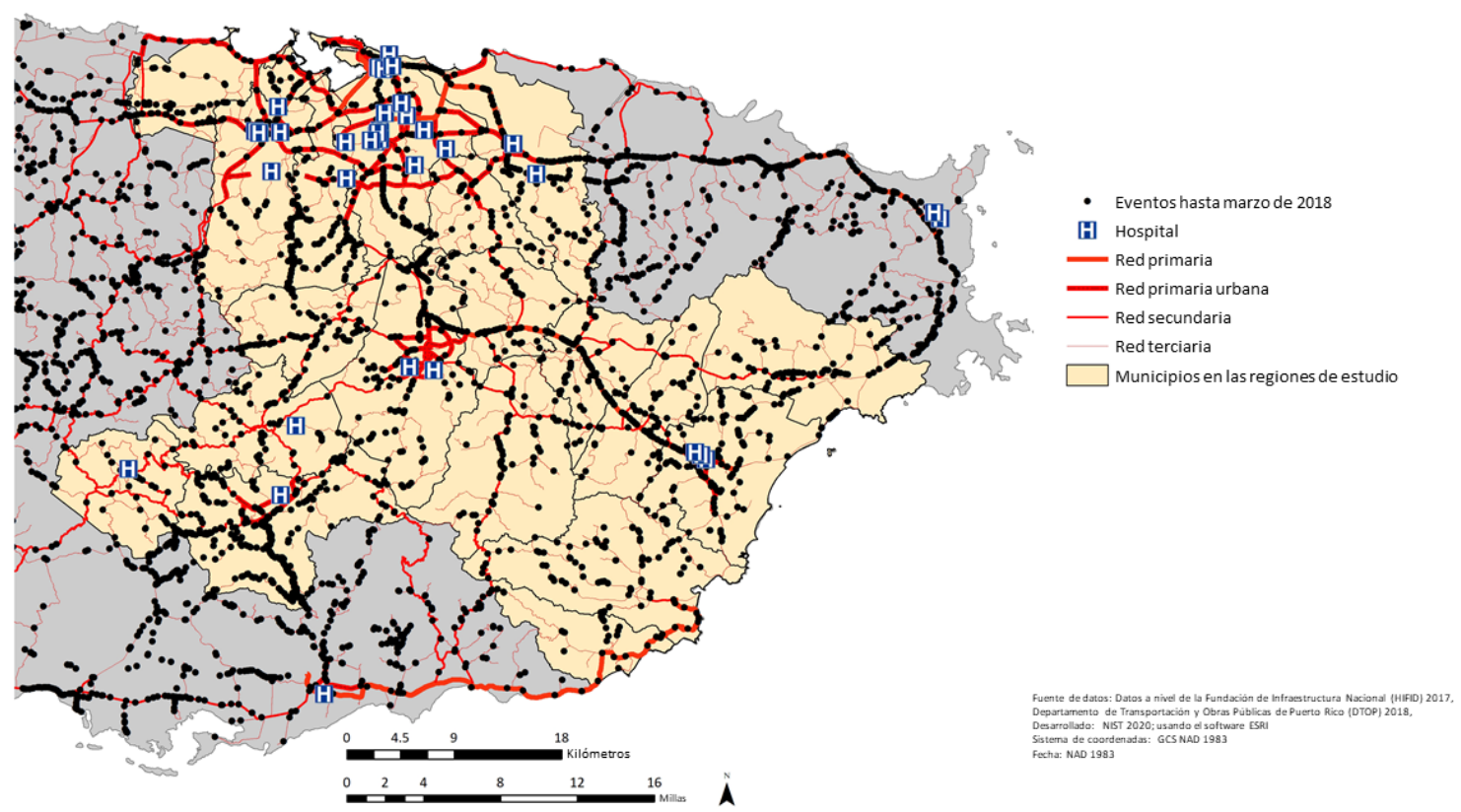

Figura 20. Eventos del sistema de transporte asociados con los huracanes Irma y María informados hasta marzo de 2018 para carreteras/puentes, mostrados con ubicaciones de hospitales para un subconjunto de los municipios incluidos en el proyecto de infraestructura.

- Se han elaborado guías preliminares de encuestas y entrevistas para la recopilación de datos sobre el soporte de infraestructura de edificios críticos.

- Se han identificado oportunidades de recopilación de datos para brindar una mejor comprensión de las causas de la pérdida de funcionalidad y la interrupción prolongada del sistema de comunicación inalámbrica en Puerto Rico después del huracán María. Los proveedores de servicios e infraestructura de comunicaciones inalámbricas también proporcionaron información.

- El NIST estableció un acuerdo con American Tower Corporation, lo que permite compartir datos. Posteriormente, el NIST recibió una biblioteca de fotos posterior a la tormenta que documenta las condiciones en más de 100 sitios de torres.

- Un viaje de recolección de datos a Puerto Rico en octubre de 2019 incluyó visitas de campo a cuatro sitios de torres y una torre montada en el techo y reuniones con la Junta Reguladora de Telecomunicaciones y PR Wireless.

- Se han recopilado los códigos y normas de construcción para estructuras de telecomunicaciones adoptados por Puerto Rico desde 1968 hasta la actualidad.

- Se ha documentado la historia de las disposiciones sobre cargas de viento en las normas de construcción para proporcionar contexto a la fecha de construcción de cualquier torre o edificio estudiado. 
Desde el establecimiento del Equipo Nacional de Seguridad en la Construcción del Huracán María en febrero de 2018, el NIST ha estado recibiendo consejos y observaciones de expertos respetados internacionalmente en una variedad de campos que sirven en el Comité Asesor del NCST de la agencia. ${ }^{44} \mathrm{El} \mathrm{Comité} \mathrm{brinda} \mathrm{asesoramiento} \mathrm{sobre} \mathrm{las} \mathrm{funciones} \mathrm{de} \mathrm{los} \mathrm{Equipos}$ Nacionales de Seguridad en la Construcción, la composición de los Equipos, el ejercicio de las autoridades enumeradas por la Ley y otros elementos necesarios para que el Director del NIST pueda cumplir con la Ley. Además, tanto el Comité como el NIST, son responsables de los informes anuales al Congreso. El informe del Comité incluye una evaluación de las actividades del Equipo, junto con recomendaciones para mejorar el funcionamiento y la eficacia de los Equipos y una evaluación de la implementación de las recomendaciones de los Equipos y del Comité Asesor. El informe del NIST incluye una respuesta al consejo del Comité, así como actualizaciones sobre las actividades del NCST. La investigación del huracán María NCST se aborda en los informes del Comité al Congreso presentados en diciembre de $2018^{45}$ y diciembre de 201946 y en los informes del NIST al Congreso para los años fiscales $2018^{47}$ y $2019 .{ }^{48} \mathrm{El}$ siguiente es un extracto del Informe del Comité al Congreso en diciembre de 2019:

Se debe elogiar al NIST por reunir un equipo diverso de investigadores altamente calificados en una variedad de áreas críticas, incluida la caracterización de peligros (viento e inundaciones), el desempeño de los edificios y la infraestructura crítica, la comunicación de riesgos, la logística comercial y de la cadena de suministro, y la salud y la medicina. Además, han involucrado con éxito a profesionales, incluidos científicos sociales e ingenieros, del área afectada. Creemos que la inclusión de profesionales locales fue particularmente importante para este estudio. La amplitud del equipo resultó en el requisito de un nivel considerable de apoyo en la gestión de proyectos y comunicación, lo que NIST ha hecho muy bien.

Aplaudimos las acciones de vincular las distintas partes de este estudio. En particular, es probable que los esfuerzos combinados de las ciencias sociales y la ingeniería ofrezcan nuevos conocimientos que no podrían lograrse sin la colaboración de las dos disciplinas.

El Equipo ha brindado múltiples sesiones informativas públicas al Comité Asesor sobre los planes y el progreso de la investigación. Todas las presentaciones del NIST a este comité se han realizado en sesiones abiertas y están disponibles en el sitio web del NIST sobre el huracán María. El 20 de febrero de 2018 se presentaron al Comité Asesor las observaciones sobre el

\footnotetext{
44 www.nist.gov/topics/disaster-failure-studies/national-construction-safety-team-ncst/advisory-committee

45 www.nist.gov/system/files/documents/2019/02/04/ncstac 2018 report to congress.pdf

46 www.nist.gov/system/files/documents/2020/03/13/2019 NCSTAC ReporttoCongress.pdf

47 www.nist.gov/system/files/documents/2019/10/31/nist ncst fy 18 annual report to congress 10-8-19.pdf

48 www.nist.gov/system/files/documents/2020/07/27/NIST NCST FY19 Annual Report to Congress\%207-102020.pdf
} 
reconocimiento preliminar de los impactos del huracán María en Puerto Rico. ${ }^{49} \mathrm{El} 16$ de mayo de 2018,50 el 18 de agosto de 2018,51 el 6 de septiembre de 201952 y el 30 de junio de 2020,53 el Comité Asesor del NCST recibió actualizaciones sobre los planes y el progreso de los proyectos realizados en el marco del Programa del Huracán María. De acuerdo con los estatutos del comité, los miembros del Comité Asesor proporcionaron observaciones y asesoramiento sobre los proyectos del NCST. El Comité Asesor también recibió información sobre los proyectos del huracán María que se encuentran bajo la autoridad estatutaria del NWIRP, aunque no están autorizados a hacer recomendaciones consensuadas relacionadas específicamente con estas actividades.

${ }^{49}$ www.nist.gov/topics/disaster-failure-studies/ncstac-february-20th-2018-presentations

50 www.nist.gov/topics/disaster-failure-studies/ncstac-may-16-2018-presentations

51 www.nist.gov/topics/disaster-failure-studies/ncstac-meeting-august-2018-agenda-and-presentations

52 www.nist.gov/topics/disaster-failure-studies/ncstac-meeting-september-2019-agenda-and-presentations

53 www.nist.gov/system/files/documents/2020/06/24/NCSTAC Meeting Agenda 2020June30 July01.pdf 
